João Ricardo Filipini da Silveira

\title{
Modelamento do efeito do tamanho de grão sobre o campo coercivo de aços elétricos
}


João Ricardo Filipini da Silveira

\title{
Modelamento do efeito do tamanho de grão sobre o campo coercivo de aços elétricos
}

\author{
Dissertação apresentada à Escola \\ Politécnica da Universidade de \\ São Paulo para obtenção do título \\ de mestre em engenharia \\ metalúrgica
}

Área de concentração: engenharia metalúrgica e de materiais.

Orientador: Prof. Dr. Fernando José Gomes Landgraf

São Paulo 
Autorizo a reprodução e divulgação total ou parcial deste trabalho para fins de estudo ou pesquisa, desde que citada a fonte.

Este exemplar foi revisado e alterado em relação à versão original, sob responsabilidade única do autor e com a anuência de seu orientador.

São Paulo, de agosto de 2011.

Assinatura do autor

Assinatura do orientador

FICHA CATALOGRÁFICA

Silveira, João Ricardo Filipini da Modelamento do efeito do tamanho de grão sobre campo coercivo em aços elétricos / J.R.F. da Silveira. -- ed.rev. -- São Paulo, 2011.

$131 \mathrm{p}$.

Dissertação (Mestrado) - Escola Politécnica da Universidade de São Paulo. Departamento de Engenharia Metalúrgica e de Materiais.

1. Materiais magnéticos 2. Aço elétrico I. Universidade de São Paulo. Escola Politécnica. Departamento de Engenharia Metalúrgica e de Materiais II. t. 
"[...] Hay cines,

hay trenes, hay cacerolas.

Hay formulas hasta para describir

la espiral de una caracola.

Hay más: hay tráfico, créditos, cláusulas, salas vip [...]"

Jorge Drexler, "Guitarra y vos", grifo do autor deste trabalho 


\section{Agradecimentos}

Gostaria de agradecer, não necessariamente nesta ordem,

a Miriam Soares Sousa, pela confecção da ilustração 27;

a Daniel Rodrigues Jr., pelo apoio e companheirismo;

a Marcos Flávio de Campos, pela recomendação dos artigos do Sheiko sobre o efeito $\mu^{*}$;

a Antônio Domingues dos Santos, pelo auxílio na observação de domínios por efeito KERR;

a Lucas Vignoli Reis, pelas discussões epistemológicas;

a Fernando José Gomes Landgraf, pela confiança. 


\section{Resumo}

Chapas de aço elétrico $(0,7 \% \mathrm{Si}$ e $0,3 \% \mathrm{Al})$ foram laminadas a diferentes graus de deformação e recozidas $\left(760^{\circ} \mathrm{C}, 2 \mathrm{~h}\right)$ de modo a obter diferentes tamanhos de grão por recristalização. Um outro conjunto de chapas do mesmo material foi recozido a tempos e temperaturas diferentes de modo a obter tamanho de grão variado por crescimento de grão.

Os tamanhos de grão foram medidos pelo método dos interceptos e os parâmetros da distribuições de tamanho de grão determinados por um método semi-analítico que se baseia na medição das áreas individuais de cada grão na micrografia. A partir do ensaio quase-estático de histerese magnética no quadro de Epstein obtiveram-se os campos coercivos de cada amostra, a diferentes induções máximas $(0,6-0,8-1,0-1,2-1,4$ e 1,5T).

Notou-se que o conjunto dos dados se enquadra com menos de $4 \%$ de desvio médio absoluto uma lei fenomenológica do tipo:

$$
H_{c}=\frac{a}{T G} B_{\max }{ }^{c}+b B_{\max }{ }^{d}
$$

Na qual $H_{c}$ é o campo coercivo, TG é o tamanho de grão, $B_{\max }$ é a indução máxima do ensaio de histerese e $a, b, c$ e $d$ são os parâmetros de ajuste.

A partir da inserção do efeito do campo desmagnetizante no contorno de grão no modelo físico de Mager obteve-se uma boa estimativa para os valores dos parâmetros independentes da indução $a$ e $b$, além de propor um significado físico para os mesmos.

Com a integração dos modelos Mager e Preisach, determinou-se uma equação diferente para o ajuste dos dados, a qual oferece um valor aproximado de $c$. Para que o modelo físico explique completamente a relação fenomenológica resta ainda elucidar o parâmetro $d$. 


\section{Abstract}

Electrical steel sheets $(0,7 \% \mathrm{Si}$ and $0,3 \% \mathrm{Al})$ were cold-rolled and annealed $\left(760^{\circ} \mathrm{C}, 2 \mathrm{~h}\right)$ in order to obtain different grain sizes through recristallization. Another set of sheets from the same material were annealed at different temperatures and time-frames, so as to produce different grain sizes through grain growth.

Grain size was measured through the intercept method and grain size distribution parameters were determined via a semi-analytical method based on measurement of individual grain areas upon micrographs. From quasistatic hysteresis measurements in an Epstein frame, the coercive field of each sample was determined at various maximum induction values $(0,6-0,8-1,0$ $-1,2-1,4$ e 1,5T).

The data set fits with less than $4 \%$ average deviation a phenomenological law of the type:

$$
H_{c}=\frac{a}{T G} B_{\max }{ }^{c}+b B_{\max }{ }^{d}
$$

In which $H_{c}$ is the coercive field, $T G$ is the grain size, $B_{\max }$ is the maximum induction value and $a, b, c$ and $d$ are the fitting parameters.

By introducing the grain boundary demagnetizing field effect on Mager's physical model, a good estimate of the values of $a$ and $b$ was obtained, as well as a reasonable explanation to their physical meaning.

Integrating Mager and Preisach models, a different equation for the data was obtained, which offered an approximate value of $c$. In order for physical models do fully explain the phenomenological equation, there is still need to understand the parameter $d$. 


\section{Sumário}

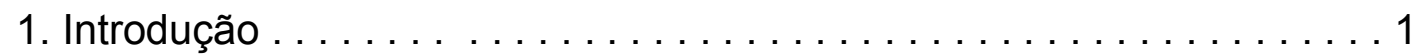

2. Revisão bibliográfica $\ldots \ldots \ldots \ldots \ldots \ldots \ldots \ldots \ldots \ldots \ldots \ldots \ldots \ldots \ldots \ldots$

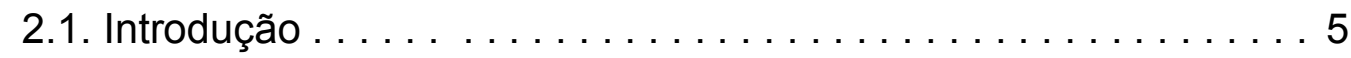

2.2. Histórico da teoria dos domínios $\ldots \ldots \ldots \ldots \ldots \ldots$

2.3. Micromagnetismo . . . . . . . . . . . . . . . . . . 12

2.4. Modelo Jiles-Atherton . . . . . . . . . . . . . . . . . . 16

2.5. Modelo de Preisach . . . . . . . . . . . . . . . . . . 19

2.6. Recapitulação . . . . . . . . . . . . . . . . . . . 23

3. Materiais e métodos . . . . . . . . . . . . . . . . . 25

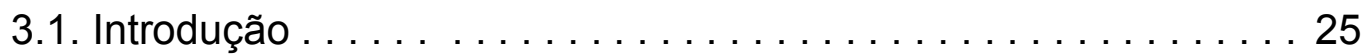

3.2. Obtenção das amostras . . . . . . . . . . . . . . . . 26

3.3. Medidas magnéticas . . . . . . . . . . . . . . 28

3.4. Tamanho de grão . . . . . . . . . . . . . . . . . . . 29

3.4 .1 Introdução . . . . . . . . . . . . . . . . . . . 29

3.4.2 Método semi-automático . . . . . . . . . . . . . . . . . 29

3.4.3 Ajuste lognormal da distribuição de TG . . . . . . . . . . . 34

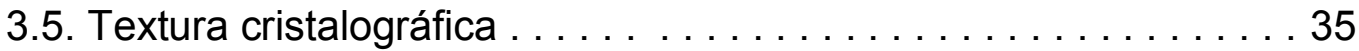

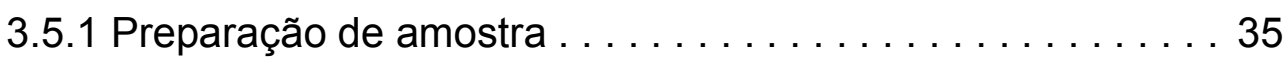

3.5 .2 Análise EBSD . . . . . . . . . . . . . . . . . . 37

3.6. Observação de domínios por efeito Kerr . . . . . . . . . . . . . . 39

3.7. Modelamento micromagnético . . . . . . . . . . . . . . . . 39

4. Resultados e discussão . . . . . . . . . . . . . . . . . . . . . 40

4.1. Tamanho de grão . . . . . . . . . . . . . . . . . 40

4.1.1 Valores obtidos pelos dois métodos . . . . . . . . . . . 40

4.1.2 Comparação entre os dois métodos . . . . . . . . . . . 43

4.2. Textura cristalográfica . . . . . . . . . . . . . . . . . 45

4.3. Campo coercivo . . . . . . . . . . . . . . . . . 52

4.3.1. Modelo fenomenológico . . . . . . . . . . . . . . . . 54

4.3.2. Extensão do modelo de Mager . . . . . . . . . . . . . 58

4.3.3. Dependência com a indução máxima . . . . . . . . . . 65

4.4. Visualização de domínios por efeito Kerr . . . . . . . . . . . 73

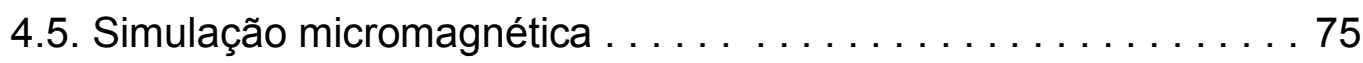

5. Conclusões, sugestões para trabalhos futuros $\ldots \ldots \ldots \ldots \ldots 77$

6. Referências . . . . . . . . . . . . . . . . . . . . . . . 79

7. Apêndice . . . . . . . . . . . . . . . . . 83 


\section{Índice de tabelas}

Tabela 1 - Composição química do aço utilizado . . . . . . . . . . . . 27

Tabela 2 - Deformação real e espessura das amostras recristalizadas . . 27

Tabela 3 - Parâmetros de recozimento das amostras de crescimento . . . 27

Tabela 4 - Número de grãos utilizados pelo método semi-automático . . . 33

Tabela 5 - Passo de análise EBSD ("step size") . . . . . . . . . . . . 38

Tabela 6 - Tamanho de grão pelo método dos interceptos . . . . . . . . . . 40

Tabela 7 - Parâmetros da distribuição lognormal de TG . . . . . . . . . . . . 41

Tabela 8 - Valores de TG obtido pelos dois métodos . . . . . . . . . . . 42

Tabela 9 - Razão entre TG medido pelos dois métodos . . . . . . . . . . . . 44

Tabela 10 - Valores de $B_{50}$ obtidos no quadro de Epstein . . . . . . . . . 46

Tabela 11 - Energia de anisotropia média obtida [27] a partir de EBSD . . 47

Tabela 12 - Parâmetros de ajuste de $H_{c} \times 1 / \ell$ em função de Bmax . . . . . 52

Tabela 13 - Parâmetros de ajuste de $H_{c} \times 1 / d_{A}$ em função de Bmax . . . . 54

Tabela 14 - Comparação do modelo Mager estendido com resultados . . 63 


\section{Índice de llustrações}

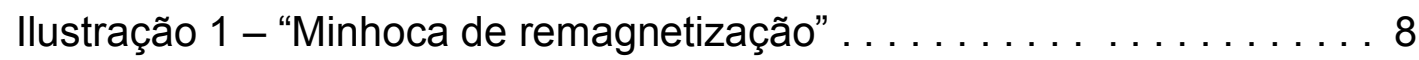

llustração 2 - Domínios de fechamento . . . . . . . . . . . . . . . 10

Ilustração 3 - Erros comuns ao desenhar domínios . . . . . . . . . . 11

llustração 4 - Curva anisterética ....................... 17

llustração 5 - Entidade magnética / Histerão de Preisach . . . . . . . . 19

llustração 6 - Três histerões no plano de Preisach . . . . . . . . . . 20

llustração 7 - Estados possíveis do histerão . . . . . . . . . . . . 21

Ilustração 8 - Exemplo de plano de Preisach com $\mathrm{H}$ aplicado crescente . 22

llustração 9 - Exemplo de plano de Preisach p/ material desmagnetizado .23

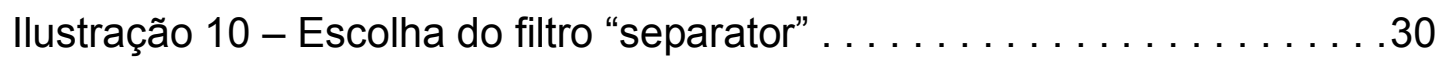

llustração 11 - Características do "separator" . . . . . . . . . . . . . 31

llustração 12 - Traçando contornos manualmente . . . . . . . . . . 32

llustração 13 - Ferramenta "Magic Wand" . . . . . . . . . . . . . . . 32

llustração 14 - Escolha das medidas . ......................33

llustração 15 - Curva de recristalização do aço . . . . . . . . . . . . .40

llustração 16 - Largura da distribuição de tamanho de grão . . . . . . . . . 41

llustração 17 - Valores de TG obtidos pelos dois métodos . . . . . . . . 43

llustração 18 - Comparação entre os ajustes de $H_{c}$ com $\ell$ e $d_{A}$ para 1,5T . 45

llustração 19 - (Ausência de) Correlação entre $B_{50}$ Epstein e $E_{a} \ldots \ldots$. . 47

llustração 20 - Valores de $B_{50}$ medidos pelo ensaio Soken ......... 48

llustração 21 - Comparação dos três métodos de análise de textura . . . . 49

llustração 22 - Figuras de polo inversas das amostras recristalizadas . . . 50

llustração 23 - Figura de polo inversas das amostras de crescimento . . . 51

llustração 24 - Campo coercivo em função do inverso de TG . . . . . . . . 52

llustração 25 - Variação dos parâmetros a e $b$ com a indução máxima . . . 56

llustração 26 - Desvio de $H_{c}$ pelas equações fenomenológicas. . . . . . . 57

llustração 27 - Minhoca de remagnetização em grãos cilíndricos . . . . . . 60

llustração 28 - Identificação de grãos com histerões com $H_{c} \ldots \ldots \ldots 65$

llustração 29 - Conversão de histerões desde o estado desmagnetizado . 66

llustração 30 - Relação de $B_{\max } \operatorname{com} F_{\max } \ldots \ldots \ldots \ldots \ldots \ldots \ldots .66$

llustração 31 - Histerões inertes para a amplitude $H_{\max } \ldots \ldots \ldots \ldots \ldots .67$

llustração 32 - Desvio de $H_{c}$ para modelos físico e fenomenológicos . . . 70

llustração 33 - Coeficiente angular de $H_{c} \times 1 /$ TG em função de Bmax . . . 71

llustração 34 - Visualização de domínios por efeito Kerr na região $A$. . . . .73

llustração 35 - Visualização de domínios por efeito Kerr na região $B$. . . . 74

llustração 36 - Histerese de barra simulação OOMMF . . . . . . . . 75 


\section{Índice de Equações}

Equação 1 - A variação da energia livre no crescimento de um domínio . . 9

Equação 2 - Energia de troca . . . . . . . . . . . . . . . . . . . 12

Equação 3 - Energia de anisotropia magnetocristalina . . . . . . . . . . . 12

Equação 4 - Energia de magnetostricção . . . . . . . . . . . . . 13

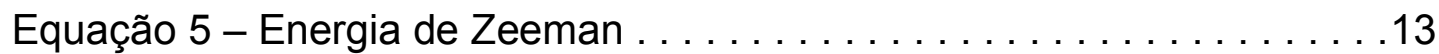

Equação 6 - Energia devida ao campo desmagnetizante . . . . . . . . . 13

Equação 7 - Potencial magnetostático . . . . . . . . . . . . . . . . . . 14

Equação 8 - Ajuste de Langevin da curva anisterética [3] . . . . . . . . . 16

Equação 9 - Campo efetivo [3] . . . . . . . . . . . . . . . . . . . . . . . 17

Equação 10 - Equação diferencial para $M(H)$ [3] . . . . . . . . . . . . . 18

Equação 11 - Integral de $M$ no modelo Preisach . . . . . . . . . . . . . 21

Equação 12 - Dados experimentais da distribuição de tamanho de grão . . 34

Equação 13 - Parâmetros de ajuste da distribuição de tamanho de grão . .34

Equação 14 - Fração de área para grão com tamanho $d_{i} \ldots$. . . . . . . . 34

Equação 15 - Fração de área acumulada para grão com tamanho até $d_{i}$. 35

Equação 16 - Mediana $d_{M}$ e esperança $d_{A}$ da distribuição de TG . . . . . . 35

Equação 17 - Equações fenomenológicas para $H_{c} \ldots \ldots \ldots \ldots$. . . . . 56

Equação 18 - Aplicação numérica da energia desmagnetizante . . . . . . . 59

Equação 19 - Energia desmagnetizante no modelo Mager estendido . . . . 59

Equação 20 - Balanço energético para crescimento longitudinal . . . . . . . 60

Equação 21 - Variação da energia desmagnetizante . . . . . . . . . . . . 60

Equação 22 - Considerações para balanço energético . . . . . . . . . . . . . 61

Equação 23 - Campo coercivo segundo o modelo Mager estendido . . . . 61

Equação 24 - Aplicação numérica de $H_{c}$ Mager estendido . . . . . . . . . . 62

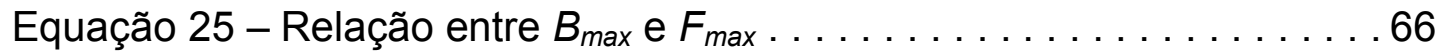

Equação 26 - Relação entre histerões convertidos e disponíveis . . . . . . 67

Equação 27 - Distribuição lognormal de grãos . . . . . . . . . . . . . . . 68

Equação 28 - Diâmetro do grão médio convertido na histerese com $B_{\max }$. 68

Equação 29 - Dependência de $H_{c}$ cl $B_{\max }$ e distribuição de TG . . . . . . 68

Equação 30 - Aplicação numérica da dependência de $H_{c}$ com $B_{\max }$ e TG . 69

Equação 31 - Variação do termo dependente de TG com $B_{\max } \ldots$. . . . . . 71 


\section{Introdução}

$\mathrm{Na}$ última página de seu livro sobre domínios magnéticos [1], Hubert e Schäfer apresentam três alternativas para o modelamento da histerese magnética, as quais se provêem de conceitos chave da teoria dos domínios magnéticos: o primeiro está ligado com o modelo de Preisach [2] da histerese, o segundo com o modelo Jiles-Atherton [3], e o terceiro com o trabalho de Bertotti et al.[4].

Como um comentário sobre estas teorias os autores do livro acrescentam: "Uma das tarefas da análise de domínios no futuro será melhorar o elo entre compreensão microscópica e descrição global de uso prático.”

Foi precisamente esta tarefa que no presente trabalho buscou-se cumprir, tomando o campo coercivo, $H_{c}$, como a propriedade magnética de interesse na escala macrométrica, e o tamanho de grão, TG, como variável microscópica de principal influência.

O trabalho de Mager [9] nos dá um ponto de partida para explorar esta correlação, porque prevê corretamente uma dependência linear de $H_{c}$ com 1/TG. Porém, ao assumir esta abordagem uma contradição aparente surge no caminho. Graças a isso, nota-se uma dificuldade de inserção deste efeito na literatura do magnetismo [5].

Por um lado, existe uma correlação facilmente observável experimentalmente traçando-se a curva $H_{c} \times 1 / T G$, como já foi feito por outros autores no passado [7, 32, 6, 13].

Por outro lado, existe uma compreensão profunda dos fenômenos físicos que ocorrem ao longo da histerese na escala nanométrica, através da teoria de domínios [11]. Mais ainda, a linha de pesquisa apresentada no presente trabalho foi orientada por algumas referências datando dos primórdios da teoria dos domínios magnéticos $[7,8,9]$. 
Isto gera a impressão de que o tema está esgotado, já que a parte experimental e teórica do mesmo foram amplamente exploradas, e a linha de pensamento de Mager foi superada por uma abordagem focada na curva de histerese, nos modelos de Jiles-Atherton e Preisach.

Mas esta concepção é errônea. Não se trata aqui de "reinventar a roda" repensando a razão física primordial por detrás do fenômeno, na pessoa da mecânica estatística, física quântica e termodinâmica, o que já foi feito nas teorias de Preisach, micromagnetismo e teoria das fases, respectivamente.

Pelo contrário, se trata de abraçar as técnicas de modelamento existentes, aplicando-as ao exemplo específico da influência do tamanho de grão e outras variáveis microestruturais.

Do ponto de vista experimental, não existe um estudo sistemático que inclua uma análise da influência de outras variáveis na relação $H_{c} \times 1 / T G$, afora o trabalho sobre inclusões de Adler \& Pfeiffer [10]. Como estamos lidando com um sistema em que diversas variáveis têm um papel significativo, tal estudo é necessário para atestar à generalidade da correlação estudada.

Então, se existe uma literatura tanto experimental quanto teórica que cobre ou quase cobre o assunto $H_{c} \times 1 / T G$, elas não estão integradas entre si. Não existe uma ponte de natureza estatística ou da ciência dos materiais que permita estabelecer uma relação de causalidade entre o que se sabe na escala nanométrica e o que se mede na escala macrométrica.

Os modelos de Jiles-Atherton e Preisach, por exemplo, são de natureza fenomenológica e têm a descrição matemática da curva de histerese magnética como seu principal objetivo. Não se tardam na análise da microestrutura a ponto de determinar o mecanismo segundo o qual ela influencia as propriedades magnéticas. 
Jiles e Atherton afirmam explicitamente em seu artigo seminal [3] que não se preocupam com a natureza dos defeitos cristalinos que servem como impedimentos ("pinning sites") à movimentação das paredes de domínio. Porém, aquilo que se pode controlar no processo de fabricação do aço elétrico é justamente a natureza dos defeitos cristalinos.

Como engenheiros de materiais, somos úteis através daquilo que melhor compreendemos: defeitos cristalinos. Justamente este ponto que muitas vezes carece nos pesquisadores da área do magnetismo, e que portanto mais provoca questionamento da parte dos revisores dos artigos enviados a revistas internacionais.

Relendo a conclusão do artigo de Della Torre [11] estamos em condições de entender porque um assunto tão importante e relevante para a indústria cujos principais artigos apareceram em 1940 ainda não foi claramente explicado:

"Tanto o modelamento micromagnético quanto o modelo [de Preisach] da histerese estão à beira de se tornar campos maduros. Eles ainda não são maduros porque não tiveram impacto sobre os projetistas devido à dificuldade dos cálculos. Este impedimento pode ser sobrepujado por pacotes de "software" que operem em computadores pessoais e que não requeiram grandes conhecimentos matemáticos. [...]"

A física dos domínios magnéticos já foi amplamente explorada, mas uma engenharia que se apóia nos conceitos por ela desenvolvidos está apenas florescendo.

A conclusão desta pequena reflexão é que o melhor caminho a ser seguido é familiarizar-se com as alternativas de modelamento existentes, trazendo a elas a contribuição de que compreende a microestrutura do material, sempre com a propriedade final em vista.

Por isso, na revisão bibliográfica que segue, objetivamos traçar um panorama geral das técnicas de modelamento existentes. A partir desta revisão, 
concluímos que o caminho a ser seguido para encontrar o mecanismo da influência de TG sobre $H_{c}$ é assumir as hipóteses de Mager na escala micrométrica, analisar se elas são válidas a partir de simulações micromagnéticas e por fim utilizar o modelo de Preisach para estendê-las até a escala macrométrica.

$\mathrm{Na}$ parte de experimental foi dedicado um esforço considerável para a caracterização da microestrutura. O levantamento da distribuição de $T G$ e a medição da textura cristalográfica e permitem explorar com maior sutileza os efeitos da microestrutura sobre as propriedades magnéticas.

Exploramos a técnica de modelamento micromagnético com programas como Nmag e OOMMF, além da observação de domínios por efeito Kerr, buscando uma melhoria da compreensão de como os domínios magnéticos preenchem um aço elétrico não-orientado.

A medição do campo coercivo a diversas induções máximas permite romper com a visão idealizada em que o material oscila sempre entre a saturação em uma direção ou outra. 


\section{Revisão bibliográfica}

\subsection{Introdução}

Entre os diversos caminhos de estudo do efeito das variáveis microestruturais nas propriedades magnéticas, podemos citar o modelo de histerese de Preisach[1], o micromagnetismo de Brown[12], e o modelo Jiles-Atherton[3], além da abordagem de Bertotti et al.[4].

No âmbito de modelamento, diferenciam-se, de forma geral, dois tipos: físico e fenomenológico. $\mathrm{O}$ modelo fenomonológico se baseia no ajuste matemático de uma função aos dados experimentais. Acredita-se que quanto menos parâmetros possui esta função, melhor é o modelo. Além disso, o modelo é muito forte quando ele permite interpolações e extrapolações para situações diferentes daquela na qual ele inicialmente foi traçado.

A vantagem deste tipo de modelo é que permite partir de uma base sem suposições prévias e chegar diretamente às equações que determinam o fenômeno. Porém, os parâmetros obtidos, como o expoente de algum termo, ou um fator multiplicativo, podem não possuir nenhum significado físico.

Como exemplo de modelos fenomenológicos, temos os modelos da histerese de Preisach e Jiles-Atherton. Bertotti afirma que a equivalência de ambos foi provada [13], algo esperado, visto que ambos descrevem com grande precisão o mesmo formato de curva.

Ambos dependem da determinação experimental de funções que descrevem os estados de equilíbrio (mínimos locais de energia) pelos quais o material passa ao longo da histerese, seja no caso de curva anisterética de Jiles, ou no caso da distribuição de histerões no plano de Preisach. A pergunta passa a ser, até que medida se pode correlacionar estas funções com variáveis microestruturais. 
O modelo físico parte do fundamento físico do fenômeno e procura estabelecer um equacionamento em que cada parâmetro possui um significado físico bem claro. O problema com esta abordagem é que, se o mecanismo suposto não está correto, o modelo aparenta sustentar-se porque descreve certas situações, até que se descobre que não pode ser extrapolado.

Como exemplo de modelo físico, temos o modelo de Mager [8] da influência do $H_{c}$ sobre $T G$, que apresenta a abordagem característica dos início do século XX. Ele aborda especificamente a dependência de $H_{c}$ com $T G$, em um artigo muito curto, o qual não permite o desenvolvimento completo de sua teoria.

Talvez este modelo não possa ser efetivamente extrapolado para explicar um mecanismo da histerese ela própria (como deveria ocorrer, se as suposições nele feitas fossem verdadeiras), mas ele representa o único caminho aberto nesta direção.

O principal modelo físico é o micromagnetismo, que tem suas raízes na teoria de domínios. Devido à dificuldade dos cálculos envolvidos, o micromagnetismo só pode ser utilizado com rigor através de métodos computacionais. Dessa forma, sua aplicabilidade fica restrita conforme a capacidade de processamento da máquina utilizada.

Como não se pode observar domínios no interior do material, espera-se que, à medida que essas dificuldades computacionais são superadas, as suposições de diversos pesquisadores sobre estruturas de domínios, como Mager, possam enfim ser comprovadas ou refutadas por esta técnica.

No texto que segue, procuramos traçar uma visão histórica do desenvolvimento da teoria de domínios, para mostrar que o micromagnetismo é sua descendência direta, enquanto os modelos fenomenológicos foram 
constituídos através de uma abordagem diferente, focada na descrição matemática da curva de histerese.

Após a revisão histórica da teoria de domínios, observamos com maiores detalhes o micromagnetismo, o modelo Jiles-Atherton e o modelo de Preisach.

Ao longo desta exposição, procuramos a melhor alternativa para analisar o comportamento da magnetização frente à geometria dos defeitos cristalinos.

\subsection{Histórico da teoria dos domínios}

Do ponto de vista histórico, a teoria do domínios magnéticos é muito interessante. Já em 1906, em sua teoria do ferromagnetismo, Weiss ${ }^{1}$ propôs a existência de regiões extensas no interior do material dentro das quais a magnetização possuía orientação constante.

Do ponto de vista experimental, podemos remontar aos experimentos de Barkhausen ${ }^{2}$ em 1919, os quais confirmam a existência de descontinuidades no processo de magnetização, causando um ruído característico o qual poderia ser tornado audível com o uso de amplificadores. Devido à sua grande sensibilidade às características microestruturais, a análise deste ruído constitui até hoje uma linha de pesquisa promissora.

$\mathrm{Na}$ época, para facilitar a interpretação destes fenômenos, lançou-se mão de condições experimentais simplificadas, como o caso de fios tracionados, para os quais a magnetização ocorre com apenas um único salto de Barkhausen. Os famosos experimentos de Sixtus e Tonks [14] confirmaram a hipótese de que isto se devia à propagação de uma parede de domínio ao longo do fio.

\footnotetext{
${ }^{1}$ Weiss, P., Journal de Physique, v. 6, pp. 661, 1907 apud [38].

2 Barkhausen, H., "Zwei mit Hilfe der neuen Verstärker entdeckte Erscheinungen", Physikalische Zeitschritf, v. 20, pp. 401-403, 1919 apud [1].
} 
Por sua vez, Bloch ${ }^{3}$ notou que, devido à energia de troca de Heisenberg, a parede deveria ser constituída do momentos magnéticos atômicos que se rotacionam gradualmente de uma direção à direção contrária, tendo assim uma espessura de 200nm, por exemplo, no ferro.

No livro-texto de 1940 de Becker e Döring [15] foram resumidas diversas outras propriedades recém-descobertas da magnetização com relação à estrutura cristalina, como a existência de eixos fáceis de magnetização, magnetostricção e a presença de paredes de $90^{\circ}$ relacionadas com tensões elásticas.

Foi inspirado no trabalho de Döring que Mager escreveu seu curto artigo [8] sobre a influência do tamanho de grão no campo coercivo. O modelo de Mager supõe que a magnetização de material se inicia pelo crescimento longitudinal de domínios conjugados favoravelmente orientados cuja largura é no máximo igual ao tamanho de grão.

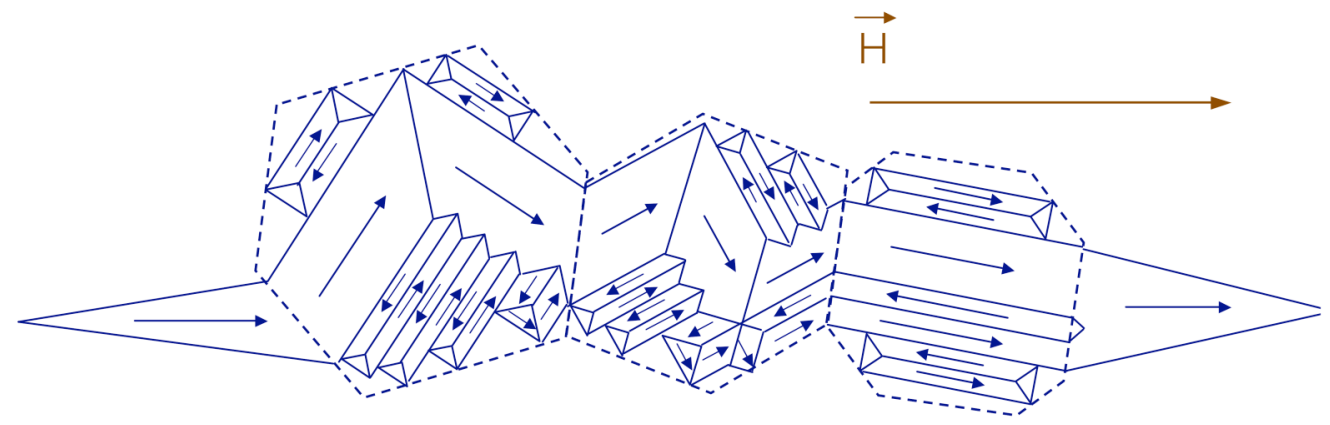

Ilustração 1 - "Minhoca de remagnetização", adaptado de [5].

O equacionamento é o mesmo que utilizado por Döring [16] para interpretar o crescimento de domínios elipsoidais nos experimentos de Sixtus \& Tonks. Este mesmo tema foi abordado de forma marginal em 1954 por Goodenough, em seu extenso artigo [17] sobre campo coercivo.

3 Bloch, F., "Zur Theorie des Austauschproblems und der Remanezerscheinung der Ferromagnetika”, Zeitschrif für Physik, v.74, pp. 295-335, 1932 apud [1]. 
Tanto Mager quanto Goodenough se serviram dos resultados experimentais de Yensen [7], para propor uma lei de dependência linear para a curva $H_{c} \mathrm{e}$ 1/TG. Ouando um domínio orientado paralelo ao campo externo cresce em detrimento de um domínio orientado oposto a ele, podemos fazer o equilíbrio das energias envolvidas.

De forma simplificada, temos apenas a energia magnetostática devida à mudança de orientação no volume do domínio, a qual depende da sua largura à terceira potência e a energia devida ao aumento da parede do domínio, a qual depende da sua largura ao quadrado.

$$
\begin{aligned}
& \Delta E=2 H J_{S} \Delta V-\gamma \Delta A ; \\
& 0=2 H J_{s} c_{1} L^{3}-\gamma c_{2} L^{2} ; \\
& H=\frac{c_{2}}{2 c_{1}} \frac{\gamma}{J_{s} L}
\end{aligned}
$$

Equação 1 - A variação da energia livre no crescimento de um domínio, $\Delta E$, está ligada com a variação de seu volume, $\Delta V$, a variação de sua área, $\Delta A, 0$ campo aplicado, $\boldsymbol{H}$, a polarização de saturação, $J_{s}$, a energia de parede, $\gamma$, sua largura, $L$, e constantes geométricas $c_{1}$ e $c_{2}$.

Desta forma, se o campo coercivo é aquele que permite o crescimento deste domínio sem alteração da energia livre de Helmholtz, então ele é proporcional ao inverso da largura do domínio. Acredita-se que a largura do domínio está atrelada à largura do grão devido ao efeito do campo desmagnetizante no contorno de grão.

Por outro lado, em 1935, Landau e Lifshitz ${ }^{4}$ propuseram a estrutura de domínios de fechamento, os quais minimizam a energia de campo

\footnotetext{
${ }^{4}$ Landau, L.D., Lifshitz, E., "On the theory of the dispersion of magnetic permeability in ferromagnetic bodies", Physikalische Zeitschirft der Sowjetunion, v. 8, pp. 153-169, 1935 apud [1].
} 
desmagnetizante associada à superfície do material. Néel ${ }^{5}$ se serviu desse conceito para propor domínios de fechamento ao redor de uma inclusão não magnética, além de descrever o comportamento de diversas estruturas de domínios.
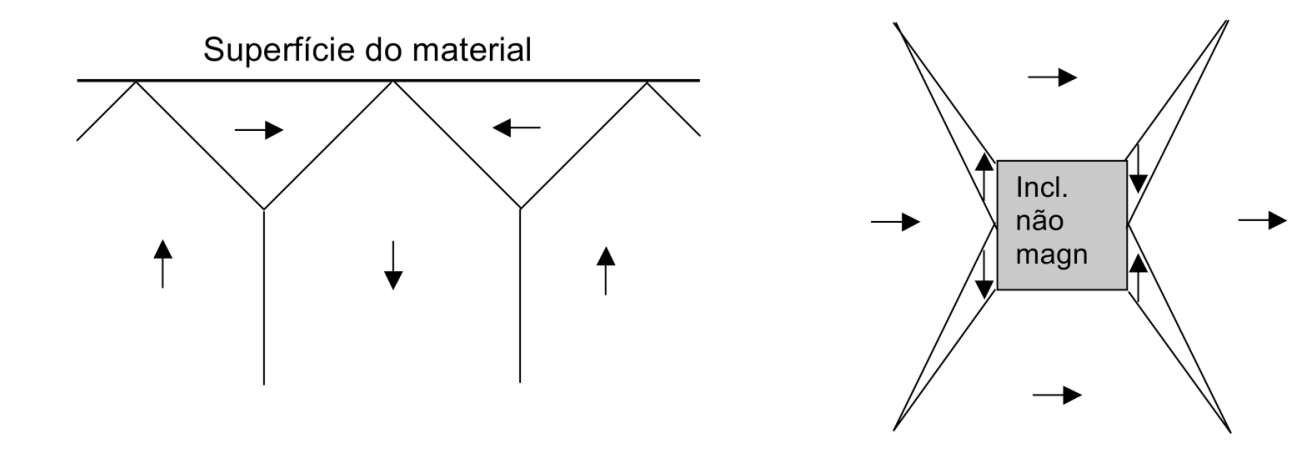

\section{Ilustração 2 - Domínios de fechamento na superfície e ao redor de uma inclusão não magnética, adaptado de [1].}

Talvez este rico período tenha culminado com os trabalhos de Williams, Bozorth e Shockley, [18] e a revisão de Kittel [19] ambos em 1949, ponto a partir do qual a teoria de domínios passou a ser amplamente aceita.

Data desta época também o modelo Stoner-Wohlfarth [20], que considera apenas a energia de anisotropia magnetocristalina e a energia magnetostática de campo aplicado em uma partícula elipsoidal de magnetização uniforme.

Por fim, o micromagnetismo surge na vigília de todo este desenvolvimento, nos anos 60, quando William Fuller Brown Jr. [11] tenta unificar as diferentes contribuições numa formulação teórica genérica que descende diretamente das equações de Maxwell.

Como ele próprio argumenta, a teoria de domínios magnéticos foi constituída por uma "colcha de retalhos", funcionando por vezes como uma

\footnotetext{
${ }^{5}$ Néel, L., "Effet des cavités et des inclusions sur le champ coercitif", Cahiers de
} 
racionalização da observação experimental ao invés de realizar efetivas predições teóricas.

A abordagem do micromagnetismo possui a vantagem de não supor antecipadamente a existência de nenhuma estrutura em particular como paredes de domínios, ou os domínios eles próprios; isto é relevante porque ele busca uma teoria que explique também o caso de partículas pequenas estudadas por Kittel para as quais não há estrutura de domínios possível, além de singularidades que surgem em alguns casos, como vórtices.

Um exemplo de suas diversas críticas é o fato de que, à exceção de Néel, os pesquisadores mais proeminentes só reconheceram o modelo de domínios de fechamento de Landau e Lifshitz depois de 1945 e Döring (bem como Mager, acrescenta o autor deste texto) ignora completamente o campo desmagnetizante em seus cálculos. Isso fundamentou o hábito, infelizmente comum até hoje, de desenhar domínios magnéticos apontando em qualquer direção fácil sem levar em conta a energia magnetostática de campo desmagnetizante:

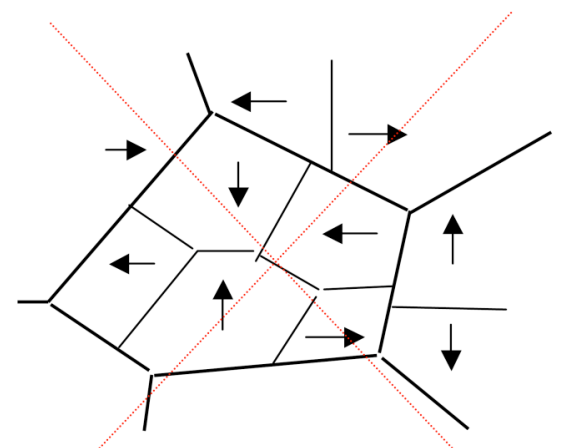

Errado

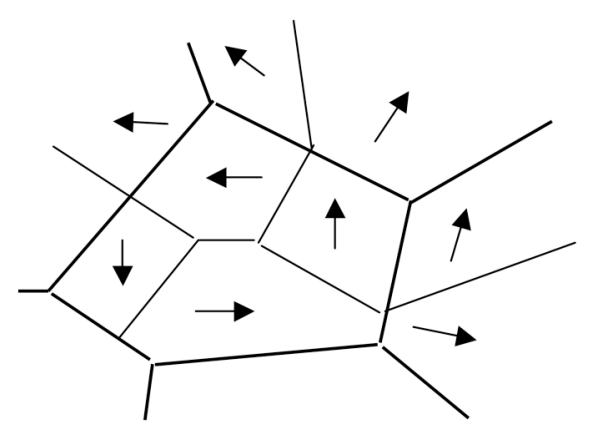

Certo

Ilustração 3 - Erros comuns ao desenhar domínios em material policristalino.

Physique, v. 25, 21-44, 1944 apud [1]. 


\subsection{Micromagnetismo}

Na prática, a teoria do micromagnetismo parte da suposição de que existe uma função contínua $M(r)$ que determina a direção da magnetização em cada ponto de material. Isto não é rigorosamente verdadeiro, já que na escala atômica existem descontinuidades de $M$. A energia total depende então de 5 contribuições distintas:

A energia de troca, $E_{J}$, de natureza quântica, a qual produz uma tendência de que as magnetizações de pontos adjacentes tenham a mesma direção.

$$
E_{J}=C / 2 \int|\nabla \cdot \vec{M}|^{2} d V
$$

Equação 2 - Energia de troca, na qual $C$ é duas vezes a constante de troca do material.

A energia de anisotropia magnetocristalina, $E_{m c}$, dependente da cristalografia do material, influenciando a magnetização a cada ponto a se alinhar com uma das direções de fácil magnetização.

$$
E_{m c}=\int\left[K_{1}\left(\alpha_{1}^{2} \alpha_{2}^{2}+\alpha_{1}^{2} \alpha_{3}^{2}+\alpha_{2}^{2} \alpha_{3}^{2}\right)+K_{2} \alpha_{1}^{2} \alpha_{2}^{2} \alpha_{3}^{2}\right] d V
$$

Equação 3 - Energia de anisotropia magnetocristalina, na qual $K_{1}$ e $K_{2}$ são as constantes de anisotropia magnetocristalina, e $\alpha_{1}, \alpha_{2}, \alpha_{3}$ são os cossenos do ângulos formados entre a magnetização e os três eixos do reticulado no caso de um material cúbico.

A energia de anisotropia magnetoelástica, $E_{m e}$, dependente da cristalografia e das tensões elásticas sobre o reticulado, levando $M$ a se alinhar a certo ângulo da tensão elástica conforme o material. 


$$
E_{m e}=3 / 2 \int \sigma \lambda \cos ^{2} \phi d V
$$

Equação 4 - Energia de magnetostricção, na qual $\lambda$ é a magnetostricção à saturação, $\sigma$ é a tensão aplicada e $\phi$ é o ângulo formado entre a direção da tensão e a magnetização.

A energia magnetostática de campo externo (ou energia de Zeeman), $E_{m s}$, surge na presença de um campo magnético externo aplicado $H_{0}$, criando a tendência de que $M$ se alinhe a ele ponto a ponto.

$$
E_{m s}=-\int \vec{M} \cdot \vec{H}_{0} d V
$$

Equação 5 - Energia de Zeeman.

A energia magnetostática de campo desmagnetizante, $E_{\text {desmag, surge na }}$ presença de um campo desmagnetizante $H_{\text {desmag, }}$ criando a tendência de que $M$ possua a menor divergência possível por todo o espaço.

$$
E_{\text {desmag }}=-1 / 2 \int \vec{M} \cdot \vec{H}_{\text {desmag }} d V
$$

Equação 6 - Energia devida ao campo desmagnetizante.

E, por fim, a etapa mais onerosa é o cálculo do campo desmagnetizante através do potencial magnetostático: 


$$
\Phi_{m a g}(\vec{r})=\iiint_{V} \frac{\nabla \cdot \vec{M}}{\left\|\vec{r}-\vec{r}^{\prime}\right\|} d^{3} \vec{r}^{\prime}+\iint_{A} \frac{\sigma_{M}}{\left\|\vec{r}-\vec{r}^{\prime}\right\|} d^{2} \vec{r}^{\prime}
$$

Equação 7 - Potencial magnetostático, na qual $r$ é o vetor posição, $r$ ' percorre as regiões a serem integradas, $V$ é o volume analisado, $A$ é a área da superfície que separa dois meios e $\sigma_{M}$ a divergência da magnetização ${ }^{6}$ ao longo desta superfície.

O campo desmagnetizante pode ser obtido a partir das suas derivadas parciais $H_{\text {desmag }}=-\operatorname{grad}\left(\Phi_{\text {mag }}\right)$.

Nota-se, por exemplo, que não existe um termo para a energia de parede de domínio; isso se dá porque se calcula a energia ponto a ponto, sem jamais se perguntar se aquele ponto pertence a uma parede ou a um domínio.

Ao invés de supor uma estrutura de domínios particular e tentar calcular analitica ou numericamente o valor de cada contribuição energética, esta abordagem permite obter diretamente o valor da função $M$ em cada ponto do espaço que minimiza a energia total. Com isso, evita-se uma etapa de cálculo que poderia induzir ao erro em muitos casos.

Para tanto, é preciso lançar mão de métodos computacionais. O cálculo pode ser resolvido com métodos de elementos finitos ou diferenças finitas [11, 21]. O método das diferenças finitas utiliza malhas regulares (compostas de paralelepípedos), calculando os valores das incógnitas em cada nó. Devido à estrutura da malha, as equações de interação entre cada nó e seus vizinhos são idênticas, de forma que podem ser geradas à medida que se desenvolve

\footnotetext{
${ }^{6}$ A rigor, a definição de $\sigma_{M}$ é a diferença entre as componentes normais da magnetização de um lado e de outro da superfície: $\sigma_{M}=M_{s} \cdot\left(\hat{n}_{2}-\hat{n}_{1}\right)$. Porém, se a magnetização é constante em ambos os lados de um superfície plana, o valor da divergência da magnetização, $\nabla \cdot \vec{M}$, calculado para qualquer volume de altura infinitesimal construído ao redor desta superfície, se reduz a $\sigma_{M}$.
} 
o cálculo ("on the fly"). Com isso evita-se o cálculo da matriz de interação poupando memória e tempo de execução.

O método de elementos finitos utiliza uma malha tetraedral, permitindo uma melhor aproximação de formas circulares ou elipsoidais, porém com um custo de tempo de execução e memória associado. Além da questão da forma, uma grande vantagem do método dos elementos finitos é a compatibilidade com programas de criação de malhas, de forma que se pode simular com maior facilidade a estrutura de um defeito cristalino.

Em 1992, Koehler [21] fez uma discretização das fórmulas de energia, aplicando-a a uma rede de elementos finitos para o cálculo da magnetização em pequenas partículas magnéticas. Ele utilizou um método de elementos de fronteira para reduzir o tempo de processamento. Seu critério para encontrar condições de equilíbrio se baseava num algoritmo de busca: fazem-se palpites da direção de magnetização e calcula-se a energia para cada caso, baseados nos valores de $E$ são feitos novos palpites da orientação de $M$ e assim por diante, até atingir um mínimo de $E(M)$.

Atualmente, utiliza-se as equações do micromagnetismo para calcular o campo $H$ efetivo em cada ponto da malha, devido a cada uma das 5 contribuições energéticas, e depois calcula-se a magnetização a partir da equação de Landau-Lifshitz para cada instante de tempo (time-stepping), com intervalos na ordem picosegundos.

Ao longo de uma histerese, por exemplo, quando a velocidade de rotação (ângulo/picosegundo) da magnetização atinge em cada ponto um valor menor do que o limite determinado pelo usuário, considera-se que o sistema está em equilíbrio, e o campo externo é alterado.

Existem apenas dois programas de código livre disponíveis para modelamento micromagnético: OOMMF que trabalha com o método das diferenças finitas, é mais simples de operar e permite acompanhar a evolução de sistema enquanto são realizadas as iteração; e NMAG que 
trabalha com o método dos elementos finitos, suporta maior complexidade, mas depende de algumas etapas auxiliares para que se posso visualizar os resultados por ele obtidos.

Em ambos os casos, em um computador de uso pessoal, não se pode simular um volume maior de que $1 \mu \mathrm{m}^{3}$, pois os nós da malha devem distar de no máximo $20 \mathrm{~nm}$, para permitir o cálculo correto da energia de troca. Esta grande requisição de capacidade computacional restringe muito a aplicabilidade deste modelo.

\subsection{Modelo Jiles-Atherton}

Talvez por ser um modelo de natureza fenomenológica, o modelo JilesAtherton tem uma simplicidade muito elegante, e muitos consideram como a solução definitiva para a histerese magnética. Muito embora esteja repleto de argumentos da teoria de domínios magnéticos, este modelo depende fundamentalmente da escolha arbitrária da função que melhor se enquadra aos dados experimentais.

Está baseado na suposição de que a magnetização do material ao longo de uma curva anisterética em função do campo efetivo pode ser aproximada por uma função de Langevin:

$$
M_{a n}\left(H_{e}\right)=M_{s}\left[\operatorname{coth}\left(H_{e} / a\right)-a / H_{e}\right]
$$

Equação 8 - Ajuste de Langevin da curva anisterética [3], na qual $\boldsymbol{M}_{a n}$ é a magnetização ansiterética, $H_{e}$ é o campo efetivo, a é um parâmetro de aproximação, $M_{s}$ deveria ser a magnetização da saturação do material, mas muitas vezes é utilizado como um parâmetro de ajuste adicional. 
Sendo que o campo efetivo $H_{e}$ descreve o efeito conjugado do campo externo e de interações entre domínios no interior do material através da constante de campo médio $\alpha$, a ser determinada experimentalmente:

$$
H_{e}=H+\alpha M
$$

Equação 9 - Campo efetivo [3], na qual a constante de campo médio, $\alpha$, é um parâmetro de aproximação.

A curva anisterética representa uma sucessão de estados de equílibrio, os quais o material atinge conforme o campo aplicado. Está associada a um comportamento idealizado em que as paredes do domínio se movem de forma reversível no interior do material, sem dispêndio de energia:

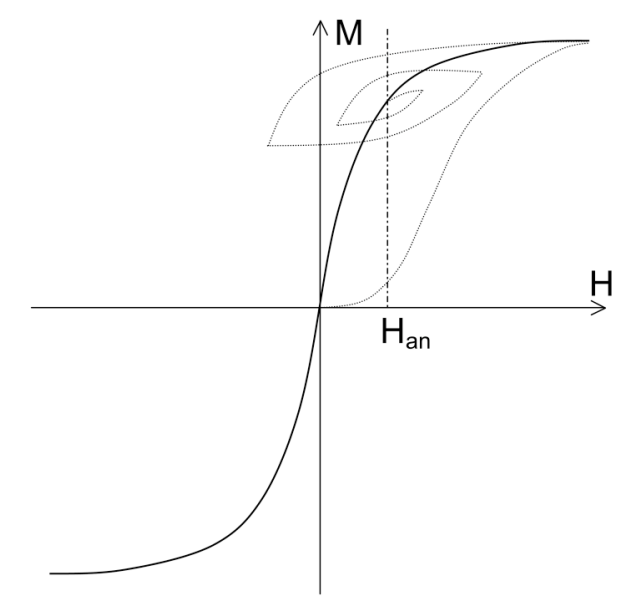

Ilustração 4 - Curva anisterética.

Esta curva pode ser traçada experimentalmente aplicando um $H$ conhecido $H_{\text {an }}$, conjuntamente com um campo alternado de baixa frequência e amplitude decrescente $H_{\text {rev }}$ até o ponto em que o mesmo se anule, ponto este em que se mede a indução resultante.

Porém, para compreender o comportamento real do material considera-se que existem impedimentos para a movimentação de paredes no seu interior. A partir daí, a energia armazenada na magnetização é a diferença entre a 
energia armazenada no caso ideal, menos o trabalho realizado na superação dos impedimentos. Além disso, existe uma terceira componente da magnetização, que é devida à flexão de paredes de domínio.

Omitindo o equacionamento das contribuições de superação de impedimentos e flexão de paredes, somando todas as três componentes, temos:

$$
\frac{d M}{d H}=\frac{1}{(1+c)} \frac{M_{a n}-M}{ \pm k / \mu_{0}-\alpha\left(M_{a n}-M\right)}+\frac{c}{(1+c)} \frac{d M_{a n}}{H}
$$

Equação 10 - Equação diferencial para $M(H)$ [3], na qual $c$ é um parâmetro de aproximação e o termo relacionado com energia média de impedimentos, $k / \mu_{0}$, deve ser somado no ramo ascendente da histerese e subtraído no ramo descendente.

A solução para esta equação diferencial é uma função $M(H)$ a qual aproxima muito bem as curvas de histerese de materiais policristalinos, dado que os parâmetros $\alpha, c$ e $k$ sejam determinados experimentalmente, o que se escolha o valor correto para os parâmetros a e $M_{s}$, utilizado na equação de Langevin para $M_{a n}$.

A força deste modelo está nos argumentos extremamente simples e distanciados das vicissitudes da microestrutura utilizados para obter as equações. Como a dupla indica, os mecanismos propostos (superação de impedimentos e flexão de paredes) e parte de seu equacionamento já haviam sido explorados em outros trabalhos.

O ponto fraco é o ajuste realizado à curva anisterética com a função de Langevin. Muito embora esta curva possa ser determinada de forma experimental, o fato de sua aproximação não estar baseada em nenhum argumento teórico caracteriza este modelo como fenomenológico. 
Esta visão da histerese, de que ocorrem transições no interior do material passando por diversos mínimos locais de energia ao longo de uma curva anisterética à qual vem se adicionar contribuições de uma parcela reversível de flexão de paredes e uma parcela irreversível de superação de impedimentos é muito atrativa e crível.

Porém, como enfatizado diversas vezes no seu principal artigo [3], este modelo não se preocupa com a natureza dos impedimentos nem sua geometria. Ora, é exatamente isto que os engenheiros de materiais são capazes de controlar, natureza e geometria dos defeitos cristalinos. Então, por toda sua elegância, o modelo Jiles-Atherton deixar a desejar como ferramenta para projetar novos materiais.

\subsection{Modelo de Preisach}

O modelo do Preisach ignora completamente o mecanismo de magnetização e considera apenas o estado do sistema num dado instante do tempo. Cada entidade magnética, chamada de histéron ou histerão, possui dois estados possíveis: sua magnetização interna está alinhada no sentido positivo; ou no sentido negativo. Este modelo é escalar em princípio, já que a magnetização do histerão só pode se orientar nestes dois sentidos, mas existem expansões vetoriais do modelo para a aplicações nos quais o campo é rotacional.

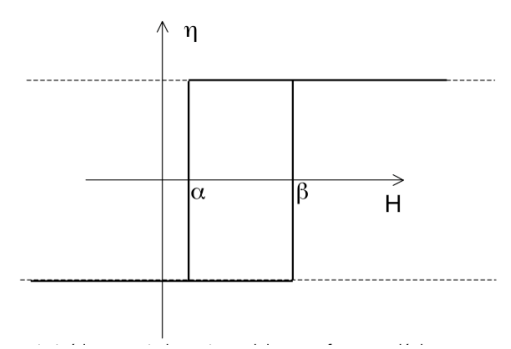

llustração 5 - Entidade magnética / Histerão de Preisach

O estado de cada histerão depende do campo aplicado e do campo de interação entre histerões. O modelo clássico de Preisach considera que, 
embora o campo de interação se altere cada vez que um histerão passa por uma transição, ele se mantém estatisticamente constante.

Cada histerão é descrito pelos campos necessários para provocar a transição de um estado a outro. Estes dois campos seriam iguais em módulo com sinais opostos se não houvessem interações no sistema. Num sistema com interações, este não é o caso. Os histerões são caracterizados por sua posição no semi-plano de Preisach, sendo que sua coordenada no eixo das abscissas é igual ao campo necessário para realizar a transição do estado positivo para o negativo e sua coordenada no eixo das ordenadas é o campo necessário para realizar a transição contrária. É requisito que $\beta_{i}$ seja sempre maior que $\alpha_{j}$.

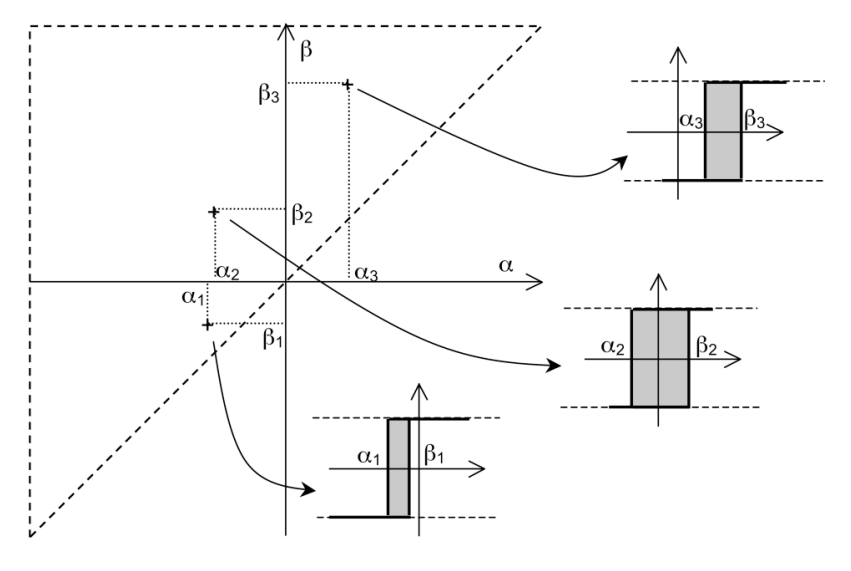

llustração 6 - Três histerões no plano de Preisach

Podemos supor a sobreposição de infinitos histerões no plano. Inclusive, diversos histerões podem estar localizados no mesmo ponto. O sistema é então caracterizado pela função que descreve a probabilidade de se encontrar um histerão em um determinado ponto, a partir das coordenadas do ponto. Esta é a função densidade de probabilidade de histerões $P(\alpha, \beta)$, também chamada função de Preisach normalizada.

A magnetização do sistema depende não só do campo aplicado num dado instante, mas também dos estados anteriores dos histerões. Se chamamos 
os campos necessários para "desligar e ligar" de $\alpha$ e $\beta$, respectivamente, o que ocorre quando um campo $\alpha<H<\beta$ é aplicado? O histerão permanece na exata mesma condição em que estava antes.

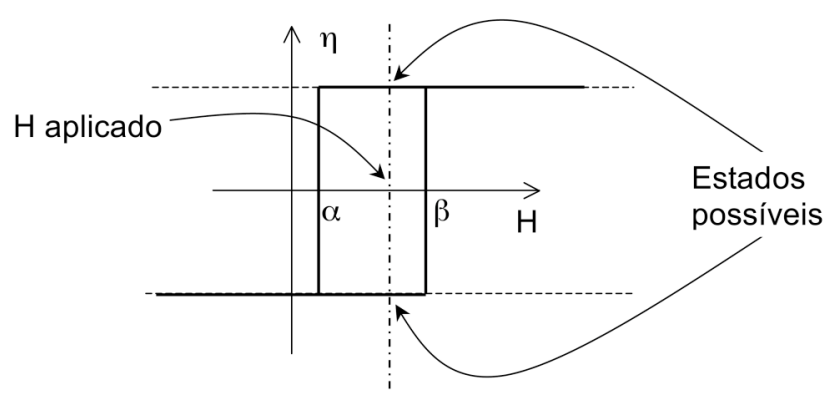

llustração 7 - Estados possíveis do histerão.

Para representar este fato, a cada ponto de semi-plano de Preisach é preciso atribuir (além da densidade de histerões no ponto) também o estado atual destes histerões, que no modelo clássico assume apenas os valores +1 ou 1. Existem modelos mais complexos nos quais há a possibilidade de estados intermediários.

Dessa forma, existe uma função memória $\eta(\alpha, \beta)$ que assume as valores +1 ou -1 para cada ponto do plano, relembrando os estados anteriores. A magnetização global é o produto da função densidade de probabilidade de histerões vezes a função de estado, integradas ao longo do semi-plano:

$$
M=M_{s} \int_{-\infty}^{+\infty} \int_{-\infty}^{\beta} P(\alpha, \beta) \cdot \eta\left(\alpha, \beta, H_{\text {aplicado }}, H_{\text {anterior }}\right) d \alpha d \beta
$$

Equação 11 - Integral de $M$ no modelo Preisach, na qual $P$ é a densidade de probabilidade de se encontrar um histerão no ponto $(\alpha, \beta)$, e $\eta$ seu estado (apenas +1 ou -1 no modelo clássico).

A interpretação geométrica do modelo é muito útil para sua compreensão. Existem aplicativos na rede [22] que permitem se familiarizar com suas características. 


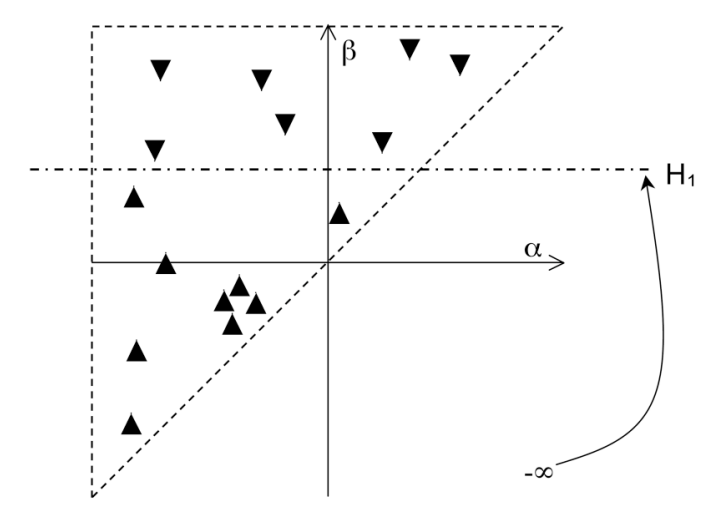

Ilustração 8 - Exemplo de plano de Preisach com $H$ aplicado crescente a partir de $-\infty$.

Partindo de um estado em que todos os histerões estão "desligados", ou seja, o material está saturado no sentido da magnetização negativa $\left(H_{\text {anterior }}=-\infty\right)$, à medida que aumentamos o campo aplicado até $H_{1}$, vemos o valor de $\beta_{i}$ é ultrapassado causando a transição para o estado +1 de todos os histerões que se localizam no plano de Preisach abaixo de uma linha horizontal cuja intersecção com o eixo y é o valor de campo $H_{1}$.

No caso representado na figura, para um campo aplicado $H_{1}$ partindo do estado saturado no sentido negativo, a magnetização do material vale: +9 histerões ligados -7 histerões desligados/ 16 histerões totais $=0,125^{*} M_{s}$

Quando reduzimos o campo a partir do valor $H_{1}$, todos os histerões que se encontram à direita de uma linha vertical cuja intersecção com o eixo $x$ é $H_{2}$ serão desligados, pois o campo aplicado é menor que o valor de seus $\alpha_{i}$. Os demais permanecem no mesmo estado anterior. 


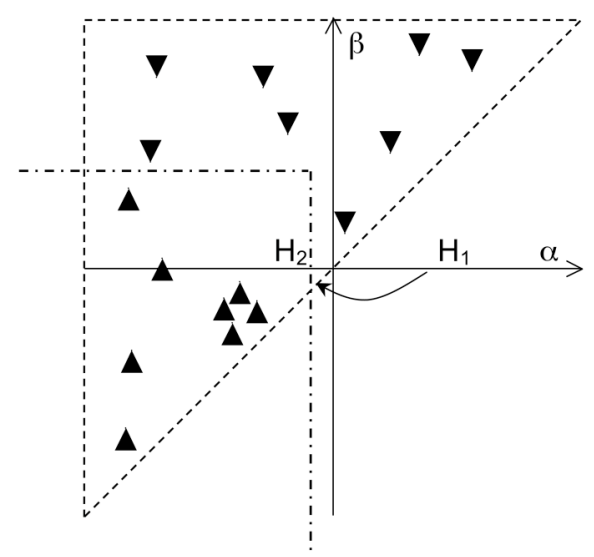

llustração 9 - Exemplo de plano de Preisach para material desmagnetizado.

Com essa transição alcançamos o estado desmagnetizado. A quantidade de histerões que melhor caracteriza melhor cada material bem como suas posições no plano de Preisach não podem ser obtidas de forma teórica, afinal, se trata de um modelo fenomenológico. Porém, existem métodos de determinação experimental destas variáveis medindo curvas de magnetização do material.

\subsection{Recapitulação}

Observando o histórico da teoria de domínios magnéticos, notamos a importância do campo desmagnetizante em determinar os limites para o surgimento e propagação de "minhocas de remagnetização" no interior do material.

Percebemos que o micromagnetismo é o caminho que permite a consideração desta contribuição em todo rigor, apoiando-se numa base teórica sólida. No entanto, esta técnica é fortemente limitada pela capacidade computacional exigida, impedindo a análise de um material policristalino com dimensões macrométricas. 
Vemos também que os modelos de Jiles-Atherton e Preisach utilizam artifícios matemáticos que driblam a interpretação da microestrutura do material em todo seu detalhe para poder descrever a histerese magnética.

No presente trabalho propomos o cálculo simplificado do campo desmagnetizante no contorno de grão em associação com a abordagem de Mager, apoiado por uma verificação utilizando micromagnetismo.

Além disso, buscamos a análise detalhada da microestrutura através da determinação da distribuição de tamanho de grão e textura cristalográfica e sua aplicação no modelo de Preisach. 


\section{Materiais e métodos}

\subsection{Introdução}

No presente trabalho buscou-se refinar os dados que dão origem à curva de campo coercivo em função de tamanho de grão, traçada em trabalhos anteriores [23].

É preciso diferenciar entre dois grupos de amostras: Além de servir-se de amostras já obtidas no passado por deformação e recozimento, cujos tamanhos de grão variaram por recristalização, novas amostras foram preparadas por recozimento direto, de forma que seu tamanho de grão variou por crescimento de grão gerando textura cristalográfica e distribuição de tamanho de grão diferenciados.

Nas amostras recristalizadas, foram realizadas novas medidas de tamanho de grão, pois acreditava-se que esta variável era a maior fonte de erro. As amostras utilizadas para metalografia haviam sido retiradas de regiões que sofreram menor deformação plástica do que as amostras analisadas por ensaio magnético. Dessa vez, uma lâmina de cada conjunto Epstein foi destruída para realizar a análise de tamanho de grão.

Ainda numa preocupação de melhorar a confiabilidade dos dados, as medidas magnéticas foram refeitas. Portanto, apesar da utilização das amostras de recristalização, todas as medidas apresentadas neste trabalho são novas. As amostras de crescimento de grão foram produzidas a partir de chapas sobressalentes do mesmo aço.

Além disso, outra variável que acreditava-se influenciar os resultados, a textura cristalográfica, foi investigada. Para tanto, foram efetuados ensaios magnéticos de lâmina única no aparelho SOKEN para obtenção de valores da indução magnética a 5000A/m, $B_{50}$, bem como difração de elétrons retro- 
espalhados (EBSD) à meia espessura do material, no microscópio eletrônico de varredura.

Por fim, para melhor compreender o efeito da indução máxima utilizada nas medições, ensaios de histerese em regime quase-estático $(5 \mathrm{mHz})$ foram realizados a $0,6-0,8-1,0-1,2-1,4$ e $1,5 \mathrm{~T}$.

Paralelamente, foi conduzido um pequeno ensaio de visualização de domínios magnéticos por efeito Kerr. Os resultados foram comparados com a figura de pólo inversa obtida por EBSD.

A primeira seção do texto que segue trata da obtenção das amostras. Depois, das medidas magnéticas, tamanho de grão e textura cristalográfica. Por fim, comenta-se a observação de domínios.

\subsection{Obtenção das amostras}

Uma chapa de aço para fins elétricos Usicore cordialmente cedida pela Usiminas Cubatão, cuja composição pode ser encontrada na Tabela 1, foi cortada em guilhotina no para produzir 7 folhas, as quais foram laminadas a diferentes graus de redução de área como visto na Tabela 2 .

O corte das amostras foi realizado ora no Departamento de Engenharia Mecânica da Escola Politécnica da USP ora no Instituto de Pesquisas Tecnológicas, sob a assistência de Sandra Munarim. A lâminação foi realizada em sua maioria no IPT, porém algumas amostras foram laminadas no Departamento de Engenharia Metalúrgica e de Materiais (POLI - USP) com apoio do prof. Dr. Ronald Lesley Plaut. 
Tabela 1 - Composição química do aço utilizado

\begin{tabular}{c||ccccccc} 
Elemento & $\mathrm{C}$ & $\mathrm{Mn}$ & $\mathrm{P}$ & $\mathrm{S}$ & $\mathrm{Si}$ & $\mathrm{Cu}$ & $\mathrm{Al}$ \\
\hline$\%$ massa & $24 \mathrm{ppm}$ & 0,5 & 0,016 & 0,0086 & 0,69 & 0,066 & 0,312 \\
\hline Elemento & $\mathrm{B}$ & $\mathrm{Nb}$ & $\mathrm{V}$ & $\mathrm{Ti}$ & $\mathrm{Mo}$ & $\mathrm{Ni}$ & $\mathrm{Cr}$ \\
\hline$\%$ massa & $1 \mathrm{ppm}$ & 0,0024 & 0,013 & 0,001 & 0,056 & 0,0108 & 0,025
\end{tabular}

Tabela 2 - Deformação real e espessura das amostras recristalizadas

\begin{tabular}{c||ccccccc} 
Nomenclatura & S343 & S400 & S451 & S475 & S488 & S501 & S511 \\
\hline Espessura (um) & 343 & 400 & 451 & 475 & 488 & 501 & 511 \\
\hline Deformação Real (\%) & 41 & 27 & 15 & 10 & 7,5 & 5,5 & 3,6
\end{tabular}

Estas amostras foram cortadas em conjuntos de 8 lâminas Epstein $(300 \times 30 \mathrm{~mm})$ e depois recozidas a $760^{\circ} \mathrm{C}$ por 2 horas em atmosfera levemente oxidante (descarbonetante), de forma a obter diferentes tamanhos de grão por recristalização.

Além disso, utilizou uma chapa adicional de aço de mesma composição para obter 6 conjuntos Epstein (8 lâminas, 300x30mm) os quais foram recozidos a tempos e temperaturas diferentes, conforme Tabela 3, para produzir diferentes tamanhos de grão por crescimento de grão:

Tabela 3 - Parâmetros de recozimento das amostras de crescimento de grão

\begin{tabular}{c||cccccc} 
Nomenclatura & E602 & E682 & E762 & E854 & E858 & E8512 \\
\hline Temperatura $\left({ }^{\circ} \mathrm{C}\right)$ & 600 & 680 & 760 & 850 & 850 & 850 \\
\hline Tempo $(\mathrm{h})$ & 2 & 2 & 2 & 4 & 8 & 12
\end{tabular}

À exceção das amostras $680^{\circ} \mathrm{C}, 2 \mathrm{~h}$ e $850^{\circ} \mathrm{C}, 12 \mathrm{~h}$ foi utilizada atmosfera de recozimento levemente oxidante, como no caso das amostras recristalizadas. 


\subsection{Medidas magnéticas}

A partir dos dados coletados no quadro de Epstein, a curva de histerese em regime quase estático $(5 \mathrm{mHz})$ foi traçada para cada um dos 13 conjuntos com 8 lâminas às induções máximas de 0,6 - 0,8-1,0-1,2-1,4 e 1,5.

Obteve-se 600 pontos $\left[H_{i}, B_{i}\right]$ por ciclo, num total de 3 ciclos por ensaio. Os valores de $H_{c}$ foram coletados através de um ajuste linear realizado em todos os pontos para os quais $\left|B_{i}\right|<0,33\left|B_{\max }\right|$ supondo-se simetria para os valores positivos e negativos de $H$.

Estas medidas foram realizadas utilizando um quadro Epstein com fluxímetro Walker MF-3D conectado à bobina secundária. A corrente primária foi suprida por um amplificador de potência KEPCO BOP 50-50 com um gerador de onda HP 33120A/dc-15MHz e medida por um resistor shunt conectado a um multímetro HP 334401A.

Os valores de corrente e indução foram coletados e gravados num banco de dados a partir do qual calculou-se o campo aplicado e a indução magnética no interior das amostras. Durante as medidas o campo B variou de forma senoidal.

Também no quadro de Epstein foram medidas as curvas de magnetização para cada conjunto de amostras. A partir de um ajuste polinomial, determinou-se o valor de indução a $5000 \mathrm{~A} / \mathrm{cm}, B_{50}$.

Além disso, foram realizados ensaios de lâmina única no aparelho SOKEN em 6 lâminas de cada conjunto, em 3 pontos diferentes de cada lâmina. Os ensaios, cujo objetivo era averiguar variações locais de textura cristalográfica, permitiram a obtenção dos valores de $B_{50}$. 


\subsection{Tamanho de grão}

\subsubsection{Introdução}

Para as medidas de tamanho de grão, após realizados os ensaios magnéticos no quadro de Epstein, foram cortados pedaços de $2 \mathrm{~cm}^{2}$ de uma lâmina de cada conjunto com disco cerâmico, para ensaio metalográfico.

Os pedaços foram embutidos em baquelita, lixados em lixas de carbeto de silício com granulometria decrescente, e polidos em panos com pasta de diamante de 9, 6 e $1 \mu \mathrm{m}$, segundo técnicas tradicionais. A estrutura de grãos foi revelada por ataque com reagente Nital 5-10\%.

Foram capturados 12 campos escolhidos às cegas de cada amostra, os quais foram analisados por dois métodos:

- Pelo método clássico dos interceptos [24], contando-se o número de intersecções de contorno de grão com um círculo de tamanho conhecido traçado sobre as micrografias.

- Por um método semi-analítico, cuja descrição e detalhes se encontram a seguir.

\subsubsection{Método semi-automático}

Os mesmos campos sobre os quais se fez a medida de intercepto médio foram analisados por um método semi-automático [25], conforme em trabalhos anteriores [23], o qual permite a obtenção da distribuição de tamanho de grão a partir das áreas individuais dos grãos, medidas diretamente da micrografia.

Este método consiste no uso dos recursos do programa de análise de imagens Altra System, instalado no laboratório de metalografia Hubertus 
Colpaert, PMT-USP. Através de filtros que consideram o contraste de luminosidade entre os diferentes pixeis, o programa reconhece os contornos de grão, e mede a área de cada grão em pixel $^{2}$.

O valor em pixel quadrado é simplesmente o número total de pixeis, considerado cada um com a mesma área de 1 pixel $^{2}$, ou seja, a soma dos pixeis que constituem a figura (não existe 0,5 pixel $^{2}$ para o software).

A seguir, estas áreas são convertidas em micrômetros e delas se obtém o diâmetro equivalente, que é definido como o diâmetro do círculo de mesma área. A listo com os valores dos diâmetros de cada grão é utilizada para obtenção dos parâmetros da distribuição de tamanho de grão segundo um ajuste lognormal conforme discutido na seção seguinte, 3.4.3 Ajuste lognormal da distribuição de TG.

As imagens foram capturadas em preto em branco, uma vez que se trata de um aço ferrítico, para o qual a cor não acrescenta informação alguma. Caso isso não tenha sido feito, é conveniente obter um imagem preto e branco utilizando filtros os separando os canais RGB.

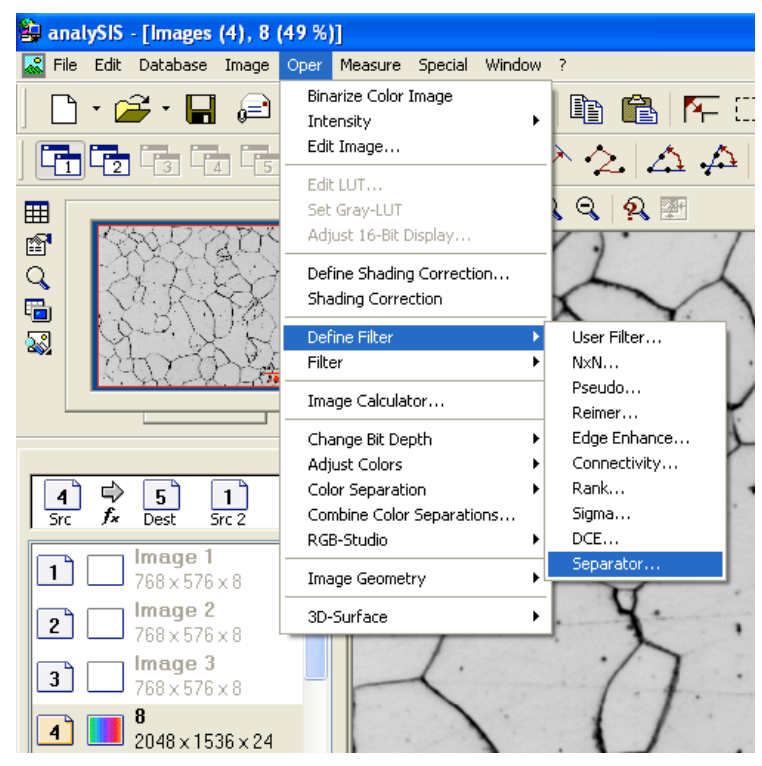

Ilustração 10 - Escolha do filtro

O programa já contém uma ferramenta de identificação de grão implementada; se trata do filtro "separator", o qual foi utilizado neste trabalho. Após entrar no programa e carregar a imagem desejada, já com sua escala, seleciona-se o filtro.

\footnotetext{
"separator"
} 


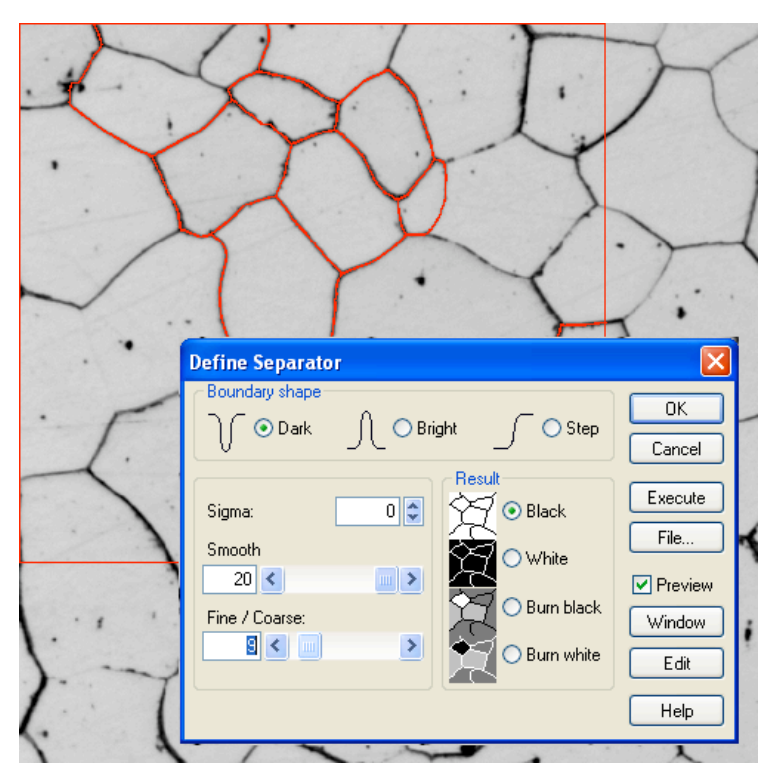

Ilustração 11 - Características do

"separator"

$\mathrm{Na}$ llustração 11, nota-se, em vermelho, aquilo que o programa detectou como sendo contornos de grão. Vê-se na caixa de diálogo "Define Separator" que ele está configurado para localizar regiões que possuam pixeis muito mais escuros do que seu arredor ("Boundary Shape" = "Dark"). É isso que ocorre com o contorno de grão do aço, no ataque pelo Nital, ele fica escuro em relação à matriz.

Alguns contornos não são reconhecidos, ou porque não foram revelados pelo ataque químico, ou porque a rotina do programa não consegue detectá-los. Clicando no botão "Edit", (mostrado na llustração 11) abrimos a caixa de diálogo que nos permite modificar a seleção, acrescentando contornos ou removendo-os. 


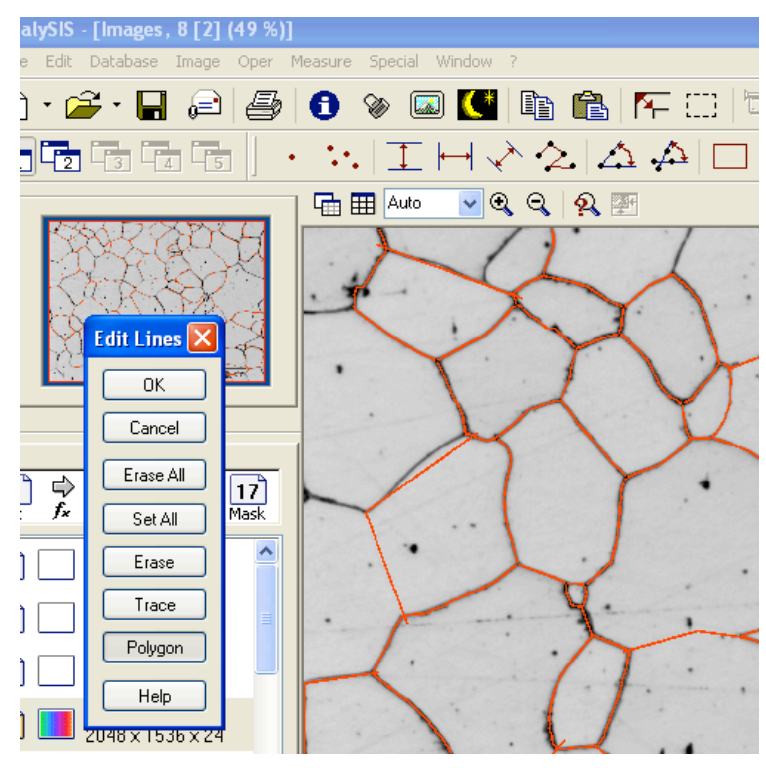

Ilustração 12 - Traçando contornos manualmente

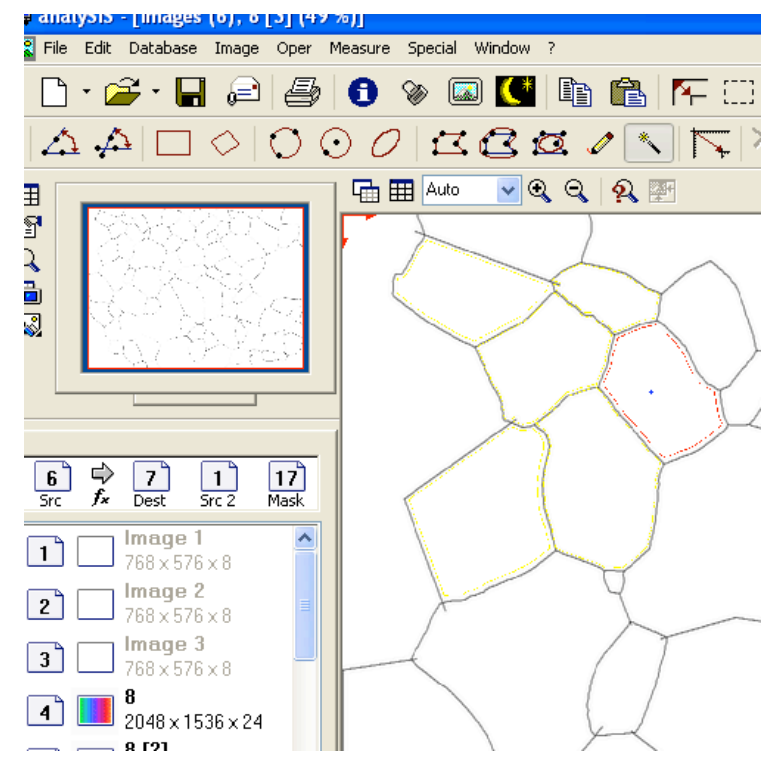

Ilustração 13 - Ferramenta "Magic

Wand"
A llustração 12 mostra a mesma região que anteriormente, já com os contornos editados manualmente com a ferramenta "Polygon". A etapa de edição dos contornos é o que caracteriza este método como semi-automático. Ela assegura que nenhum dado foi registrado sem verificação humana.

A seguir, utilizando a ferramenta "Magic Wand", seleciona-se cada grão. Esta é uma ferramenta comum de programas de análise de imagens que seleciona uma área fechada com pixies de mesma intensidade ou cor, colocando um objeto de mesma forma por sobre ela (em amarelo na llustração 13).

O objeto é completamente conhecido pelo programa. Suas dimensões em pixies e demais características podem ser consultadas a vontade. 


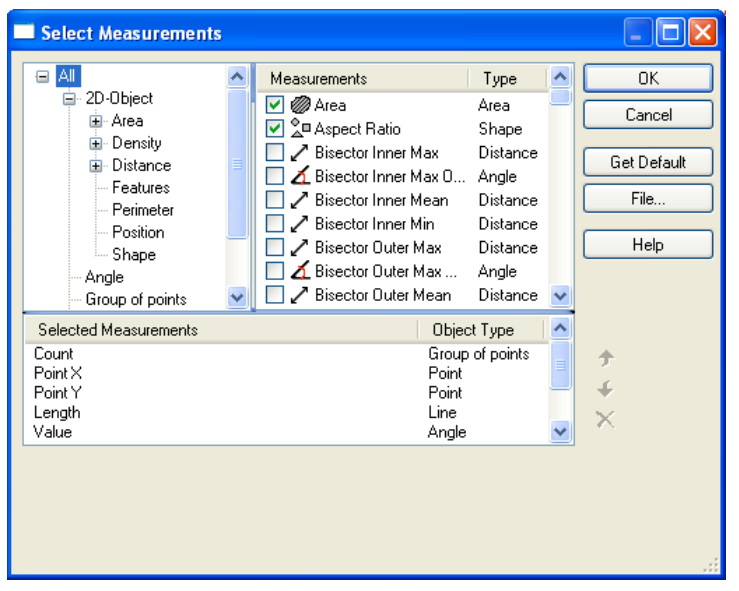

Foi selecionado que o programa gerasse uma planilha de dados contendo o diâmetro e a área de cada grão.

As planilhas de cada imagem analisada foram exportadas para $\mathrm{O}$ Microsoft Excel.

\section{Ilustração 14 - Escolha das medidas}

Foram utilizados no mínimo 600 grãos por amostra, sendo que a maior parte das distribuições contém uma quantidade maior que 1800, como se pode ver na tabela.

Tabela 4 - Número de grãos utilizados pelo método semi-automático

\begin{tabular}{c|rrrrrrr} 
Amostra & E602 & E682 & E762 & E854 & E858 & E8512 \\
\hline$n^{\circ}$ grãos & 892 & 1424 & 677 & 942 & 5823 & 2506 \\
\hline Amostra & S343 & S400 & S451 & S475 & S488 & S501 & S511 \\
\hline$n^{\circ}$ grãos & 3983 & 3044 & 2982 & 2134 & 1869 & 3018 & 1876
\end{tabular}

Este valor depende da razão (tamanho de grão) x (aumento de captura) para os campos analisados. Com preparação metalográfica de melhor qualidade é possível utilizar um aumento menor sem perda de informação. Foram capturados 12 a 14 campos por amostra, à exceção da amostra E858, a qual teve 27 campos utilizados.

O número elevado de grãos da amostra E858 se deve à necessidade de localizar um número suficiente de grãos grandes, os quais são muito escassos, para permitir que a distribuição contivesse um número suficiente de membros em cada classe de tamanho, ou seja, não ficasse truncada para os grãos maiores. 


\subsubsection{Ajuste lognormal da distribuição de TG}

Para caracterizar as distribuições de tamanho de grão obtidas, foi realizado um ajuste lognormal. Muito embora se discuta a possibilidade de outros ajustes, como uma função gama, o ajuste lognormal é uma ótima aproximação para distribuição de tamanho de grão [26].

A partir das áreas dos grãos, $A_{i}$, podem ser obtidos o diâmetro equivalente (diâmetro de círculo de mesma área) e a fração de área:

$$
d_{i}=2 \sqrt{A_{i} / \pi} ; \quad f_{i}=A_{i} / \sum A_{i}
$$

Equação 12 - Dados experimentais da distribuição de tamanho de grão.

Supondo que os tamanhos de grão seguem uma distribuição lognormal em relação à fração de área, os parâmetros da distribuição podem ser calculados por:

$$
u_{A}=\sum f_{i} \ln d_{i} ; \quad s_{A}=\sum\left[\ln d_{i}-u_{A}\right]^{2}
$$

Equação 13 - Parâmetros de ajuste da distribuição de tamanho de grão, posição do pico, $u_{A}$, e largura do pico, $s_{A}$.

Os valores obtidos de tal maneira representam uma estimativa dos parâmetros com base nos valores experimentais de $d_{i}$ e $f_{i}$. Quando número de grãos analisados tende a infinito, $u_{A}$ e $s_{A}$ tendem aos valores reais. Dessa forma, a fração de área ocupada por grãos de diâmetro $d_{i}$ fica:

$$
f_{i}=\frac{1}{d_{i} \sqrt{2 \pi s_{A}}} \exp \left(-\left[\ln d_{i}-u_{A}\right]^{2} / 2 s_{A}\right)
$$

Equação 14 - Ajuste da distribuição de TG, fração de área para grão com tamanho $d_{i}$. 
Por outro lado, a fração de área ocupada por grão de diâmetro menor de que $d_{i}$, fica:

$$
F_{i}=\int_{0}^{d_{i}} f_{i}(x) d x=\frac{1}{2}+\frac{1}{2} \operatorname{erf}\left[\frac{\ln d_{i}-u_{A}}{\sqrt{2 s_{A}}}\right]
$$

Equação 15 - Ajuste da distribuição de TG, fração de área acumulada para grão com tamanho até $d_{i}$.

A mediana e a esperança, respectivamente:

$$
d_{M}=\exp \left(u_{A}\right) ; \quad d_{A}=\exp \left(u_{A}+0,5 s_{A}\right)
$$

Equação 16 - Mediana $d_{M}$ e esperança $d_{A}$ da distribuição de $T G$.

É importante diferenciar este valor do diâmetro médio ponderado pela fração de área, usado em trabalhos anteriores [23]. Ambos possuem o mesmo significado físico e devem convergir para um mesmo valor à medida que o número de grãos analisados cresce, porém um é calculado diretamente a partir dos diâmetros equivalentes e o outro a partir dos parâmetros da distribuição.

\subsection{Textura cristalográfica}

\subsubsection{Preparação de amostra}

A partir de novos pedaços extraídos das mesmas lâminas utilizadas para metalografia, foram preparados embutimentos de área um pouco menor $\left(1 \mathrm{~cm}^{2}\right)$, para facilitar o polimento.

A seguir, as amostras embutidas foram lixadas até a meia espessura e polidas, de maneira diferente de uma preparação metalográfica tradicional. Após extensiva consulta à literatura, o autor deste trabalho deparou-se com a 
frase "preparação metalográfica cuidadosa" um sem número de vezes, de forma que parece adequado explicitar aqui algumas das sutilezas da preparação de amostras para ensaio EBSD.

Essencialmente, só existe um defeito de preparação realmente frequente para análise de difração de elétrons retroespalhados: deformação plástica. Quando se realiza o lixamento, principalmente nas granulometrias mais altas, ocorre deformação plástica apreciável até camadas subsuperficiais, de forma que é necessário remover material, sem no entanto causar nova deformação plástica.

Isso pode ser atingido através de uma preparação metalográfica cuidadosa, mas, para materiais muito moles, como aço baixo carbono de tamanho de grão grande, pode ser interessante recorrer ao ataque químico. Todas as amostras do presente trabalho foram lixadas com esta técnica.

Primeiro realizou-se a remoção de uma camada de $150 \mu \mathrm{m}$ medidos com o paquímetro, para evitar de visualizar uma textura que seja apenas característica da superfície da amostra.

A seguir, entre duas etapas de lixamento, realiza-se um ataque com reagente Nital 5-10\%, durante tanto tempo quanto seja necessário para revelar a estrutura de grãos. Além dos contornos, a superfície de alguns grãos sofre corrosão generalizada. Esta corrosão pode ser mais intensa sobre as valas dos riscos de lixamento. Isto é um indicativo de que ocorreu deformação plástica excessiva.

Isto ocorre porque os grãos cuja face que aflora para a superfície é constituída por um plano de alta densidade atômica apresentam menor dureza e sofrem maior deformação subsuperficial, e o ataque é mais intenso sobre grãos deformados plasticamente.

Realiza-se então um novo lixamento num ângulo de $90^{\circ} \mathrm{em}$ lixa de mesma granulometria, e revela-se novamente a estrutura com ataque. A cada 
repetição, a corrosão generalizada deve diminuir e restringir-se a um número menor de grãos. São feitas tantas iterações quantas necessárias para notar que não há mais melhoria, então procede-se para a lixa seguinte na escala de granulometria decrescente.

Após este lixamento, o polimento com cada granulometria de pasta de diamante deve ser realizado por um longo período (1-2h), evitando ao máximo de pressionar a amostra contra o pano, e observando que pode surgir relevo, devido ao mesmo problema de diferença de dureza entre grãos.

Se a amostra for polida cuidadosamente e por tempo suficiente, a planicidade será boa e a etapa seguinte ficará muito facilitada. Entre dois polimentos não se faz ataque porque gera relevo.

A etapa final consiste no polimento com sílica coloidal, de granulometria $0,06 \mu \mathrm{m}$. A amostra deve ser observada periodicamente em microscópio óptico de campo escuro, até notar que os riscos do polimento a $1 \mu \mathrm{m}$ desapareceram completamente. Dependendo da qualidade da sílica e do êxito das etapas anteriores, o polimento final pode durar de 15 minutos a 1 hora. Alguns riscos ou a presença de pites de corrosão causados pela sílica não são deletérios, provido que não sejam muito profundos.

\subsubsection{Análise EBSD}

Para a análise EBSD, foi utilizado um microscópio eletrônico Philpis XL30 com detector de elétrons retroespalhados MTI VE 1000SIT, localizados no laboratório de microscopia eletrônica do Departamento de Engenharia Metalúrgia e de Materiais POLI-USP.

Após preparação como descrita acima, cada amostra foi inserida na câmara do microscópio, rotacionada a um ângulo de $70^{\circ}$ (para melhorar a aquisição dos elétrons retroespalhados) e posicionada para aquisição. Foi registrada a 
orientação cristalográfica conforme deduzida a partir do padrão de linhas de Kikuchi, ponto o ponto, para diversos pontos no superfície da amostra.

O tempo médio de aquisição se manteve em torno de 16 horas, mas variou de amostra para amostra. A distância entre cada dois pontos analisados, referida no programa como "step size", variou para cada amostra, pois estas possuem diferentes tamanhos de grão.

Objetivou-se o melhor compromisso entre cobrir o maior número de grãos por amostra (passo alto) para legitimar a análise, e apresentar um número mínimo de pontos dentro do mesmo grão (passo baixo) para que se estabelecesse de forma clara o formato e área relativa dos grãos. Algumas amostras foram analisadas com "step size" mais elevado do que o lógico segundo esta consideração (E762, E854 e S501) para poupar tempo de análise devido a questões de disponibilidade do aparelho.

Tabela 5 - Passo de análise EBSD ("step size")

\begin{tabular}{c||rrrrrrr} 
Amostra & E602 & E682 & E762 & E854 & E858 & E8512 \\
\hline Passo $(\mu \mathrm{m})$ & 0,6 & 1 & 3 & & 5 & 3,1 & 2,5 \\
\hline Amostra & S343 & S400 & S451 & S475 & S488 & S501 & S511 \\
\hline Passo $(\mu \mathrm{m})$ & 1,3 & 1,5 & 2,5 & 3,3 & 4 & 7,4 & 7
\end{tabular}

A aquisição e tratamento dos dados foi realizada com o programa OIM Analysis for Windows 3.07 (2001) da empresa TexSEM. Este programa permite a elaboração de um mapa de grãos, contendo a área (em pontos analisados) e orientação cristalográfica de cada grão.

Sabendo o passo ("step size") utilizado na análise, é possível converter as áreas fornecidas pelo programa em valores em micrômetros. Após uma limpeza de ruído, na qual são removidos os pontos em que houve erro de aquisição, é possível calcular a energia de anisotropia média $E_{a}$ [27] de cada amostra, utilizando a Equação 3. 


\subsection{Observação de domínios por efeito Kerr}

A preparação de amostras para observação por efeito Kerr é idêntica à preparação para EBSD, pois ambas técnicas possuem a mesma sensibilidade à deformação plástica.

A seguir, as amostras foram levadas até o Instituto de Física da USP, aonde, com o auxílio do professor Antônio Domingues dos Santos, foram submetidas a um campo magnético variável e observadas em microscópio ótico de luz polarizada de forma a obter contraste longitudinal em termos da magnetização da superfície do material.

\subsection{Modelamento micromagnético}

Foram realizados testes preliminares de modelamento micromagnético por diferenças finitas no programa OOMMF $[28,29]$. Utilizou-se um amostra de dimensões $4 \times 1 \times 1 \mu \mathrm{m}$ com tamanho de célula de $25 \mathrm{~nm}$. A evolução no tempo foi realizada com "solver" do tipo Euler no aplicativo Osxii, que realiza análise tridimensional.

A amostra foi divida na metade em duas regiões com eixos de anisotropia magnetocristalina cúbica com orientações diferentes. Neste trabalho são apresentadas imagens mmDisp com pixeles em tons de cinza, refletindo o ângulo da magnetização do material com a horizontal. 


\section{Resultados e discussão}

\subsection{Tamanho de grão}

Inicialmente exibimos os tamanhos de grão obtidos pelos dois métodos e mostramos sua coerência entre si e com o esperado. Depois, entramos numa discussão mais aprofundada para comparar o efeito da largura da distribuição de tamanho de grão com a incerteza experimental.

\subsubsection{Valores obtidos pelos dois métodos}

Temos os tamanhos de grão medidos pelo método dos interceptos a seguir:

Tabela 6 - Tamanho de grão pelo método dos interceptos

\begin{tabular}{c||ccccccc} 
Amostra & E602 & E682 & E762 & E854 & E858 & E8512 \\
\hline TG $(\mu \mathrm{m})$ & 11 & 17 & 27 & 55 & 62 & 66 \\
\hline Amostra & S343 & S400 & S451 & S475 & S488 & S501 & S511 \\
\hline TG $(\mu \mathrm{m})$ & 26 & 30 & 51 & 66 & 81 & 114 & 144
\end{tabular}

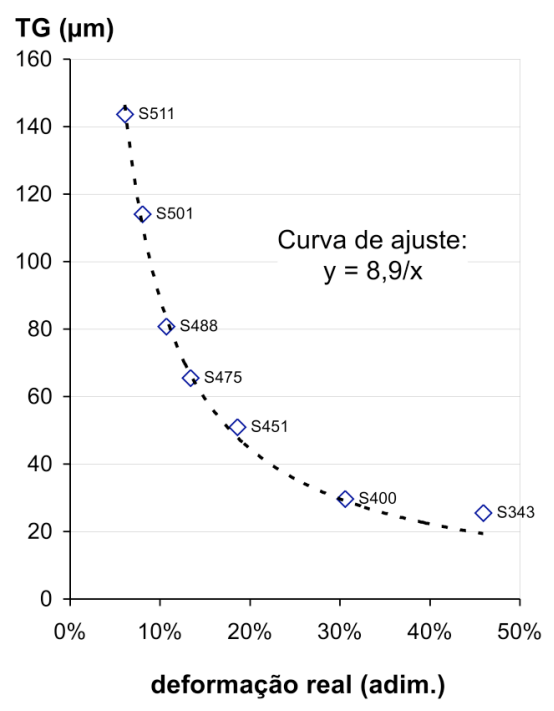

Ilustração 15 - Curva de recristalização do aço
Como era de se esperar, o valor do intercepto médio das amostras recristalizadas variou na proporção inversa do grau de deformação; pode-se visualizar este resultado na llustração 15.

No caso das amostras de crescimento de grão, este valor cresceu com o tempo e temperatura de recozimento, como notamos na Tabela 6. 
Considera-se que no caso da amostra E602, recozida a $600^{\circ} \mathrm{C}$ por 2 horas, não houve crescimento de grão, de forma que a mesma apresenta o tamanho de grão inicial do material: $\ell=11$ um.

Os parâmetros das distribuições de tamanho de grão obtidas pelo método semi-automático podem ser encontrados na Tabela 7. No caso, $u_{A}$ está relacionado com a mediana da distribuição, o que equivale à posição do pico; e $s_{A}$ com sua variância, o que equivale à largura do pico.

Tabela 7 - Parâmetros da distribuição lognormal de TG

\begin{tabular}{c||ccccccc} 
Amostra & E602 & E682 & E762 & E854 & E858 & E8512 \\
\hline $\mathrm{u}_{\mathrm{A}}$ & 2,8 & 3,3 & 3,7 & 4,4 & 4,6 & 4,6 \\
\hline $\mathrm{s}_{\mathrm{A}}$ & 0,16 & 0,19 & 0,21 & 0,23 & 0,33 & 0,25 \\
\hline Amostra & $\mathrm{S} 343$ & $\mathrm{~S} 400$ & $\mathrm{~S} 451$ & $\mathrm{~S} 475$ & $\mathrm{~S} 488$ & $\mathrm{~S} 501$ & $\mathrm{~S} 511$ \\
\hline $\mathrm{u}_{\mathrm{A}}$ & 3,7 & 3,8 & 4,4 & 4,7 & 4,8 & 5,2 & 5,4 \\
\hline $\mathrm{s}_{\mathrm{A}}$ & 0,12 & 0,13 & 0,14 & 0,16 & 0,16 & 0,14 & 0,14 \\
\hline
\end{tabular}

É interessante notar que os valores de $s_{A}$ orbitam ao redor de uma constante $(\approx 0,14)$ para as amostras recristalizadas, indicando que este fenômeno produz distribuições características de TG. Podemos visualizar os resultados na llustração 16.

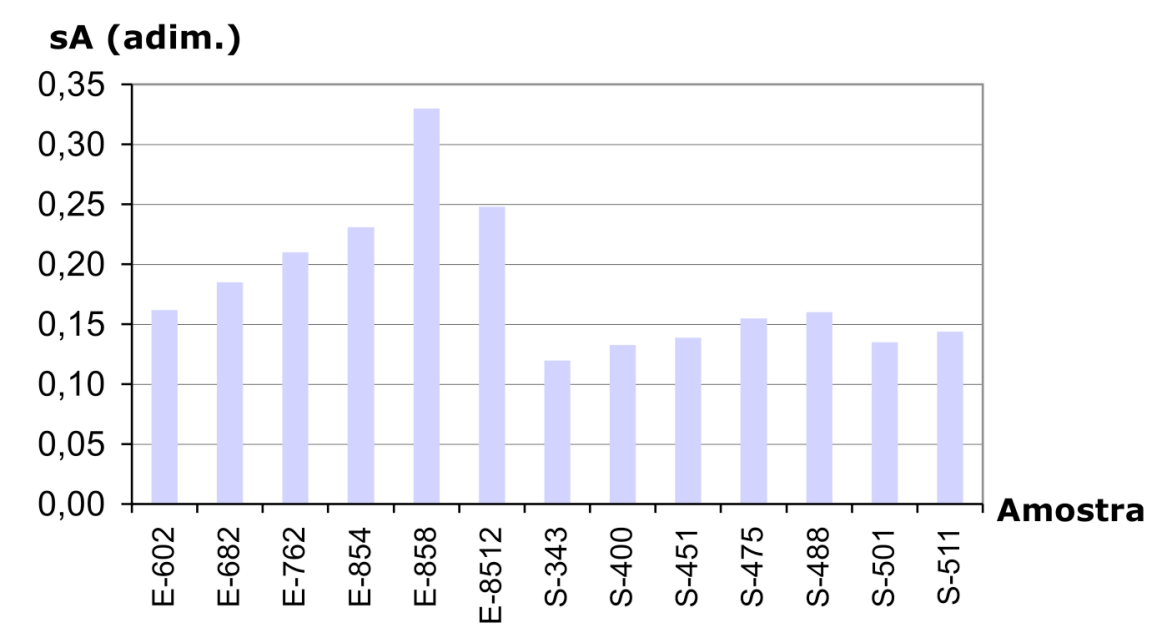

Ilustração 16 - Largura da distribuição de tamanho de grão 
Notamos também que $s_{A}$ cresce com o tempo e a temperatura de recozimento, produzindo distribuições cada vez mais amplas para as amostras de crescimento de grão, exceto para a amostra E8512. Isso provavelmente se deve à atmosfera diferente das demais utilizada em seu recozimento, a qual pode ter gerado precipitados que retiveram 0 crescimento dos grãos.

Para analisar os valores de $u_{A}$, pode-se comparar na Tabela 8 os valores de tamanho de grão médio obtidos pelos dois métodos, $\ell$ pelos interceptos e $d_{M}$ e $d_{A}$ a partir de $u_{A}$ como na Equação 16.

Tabela 8 - Valores de TG obtido pelos dois métodos

\begin{tabular}{c||ccccccc} 
Amostra & $E 602$ & $E 682$ & $E 762$ & E854 & E858 & E8512 \\
\hline$\ell(\mu \mathrm{m})$ & 11 & 17 & 27 & 55 & 62 & 66 \\
\hline$d_{M}(\mu \mathrm{m})$ & 16 & 26 & 39 & 85 & 99 & 104 \\
\hline$d_{A}(\mu \mathrm{m})$ & 18 & 29 & 43 & 95 & 117 & 118 \\
\hline Amostra & $S 343$ & 5400 & 5451 & 5475 & 5488 & 5501 & S511 \\
\hline$\ell(\mu \mathrm{m})$ & 26 & 30 & 51 & 66 & 81 & 114 & 144 \\
\hline$d_{M}(\mu \mathrm{m})$ & 39 & 47 & 83 & 107 & 120 & 188 & 226 \\
\hline$d_{A}(\mu \mathrm{m})$ & 42 & 50 & 89 & 116 & 130 & 201 & 243 \\
\hline
\end{tabular}

Podemos ver que os valores de $d_{M}$ estão muito próximos de $d_{A}$, porém o último se mantém sempre acima. Este resultado é consequência direta do fato de que tanto $d_{M}$ como $d_{A}$ foram calculados a partir da Equação 16 utilizando os valores experimentalmente determinados para $u_{A}$ e $s_{A}$.

É possível visualizar a relação entre $\ell$ e $d_{A}$ na llustração 17: 


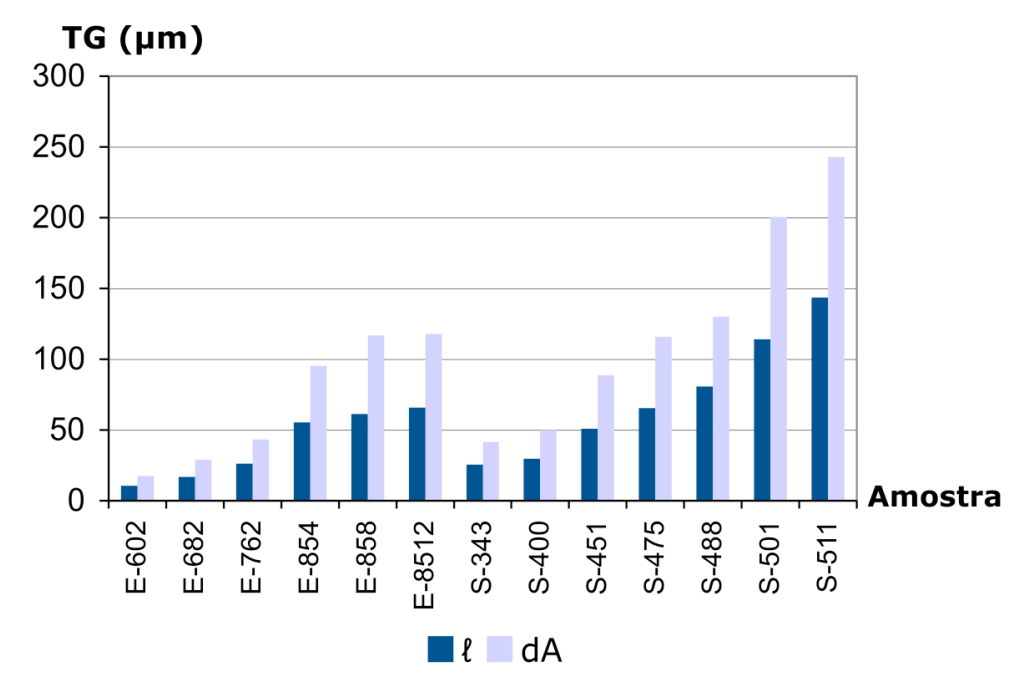

Ilustração 17 - Valores de TG obtidos pelos dois métodos

Notamos que, apesar de serem medidas diferentes do tamanho de grão, $d_{A} \mathrm{e}$ $d_{M}$ apresentam comportamento muito semelhante a $\ell$ : variam na proporção inversa do grão de deformação para as amostras recristalizadas e crescem com tempo e temperatura de recozimento para as amostras que sofreram crescimento de grão.

Este fato atesta para a coerência entre os dois métodos. Inclusive, o comportamento é tão semelhante que poderíamos supor que existe uma relação derivável pela teoria de estereologia entre $\ell, u_{A}$ e $s_{A}$, afinal, se tratam de medidas relacionadas a uma mesma grandeza, feitas no plano da micrografia.

\subsubsection{Comparação entre os dois métodos}

Do ponto de vista experimental, afora distorções na distribuição, podemos supor que há uma razão constante entre os tamanhos de grão obtidos pelos dois métodos (interceptos e áreas), conforme constatado anteriormente [23].

$\mathrm{Na}$ Tabela 9 encontram-se as razões com relação a $\ell$ para $d_{A}$ e $d_{M}$ de cada amostra. Nas últimas colunas temos os valores da média e do desvio padrão de cada conjunto de amostras (recristalização e crescimento de grão). 
Tabela 9 - Razão entre TG medido pelos dois métodos

\begin{tabular}{|c|c|c|c|c|c|c|c|c|c|}
\hline Amostra & E602 & E682 & \multicolumn{2}{|c|}{ E762 } & E854 & E858 & E8512 & Med. & D.P. \\
\hline$\ell / d_{M}$ & 0,66 & 0,64 & \multicolumn{2}{|c|}{0,68} & 0,65 & 0,62 & 0,63 & 0,65 & 0,02 \\
\hline$\ell / d_{A}$ & 0,61 & 0,59 & \multicolumn{2}{|c|}{0,61} & 0,58 & 0,53 & 0,56 & 0,58 & 0,03 \\
\hline Amostra & S343 & S400 & S451 & S475 & S488 & S501 & S511 & Med. & D.P. \\
\hline$\ell / d_{M}$ & 0,65 & 0,64 & 0,61 & 0,61 & 0,67 & 0,61 & 0,64 & 0,63 & 0,02 \\
\hline$\ell / d_{A}$ & 0,62 & 0,60 & 0,57 & 0,56 & 0,62 & 0,57 & 0,59 & 0,59 & 0,02 \\
\hline
\end{tabular}

De acordo com a idéia de que há uma relação vinda da estereologia entre estas variáveis, como $d_{M}$ independe de $s_{A}$, as razões $\ell / d_{M}$ deveriam ser iguais entre todas as amostras; por outro lado, como $d_{A}$ depende de $s_{A}$, as razões $\ell / d_{A}$ deveriam ser diferentes entre duas amostras com $s_{A}$ diferente $\mathrm{e}$ iguais entre amostras com $s_{A}$ igual.

Analisando os dados da Tabela 9 notamos que a razão $\ell / d_{M}$ não é estritamente a mesma em todos os casos. Isso se deve à imprecisão experimental. Devido às incertezas combinadas de $\ell, u_{A}$ e $s_{A}$ vemos um desvio padrão de 0,02 nesta razão.

Quando analisamos a razão $\ell / d_{A}$ para as amostras recristalizadas, notamos o mesmo desvio padrão, resultante da incerteza experimental. Até aqui, as hipóteses se mantêm.

Por fim, quando analisamos a razão $\ell / d_{A}$ para as amostras de crescimento de grão, vemos que o desvio padrão é mais elevado e as amostras com distribuição mais larga (em particular E854, E858 e E8512) realmente apresentam uma razão $\ell / d_{A}$ menor do que as demais, como era de se esperar de acordo com a Equação 16 (valores maiores de $s_{A}$ implicam em $d_{A}$ mais elevado e razão $\ell / d_{A}$ menor).

Porém, exceto pela amostra E858, a diferença é tão pequena (da mesma magnitude que a incerteza experimental) que não se refletirá em um 
coeficiente de determinação, $r^{2}$, mais elevado ao realizar-se o ajuste com $H_{c}$ com $d_{A}$ do o que seria obtido utilizando-se a variável $\ell$.

A conclusão desta análise é: frente à imprecisão experimental, apenas uma das amostras do conjunto, E858, apresentou largura de distribuição de tamanho de grão suficientemente diferente das demais para permitir a análise do efeito da distribuição de tamanho de grão.

A relação entre $H_{c}$ e TG será explorada mais adiante, porém podemos desde já notar qual será a diferença entre realizar-se o ajuste com $\ell$ ou $d_{A}$.
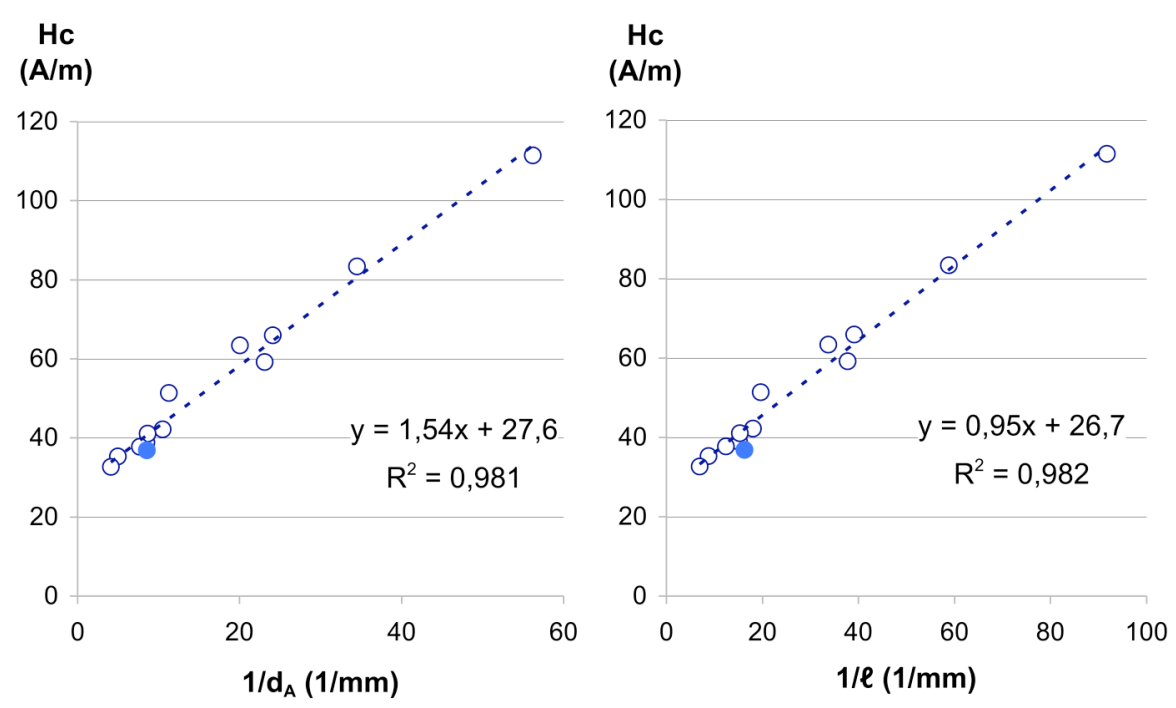

Ilustração 18 - Comparação entre os ajustes de $H_{c}$ com $\ell$ e $d_{A}$ para $B_{\max }$ de 1,5T

Na llustração 18 vemos que a amostra E858 (marcada por uma bola cheia) se aproxima mais da reta de ajuste quando utilizamos $d_{A}$ ao invés de $\ell$, porém o coeficiente de determinação, $r^{2}$, não cresceu para reta como um todo.

\subsection{Textura cristalográfica}

Foram realizadas medidas de textura cristalográfica por três métodos diferentes. As primeiras medidas relacionadas à textura aqui apresentadas são os valores de $B_{50}$ obtidos a partir das curvas de magnetização em ensaio Epstein: 
Tabela 10 - Valores de $B_{50}$ obtidos no quadro de Epstein

\begin{tabular}{c||rrrrrrr} 
Amostra & E602 & E682 & E762 & E854 & E858 & E8512 \\
\hline$B_{50}(\mathrm{~T})$ & 1,745 & 1,739 & 1,750 & 1,760 & 1,757 & 1,711 \\
\hline Amostra & S343 & S400 & S451 & S475 & S488 & S501 & S511 \\
\hline$B_{50}(\mathrm{~T})$ & 1,724 & 1,724 & 1,724 & 1,734 & 1,724 & 1,724 & 1,718
\end{tabular}

Considera-se que, quanto maior $\mathrm{o}$ valor de $B_{50}$, mais favorável a textura cristalográfica na direção do campo aplicado, isto é, maior a fração volumétrica de grãos do material que possuem uma direção de fácil magnetização alinhada com a direção do campo.

De acordo com os valores da Tabela 10 , a partir da amostra E602 $\left(B_{50}=\right.$ $1,745)$, temos uma melhoria da textura cristalográfica com o aumento de tempo e temperatura de recozimento dos conjuntos de crescimento de grão, à exceção das amostras E682 e E8512, as quais foram recozidas em atmosfera diferenciada. Isto pode se dever ao à formação de precipitados que impediram o crescimento de grãos com textura favorável.

Para as amostras recristalizadas, os valores de $B_{50}$ giram em torno de 1,724, se distanciando em dois casos apenas, por razões desconhecidas. Isto é coerente com o que foi observado para a largura da distribuição de tamanho de grão $s_{A}$. Ou seja, após a recristalização, independentemente da particularidade de cada amostra (grau de deformação por exemplo), se estabelece uma distribuição de TG com parâmetros semelhantes.

No entanto, as medidas do quadro de Epstein produzem um único valor para as 8 lâminas. Por isso, este valor pode ser influenciado por certos fatores como deformações plásticas em uma lâmina, dificuldade de contanto entre as lâminas durante o ensaio e a própria calibração dos instrumentos de medida. É possível que o valor obtido não reflita as variações de textura locais, e que ele seja influenciado por outros fatores afora a textura cristalográfica.

Para averiguar se estes valores de $B_{50}$ refletem realmente a textura 
cristalográfica, foram realizadas imagens de difração de elétrons retroepalhados, EBSD. Os resultados podem ser encontrados na Tabela 11.

Tabela 11 - Energia de anisotropia média obtida [27] a partir de EBSD

\begin{tabular}{c|ccccccc} 
Amostra & $E 602$ & $E 682$ & $E 762$ & $E 854$ & $E 858$ & $E 8512$ \\
\hline$E_{a}\left(\mathrm{~J} / \mathrm{m}^{3}\right)$ & 0,98 & 0,87 & 0,91 & 0,95 & 1,00 & 0,93 \\
\hline Amostra & $\mathrm{S} 343$ & $\mathrm{~S} 400$ & $\mathrm{~S} 451$ & $\mathrm{~S} 475$ & $\mathrm{~S} 488$ & $\mathrm{~S} 501$ & $\mathrm{~S} 511$ \\
\hline $\mathrm{E}_{\mathrm{a}}\left(\mathrm{J} / \mathrm{m}^{3}\right)$ & 1,05 & 0,98 & 0,95 & 0,89 & 0,97 & 0,92 & 0,93
\end{tabular}

A comparação entre os resultados consta na llustração 19.

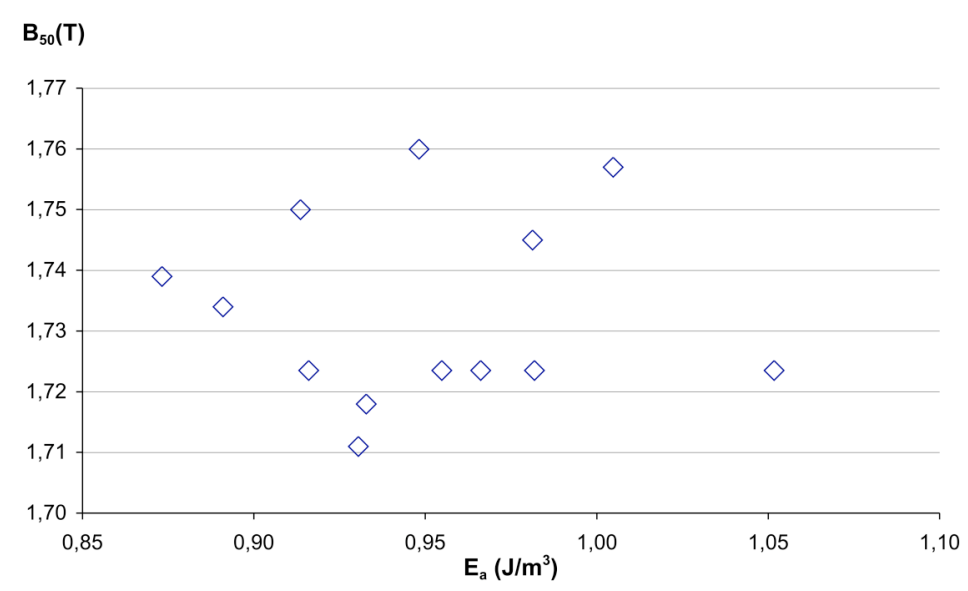

Ilustração 19 - (Ausência de) Correlação entre $B_{50}$ Epstein e $E_{a}$.

Nota-se que não existe correlação entre $B_{50}$ e $E_{a}$. Isto se deve provavelmente ao fato de que a imagem EBSD reflete uma condição local de uma região muito pequena da amostra, enquanto o quadro de Epstein realiza medidas globais.

Já o ensaio a lâmina única permite a obtenção de valores locais de $B_{50}$, para avaliar a variação de textura no interior de material. Na llustração 20 vemos os valores de $B_{50}$ ao longo de 6 lâminas, em 3 pontos de cada lâmina, para algumas amostras: 


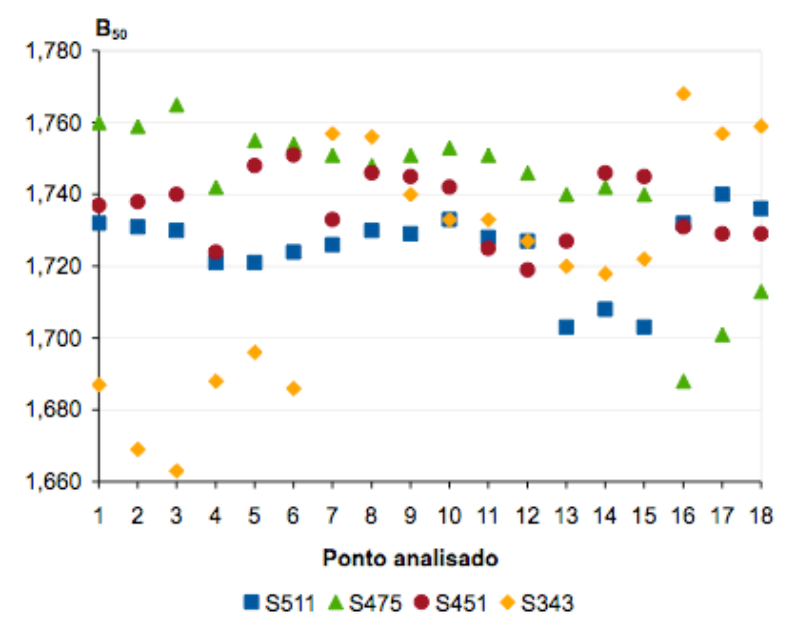

Ilustração 20 - Valores de $B_{50}$ medidos pelo ensaio Soken.

Podemos notar que existem grandes variações de $B_{50}$, isto é, comparáveis àquelas observadas entre um conjunto e outro no quadro Epstein. Estas variações são presentes tanto no interior de uma lâmina como de uma lâmina para outra do mesmo conjunto. Isto também ocorre com as demais amostras, cujos valores foram omitidos para tornar o texto mais sucinto.

É importante notar que a repetitibilidade das medidas foi muito elevada, de forma que a variação dos valores de $B_{50}$ Soken de cada ponto, após diversas repetições, nunca ultrapassou 0,003 $\mathrm{T}$.

Por outro lado, tanto no caso do quadro de Epstein quanto no aparelho Soken, os valores de $B_{50}$ são determinados a partir de medidas de largura. Então, apesar da alta repetitibilidade, existe um erro $(0,005 \mathrm{~T})$ que se propaga a partir das medidas de largura feitas com paquímetro.

Os valores médios e o desvio padrão para os 18 pontos de cada conjunto podem ser encontrado na llustração 21 , a qual reúne todas as medidas de textura cristalográfica. 


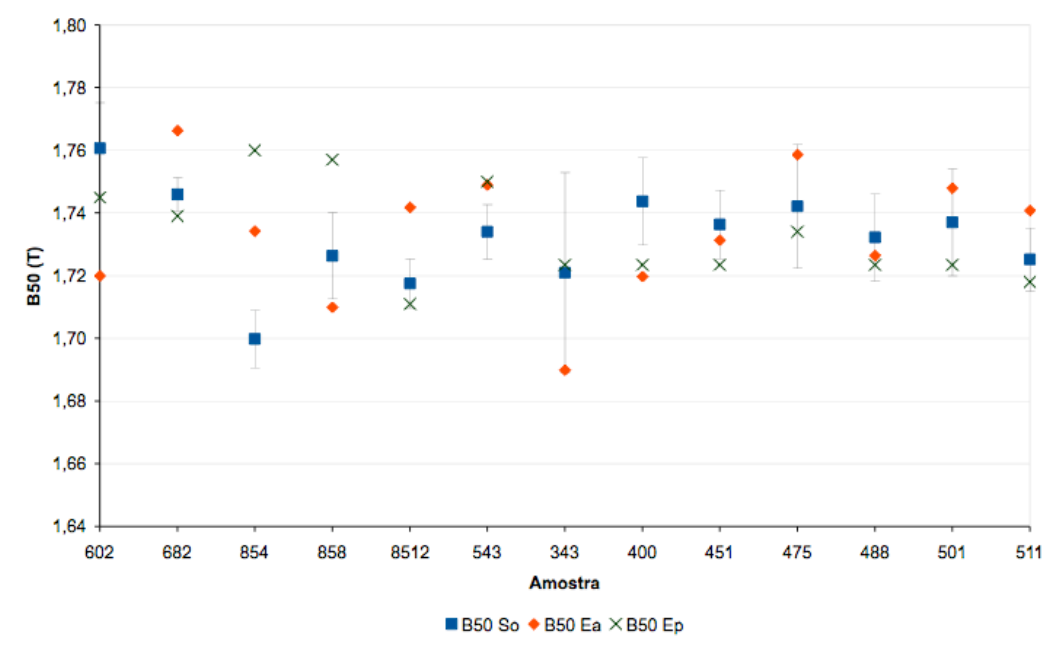

Ilustração 21 - Comparação dos três métodos de análise de textura.

As medidas de $E_{a}$ foram transformadas em $B_{50}$ pela relação $B_{50}=\left(1-0,2 E_{a}\right) J_{s}$, proposta com base em correlações já estudadas para estas variáveis [30]. As barras de erro contém os valores do desvio padrão obtido através das medidas do ensaio Soken realizadas em 18 pontos diferentes.

Nota-se que, para as amostras recristalizadas, a diferença entre os três valores é coerente com a ordem de grandeza do erro, indicando uma boa confiabilidade da análise. O valor médio de $B_{50}$ é 1,724 T, o que corresponde $\operatorname{com} E_{a}=0,97 \mathrm{~J} / \mathrm{m}^{3}$.

Existem variações locais de textura, as quais podem ser observadas por análise EBSD ou Soken, sobretudo na amostra S343, provavelmente devido ao alto grau de deformação plástica recebido, o que causou algumas dificuldades durante a laminação resultando num abaulamento excessivo das amostras e provavelmente grande heterogeneidade de deformação plástica.

No entanto, estes valores não permitem a avaliação do efeito da textura no $H_{c}$, afinal, a variável $E_{a}$ se mantém constante nesta amostras.

Para as amostras de crescimento de grão, há diferenças muito grandes nos valores obtidos, a pesar da alta repetitibilidade dos $B_{50}$ obtidos por Epstein e Soken. 
Para efeito de ilustração, temos as figuras de polo inversas de cada amostra, a seguir, na llustração 22 e na llustração 23:

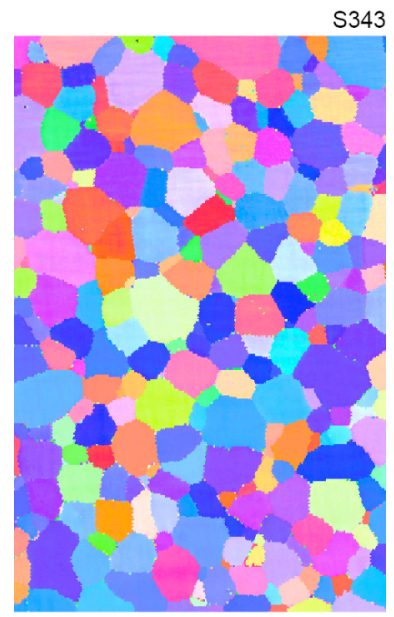

$58.50 \mu \mathrm{m}=45$ passos

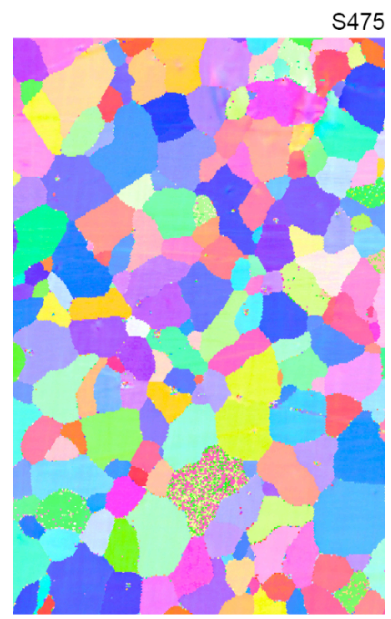

$264.0 \mu \mathrm{m}=80$ passos

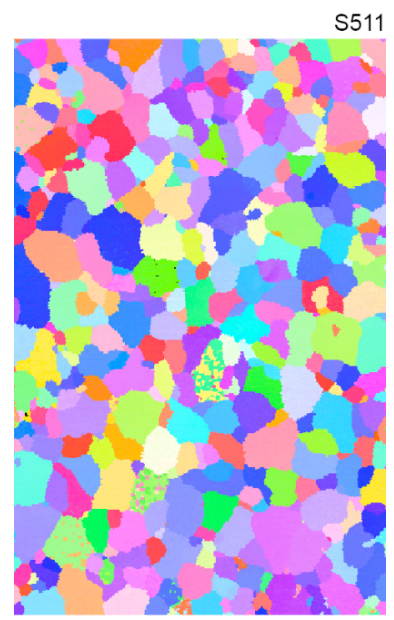

$490.0 \mu \mathrm{m}=70$ passos
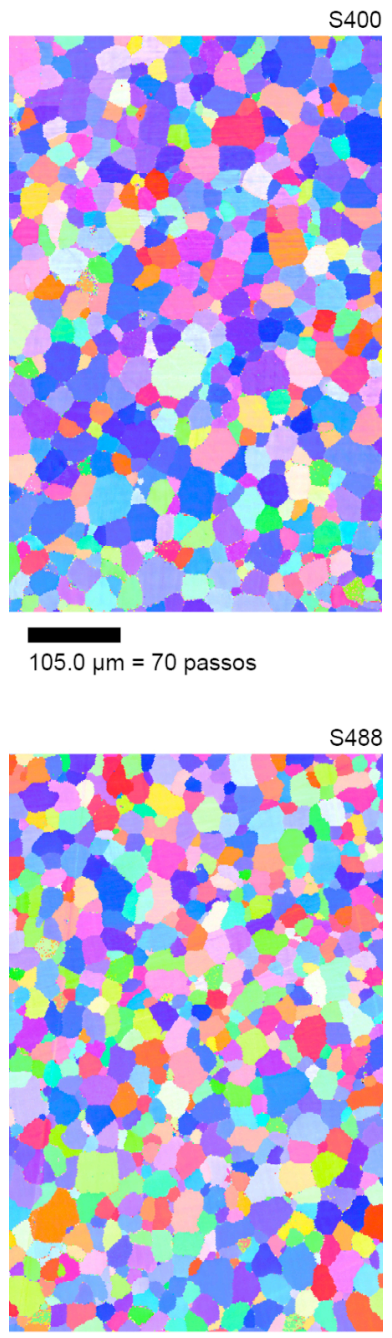

$280.0 \mu \mathrm{m}=70$ passos

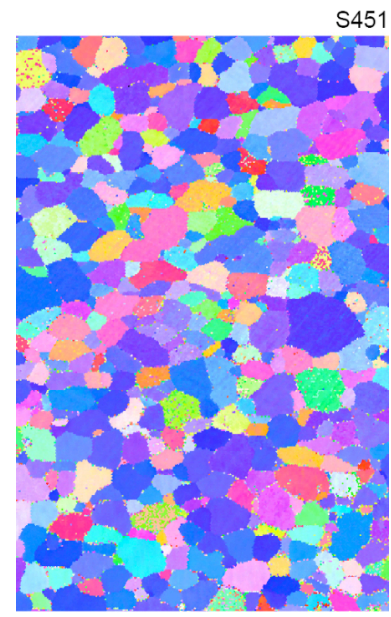

$200.0 \mu \mathrm{m}=80$ passos

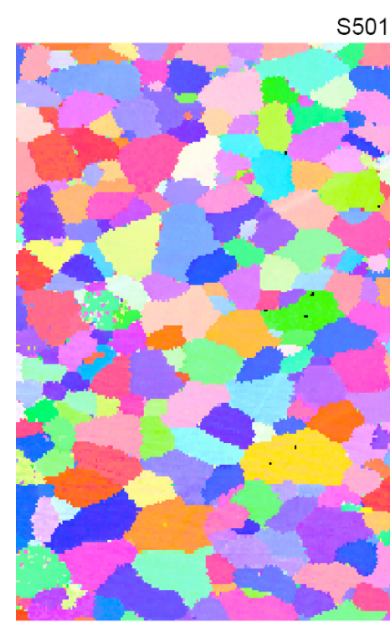

$296.0 \mu \mathrm{m}=40$ passos

Gray Scale Map Type: snone>

Color Coded Map Type: Inverse Pole Figure [001] Iron (Alpha)

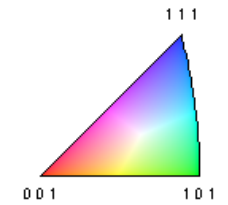

Boundaries: «none $>$ 


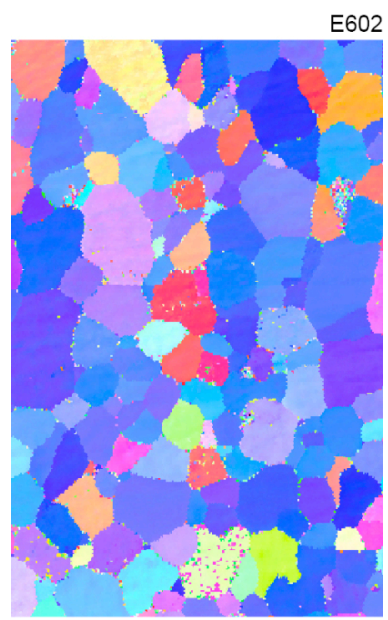

$42.00 \mu \mathrm{m}=70$ passos

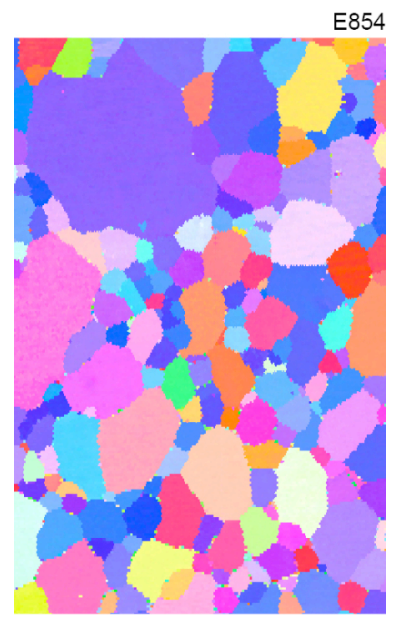

$175.0 \mu \mathrm{m}=35$ passos

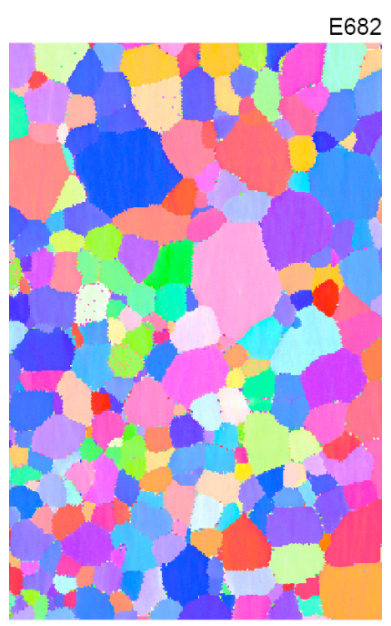

$80.00 \mu \mathrm{m}=80$ passos

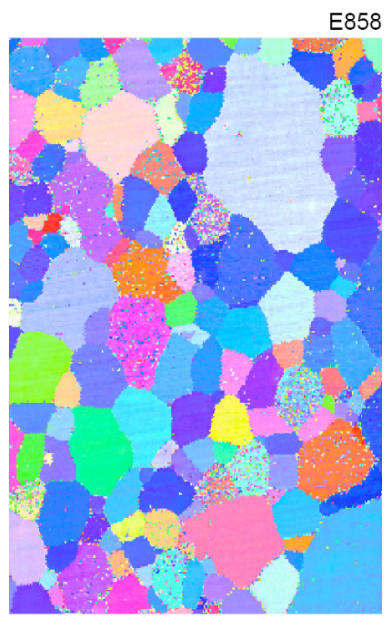

$186.0 \mu \mathrm{m}=60$ passos

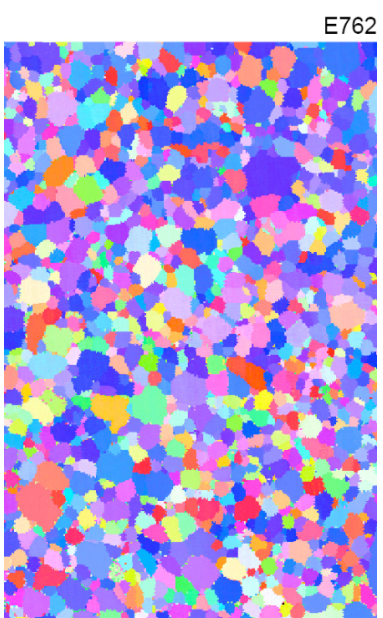

$240.0 \mu \mathrm{m}=80$ passos

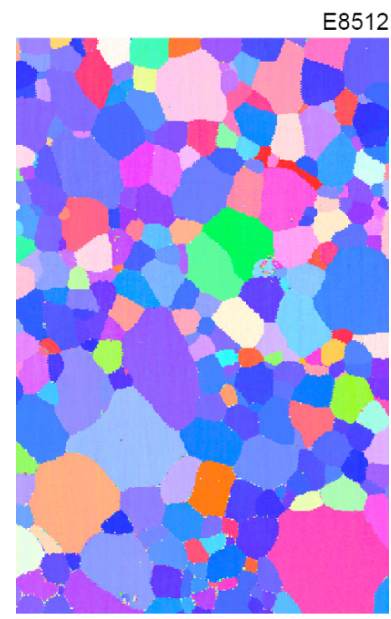

$58.50 \mu \mathrm{m}=45$ passos

Gray Scale Map Type: snone>

Color Coded Map Type: Inverse Pole Figure [001] Iron (Alpha)

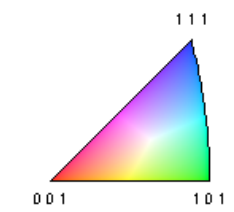

Boundaries: «none>

llustração 23 - Figura de polo inversas das amostras de crescimento de grão 


\subsection{Campo coercivo}

Em trabalhos anteriores [31], foi considerada a possibilidade de outros ajustes, porém concluiu-se que um ajuste linear $H_{c} \times 1 / T G$ é o que melhor permite a análise dos dados.

Na llustração 24, vemos os pontos de cada uma das 13 amostras para as induções 0,6, 1,0 e 1,4 T junto com seus ajustes lineares. Os pontos para as demais induções foram omitidos para facilitar a visualização.

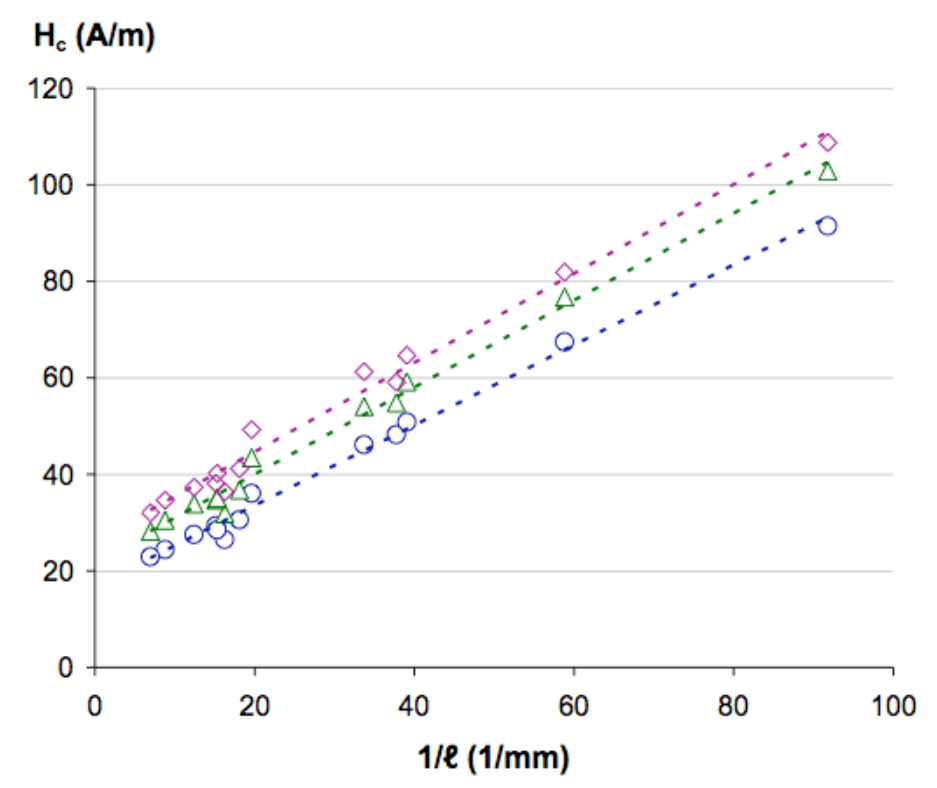

llustração 24 - Campo coercivo em função do inverso de tamanho de grão.

Para permitir a análise dos dados, temos os valores dos coeficientes linear, $a$, e angular, $b$, bem como o coeficiente de determinação, $r^{2}$, na Tabela 12 .

Tabela 12 - Parâmetros de ajuste de $H_{c} \times 1 / \ell$ em função de $B_{\max }$

\begin{tabular}{c||cccccc}
$\mathrm{B}_{\max }(\mathrm{T})$ & 0,6 & 0,8 & 1,0 & 1,2 & 1,4 & 1,5 \\
\hline $\mathrm{a}(\mathrm{mA})$ & 0,832 & 0,874 & 0,901 & 0,912 & 0,924 & 0,946 \\
\hline $\mathrm{b}(\mathrm{A} / \mathrm{m})$ & 16,9 & 19,7 & 22,0 & 24,3 & 26,2 & 26,3 \\
\hline$r^{2}$ & 0,993 & 0,991 & 0,990 & 0,989 & 0,985 & 0,982 \\
\hline
\end{tabular}


Nota-se que tanto o coeficiente linear (intercepto com eixo y) e o coeficiente angular (inclinação) da reta crescem com o aumento da indução máxima. Porém, o valor do coeficiente de determinação cai com $B_{\max }$. Isto se deve possivelmente a algum fator microestrutural, o qual é diferente entre as amostras, e que se torna mais relevante a altas induções.

Vemos também que algumas amostras em particular se distanciam da reta de ajuste, na região $1 / \ell \approx 20$. As razões para isto devem ser encontradas na análise da distribuição de tamanho de grão.

Muito embora não corresponda com as referências clássicas de Yensen [7] e Degauque [32], a inclinação obtida está em conformidade com outros trabalhos (Bertotti [13]) que utilizaram aços elétricos modernos.

No que segue, discutiremos os resultados em três etapas:

$\mathrm{Na}$ primeira, segundo uma abordagem fenomenológica que busca contabilizar o efeito da indução máxima e tamanho de grão sobre $H_{c}$ segundo as equações empíricas bem conhecidas de Yensen [7] e Steinmetz [33];

Na segunda parte, consideramos os parâmetros da reta $H_{C} \times 1 / T G$ de acordo com o equacionamento de Mager [9] estendido utilizando uma geometria cilíndrica e cálculo simplificado do campo desmagentizante;

Na terceira parte, integramos o modelo de Preisach [2] à abordagem Magerestendido, o que permite contabilizar os efeitos da indução máxima e da distribuição de tamanho de grão. 


\subsubsection{Modelo fenomenológico}

O objetivo do modelo fenomenológico é encontrar uma equação que permita calcular o campo coercivo a partir de variáveis microestruturais e da indução máxima. O desafio se inicia já na escolha da variável que caracteriza o tamanho de grão.

Já vimos na seção 4.2.2 Comparação entre os dois métodos que as amostras possuem distribuições muito semelhantes e que o efeito da largura será observável apenas na amostra E858.

Tradicionalmente, o ajuste é feito com o valor medido pelo método dos interceptos. Porém, considera-se que a variável que melhor se presta ao ajuste com $H_{C}$ é $d_{A}$.

Um certo número de grãos ocupando uma fração volumétrica grande terá uma influência maior sobre o campo coercivo do que o mesmo número de grãos ocupando uma fração volumétrica pequena. Por exemplo, se um material tem 20 grãos, 18 dos quais têm $1 \mu$ m de diâmetro, e 2 dos quais têm $100 \mu \mathrm{m}$, é de se esperar que o material se comporte como se o tamanho de grão médio fosse $100 \mu \mathrm{m}$, ignorando os grãos pequenos.

Se a fração volumétrica no material pode ser corretamente aproximada pela fração de área na micrografia, então $d_{A}$ deveria fornecer um ótimo ajuste com $H_{c}$. Podemos encontrar os parâmetros de ajuste com relação a esta variável na Tabela 13.

Tabela 13 - Parâmetros de ajuste de $H_{c} \times 1 / d_{A}$ em função de $B_{\max }$

\begin{tabular}{c||cccccc}
$\mathrm{B}_{\max }(\mathrm{T})$ & 0,6 & 0,8 & 1,0 & 1,2 & 1,4 & 1,5 \\
\hline $\mathrm{a}(\mathrm{mA})$ & 1,35 & 1,42 & 1,47 & 1,48 & 1,50 & 1,54 \\
\hline $\mathrm{b}(\mathrm{A} / \mathrm{m})$ & 17,7 & 20,5 & 22,9 & 25,1 & 27,1 & 27,6 \\
\hline$r^{2}$ & 0,992 & 0,991 & 0,990 & 0,989 & 0,985 & 0,981 \\
\hline
\end{tabular}


Se compararmos os resultados Tabela $13 \mathrm{com}$ os da Tabela 12, notamos que o coeficiente linear, $b$, e o coeficiente de determinação, $r^{2}$, se mantêm muito próximos nos dois os casos. Por outro lado, o coeficiente angular, a, se altera fortemente quando realizamos o ajuste com $1 / d_{A}$ ao invés de $1 / \ell$.

A partir daí, tiramos a conclusão de que o método de determinação do tamanho de grão não afeta o fato de tratar-se de uma lei $H_{c} \propto 1 / \mathrm{TG}$, nem mesmo a qualidade do ajuste, mas afeta os parâmetros desta lei [23]. Essa conclusão também poderia ter sido tirada do fato de que existe uma razão relativamente constante $\cong 0,64$ entre estas duas medidas de TG.

Porém, com discutido anteriormente (4.2.2 Comparação entre os dois métodos) devido ao fato de $d_{A}$ contemplar a influência de distribuição de tamanho de grão, esta variável permitirá um melhor ajuste para a amostra E858, a qual possui $s_{A}$ muito elevado. Para ilustrar a diferença da utilização de $d_{A}$ e $\ell$, retomamos a llustração 18 temos os pontos experimentais para 1,5T para ambos os casos:
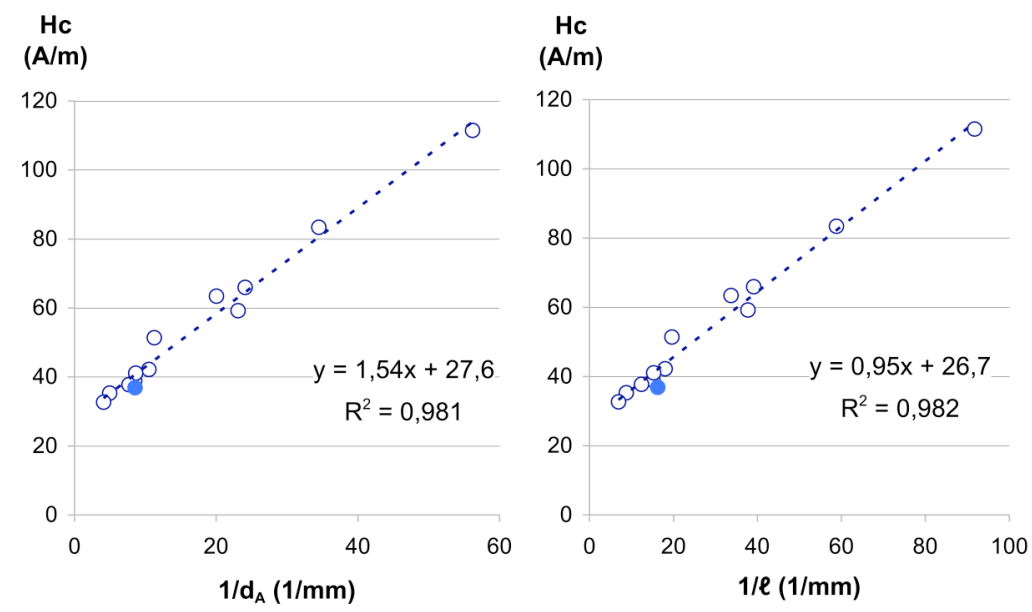

Ilustração 18 - Comparação do ajuste linear de Hc com 1/l e 1/dA.

Nota-se, em particular, que a amostra de ampla distribuição de tamanho de grão, E858, assinalada por uma bola cheia, se aproxima da reta no ajuste com $1 / d_{A}$. 
A seguir, inspirando-se na abordagem de Daniel Rodrigues [34], propõe-se a análise dos parâmetros de ajuste $H_{c} \times 1 /$ TG em função da indução máxima:

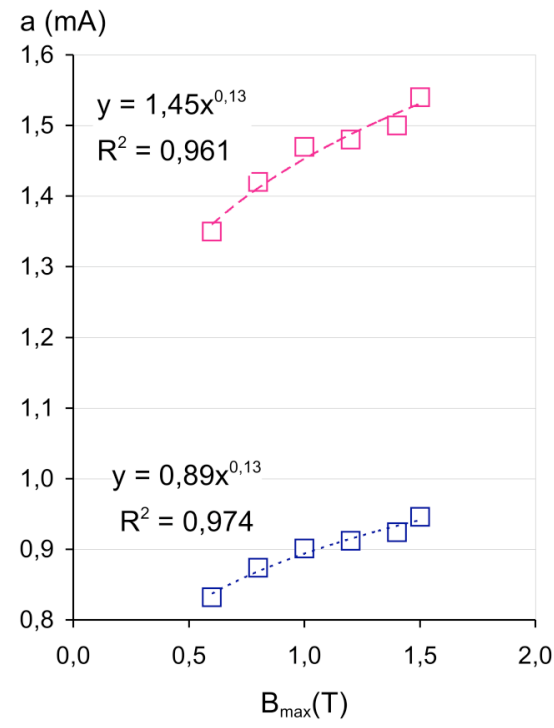

$\square \mathrm{Hc} \times 1 / \ell$

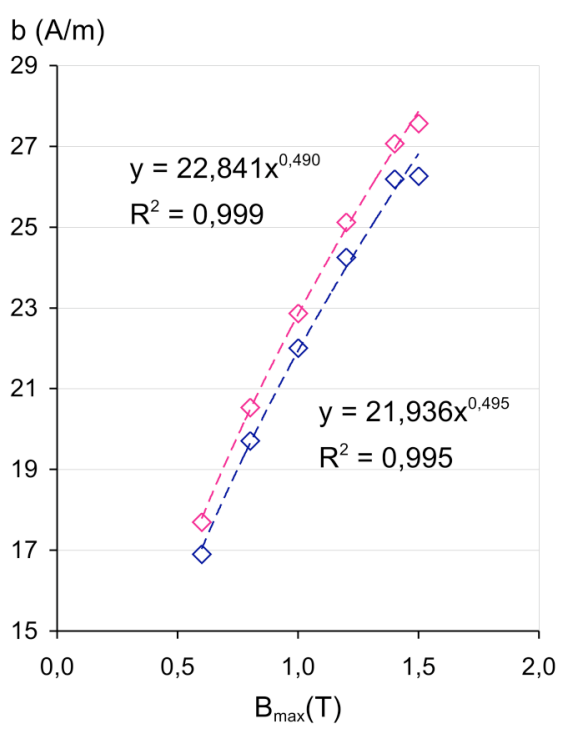

$\square \mathrm{Hc} \times 1 / \mathrm{dA}$

llustração 25 - Variação dos parâmetros a e b com a indução máxima.

Na llustração 25 vemos que uma lei de potência se enquadra bem aos dados e não há muita diferença quanto ao emprego de $\ell$ ou $d_{A}$ em termos do expoente da variação de cada parâmetro com indução máxima.

A partir daí, podemos determinar duas equações fenomenológicas para $H_{c}$ :

$$
\begin{aligned}
& H_{c}=\frac{0,9}{\ell} B_{\max }^{0,13}+22 B_{\max }^{0,5} \\
& H_{c}=\frac{1,5}{d_{A}} B_{\max }^{0,13}+23 B_{\max }^{0,5}
\end{aligned}
$$

\section{Equação 17 - Equações fenomenológicas para $H_{c}$.}

Estas equações podem nos orientar com relação à forma como $H_{c}$ depende das diferentes variáveis consideradas.

A seguir, temos o valor percentual do desvio absoluto médio em função da 
indução máxima, o qual nos permite verificar a qualidade das equações escolhidas:

$$
100 \cdot\left|H_{c}^{\text {medido }}-H_{c}^{\text {ajuste }}\right| / H_{c}^{\text {medido }}
$$

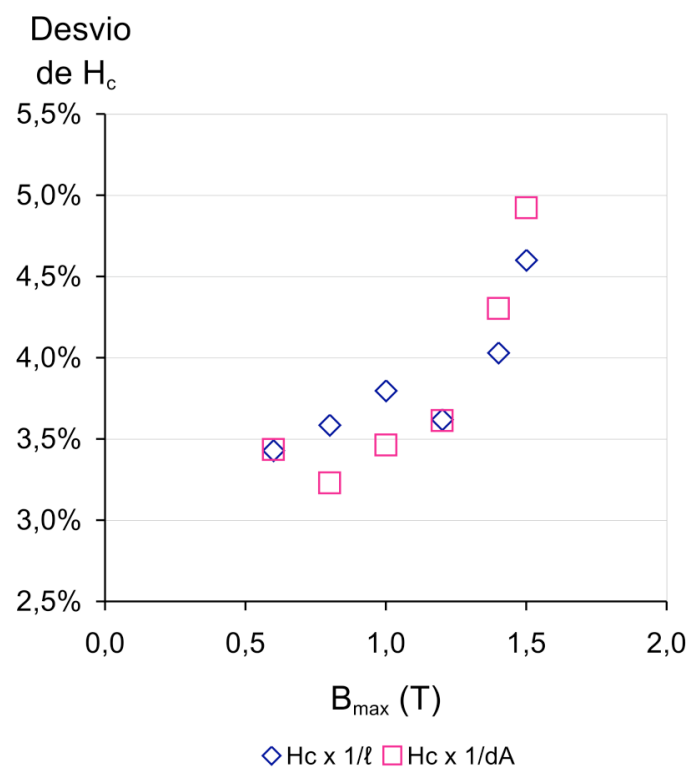

Ilustração 26 - Desvio de $H_{c}$ calculado pelas equações fenomenológicas.

Notamos na llustração 26 que o desvio de $H_{c}$ é menor no caso do ajuste com $d_{A}$ para as induções máximas de 0,8 e 1,0 T. No entanto, o desvio do ajuste com $d_{A}$ é maior para as altas induções de 1,4 e 1,5T. O desvio médio para todos os pontos no caso do ajuste com $\ell$ é igual a $3,8 \%$, e para $d_{A}$ também é $3,8 \%$.

A análise mostra que podemos estabelecer uma relação fenomenológica entre as variáveis $H_{c}$, TG e $B_{\max }$, cujo desvio médio global fica abaixo de $4 \%$. Vimos também que, exceto pelo coeficiente angular, o ajuste é muito semelhante quer se utilize $d_{A}$ ou $\ell$. 


\subsubsection{Extensão do modelo de Mager}

Nesta seção nos propomos a estender o modelo de Mager com um termo adicional que leva em conta o efeito do campo desmagnetizante no contorno de grão.

Devido ao fato de que ele prevê corretamente uma dependência linear de $H_{c}$ com 1/TG, supõe-se que o modelo de Mager fornece uma boa aproximação para a estrutura de domínios que ocorre no interior do material durante a histerese magnética.

Como não se pode observar o interior do material por efeitos magnetoópticos, devemos buscar outros testes para determinar até que ponto e com quais restrições ou modificações este modelo se adequa à realidade.

Primeiramente, nesta seção, tentamos analisar o efeito do campo desmagnetizante oriundo da divergência da magnetização contorno de grão. Este efeito não foi abordado por Mager, e resta a dúvida se ele melhora ou piora a capacidade do modelo de prever os resultados experimentais.

Considerando-se um grão cilíndrico, contendo dois domínios de orientações opostas, um crescendo em detrimento do outro, obteve-se através de um método semi-analítico a fórmula da energia desmagnetizante no contorno de grão. Vide anexo.

Ao substituir a fórmula da energia devida ao campo desmagnetizante no equacionamento de Mager, vemos o surgimento de um termo independente do tamanho de grão, e de variáveis que denunciam um comportamento sinergístico entre $T G$ e textura cristalográfica, dois aspectos apoiados pelos resultados experimentais. 
Utilizamos o resultado obtido nos anexos de que a energia é minimizada quando o raio do domínio interno é 0,7 vezes o raio do grão. Consideramos ainda um grão cilíndrico, cuja altura é igual ao diâmetro, $V=\pi\left(T G^{2} / 4\right) T G$, sabendo que $F(0,7)=-0,05484$ :

$$
\mathrm{E}_{d}=-\frac{\mu_{0} \sigma_{M}{ }^{2} V}{4} F(0,7)=\mu_{0} \sigma_{M}^{2} \pi \frac{(T G)^{3}}{16} 0,05484
$$

\section{Equação 18 - Aplicação numérica sobre aproximação analítica da energia devida ao campo desmagnetizante no contorno de grão.}

Consideramos, segundo o método $\mu^{*}$ apresentado por Bozorth [35] e utilizado por Sheiko [36] para determinar campo desmagnetizante no contorno de grão, que uma leve rotação dos momentos magnéticos dos domínios nos dois lados do contorno pode reduzir a energia desmagnetizante em uma ordem de grandeza, através do fator mulitiplicativo $A$ :

$$
\mathrm{E}_{d}=-A \frac{\mu_{0} \sigma_{M}{ }^{2} V}{4} F(0,7)=\frac{1}{8,7} \mu_{0} \sigma_{M}{ }^{2} \pi \frac{(T G)^{3}}{16} 0,05484 \cong \mu_{0} \sigma_{M}{ }^{2} \pi \frac{(T G)^{3}}{2540}
$$

\section{Equação 19 - Termo da energia devida ao campo desmagnetizante no modelo Mager estendido.}

Postulamos então a existência de uma estrutura de domínios cilíndricos concêntricos atravessando diversos grãos. No restante do material reina uma condição de remanência, com a magnetização da maior parte do volume alinhada numa direção particular (+z, por exemplo) e baixo ou quase nulo campo desmagnetizante resultante. A transição para outra condição de remanência porém com sentido oposto $(-z)$ se dá através do crescimento longitudinal de diversas "minhocas de remagnetização". 


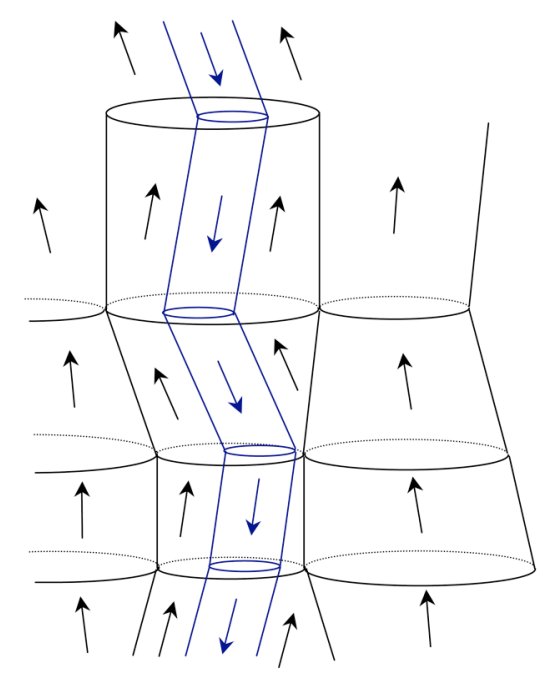

llustração 27 - Minhoca de remagnetização atravessando grãos cilíndricos.

A condição para crescimento longitudinal vem do balanço energético:

$$
\Delta E=2 H J_{s} \cos \beta \Delta V-\gamma \Delta A-\Delta C
$$

Equação 20 - Balanço energético para crescimento longitudinal, no qual $\cos \beta$ é o cosseno do ângulo entre a magnetização do domínio e o campo aplicado, e $\Delta C$ a variação da energia devida ao campo desmagnetizante.

Consideramos que o material passa de uma condição de remanência na qual a energia devida ao campo desmagnetizante é negligenciável $\left(\mathrm{C}_{\text {remanencia }}=0\right.$ devido à presença de domínios de fechamento) para uma condição em que há um domínio de remagnetização cilíndrico. Assim, como mostrado na Equação 21, podemos aproximar a variação da energia de campo desmagnetizante pelo valor calculado na Equação 19:

$$
\Delta C=C_{\text {final }}-C_{\text {inicial }}=C_{\text {cilindro }}-C_{\text {remanencia }}=E_{d}
$$

Equação 21 - Variação da energia desmagnetizante. 
De posse da variação da energia desmagnetizante, podemos apresentar o conjunto das considerações para o equacionamento do balanço energético:

$$
\begin{gathered}
V=\pi R^{2}(T G) ; \quad A=2 \pi R(T G) \\
\Delta C=\frac{J_{s}^{2}}{\mu_{0}} \Delta \cos ^{2} \beta \pi \frac{(T G)^{3}}{2540} ; \quad R=0,7 \frac{(T G)}{2}
\end{gathered}
$$

Equação 22 - Considerações para equacionamento de balanço energético, nas quais $R$ é o raio do domínio em questão.

Aplicando as condições apresentadas na Equação 22 ao balanço expresso na Equação 20, temos:

$$
\begin{gathered}
0=2 H J_{s} \cos \beta \pi 0,7^{2} \frac{(T G)^{3}}{4}-\gamma 2 \pi 0,7 \frac{(T G)^{2}}{2}+\frac{J_{s}^{2}}{\mu_{0}} \Delta \cos ^{2} \beta \pi \frac{(T G)^{3}}{2540} \\
H_{c}=\frac{2 \gamma}{0,7 J_{s} \cos \beta(T G)}+\frac{J_{s}}{620 \mu_{0}} \frac{\Delta \cos ^{2} \beta}{\cos \beta}
\end{gathered}
$$

Equação 23 - Campo coercivo segundo o modelo Mager estendido, na qual $\Delta \cos ^{2} \beta$ representa o quadrado da diferença entre os ângulos da magnetização com o campo aplicado de cada lado do contorno.

Vemos que esta equação indica:

- que o campo coercivo é inversamente proporcional ao cosseno médio do ângulo entre a direção fácil e o campo aplicado;

- que existe um termo independente do tamanho de grão, o qual depende de $J_{s}$, do cosseno médio e da desorientação média entre grãos. 
Cuja aplicação numérica fica:

$$
\begin{gathered}
H_{c}[A / m]=\frac{2 \cdot 1,2 \cdot 10^{-3}}{2,14 \cdot 0,8 \cdot T G[m m] \cdot 10^{-3}}+\frac{2,14}{620 \cdot 4 \pi \cdot 10^{-7}} \cdot \frac{0,01}{0,8} \\
H_{c} \cong \frac{2}{T G}+34
\end{gathered}
$$

Equação 24 - Aplicação numérica de $H_{c}$ Mager estendido, tomando valores médios para $\Delta \cos ^{2} \beta$ e $\cos \beta$.

Segundo este modelo, o cruzamento com o eixo y (ou coeficiente linear) da reta $H_{c} \times 1 /$ TG seria a $34 \mathrm{~A} / \mathrm{m}$; vemos também que a inclinação prevista (ou coeficiente angular) é de $2 \mathrm{~mA}$.

Ao comparar estes valores com resultados experimentais, temos diferentes opções de método de medida de tamanho de grão e indução máxima utilizada. Para o caso "padrão", tomando TG como intercepto médio $\ell$ e a indução máxima de 1,0T, vemos que estes valores são muito mais elevados do que foi obtido experimentalmente.

No entanto, segundo o modelo fenomenológico, para induções máximas elevadas como $B_{\max }=2,14 \mathrm{~T}$, o valor experimental para o coeficiente linear se aproximaria do modelado.

Vemos também que se considerarmos o caso "extremo" calculado a partir da Equação 17 para o qual TG é $d_{A}$ e a indução máxima é $B_{\max }=2,14 \mathrm{~T}$, o valor do coeficiente angular do modelo se aproxima da realidade. Os resultados estão resumidos na Tabela 14 . 
Tabela 14 - Comparação do modelo Mager estendido com resultados

\begin{tabular}{c||cc} 
Condições & Coeficiente angular $(\mathrm{mA})$ & Coeficiente linear $(\mathrm{A} / \mathrm{m})$ \\
\hline Modelo Mager-Ext. & 2,0 & 34 \\
\hline Expr. $T G(\ell), B_{\max }=1,0 \mathrm{~T}$ & 0,9 & 22 \\
\hline Fen. $T G(\ell), B_{\max }=2,14 \mathrm{~T}$ & 1,0 & 32 \\
\hline Fen. $T G\left(d_{A}\right), B_{\max }=2,14 \mathrm{~T}$ & 1,6 & 33 \\
\hline
\end{tabular}

Na Equação 21 consideramos que o material partia de uma condição na qual a energia desmagnetizante tinha um valor nulo devido à presença de domínios de fechamento. No entanto, é possível que esta condição ideal não seja atingida.

Se a energia desmagnetizante à remanência for maior do que zero, então a variação de energia será menor, e também o coeficiente linear previsto pelo modelo. Assim, é natural que o valor obtido no modelo esteja acima dos valores experimentais.

Desta forma concluímos que a análise do efeito do campo desmagnetizante no contorno de grão tem um efeito positivo sobre o modelo de Mager, adicionando o termo independente que faltava em seu equacionamento e determinando seu valor máximo.

Quanto ao coeficiente angular, vemos na Tabela 14 que o valor calculado pelo modelo está um pouco distante $(33 \%)$ do obtido experimentalmente. (Inclusive podemos considerar que o fato do valor do coeficiente linear se aproximar do modelo para altas induções foi fortuito.)

Isso se deve ao fato de que a geometria utilizada para os cálculos foi a de uma grão cilíndrico. Dificilmente uma tal simplificação representa corretamente o comportamento de grãos nos mais distintos formatos, com números e formatos de faces variáveis, com curvatura no contorno, com estruturas ramificadas do domínios magnéticos e assim por diante. 
Considerando esta ressalva, podemos dizer que o ajuste do modelo está satisfatório.

Por outro lado, este modelo não permite levar em conta a variação de $H_{c}$ com a indução máxima, e os parâmetros obtidos no modelo Mager estendido para a reta $H_{c} \times 1 /$ TG corresponderiam com os resultados experimentais apenas para um caso muito especifico, o qual sequer foi medido $\left(B_{\max }=2,14 \mathrm{~T}\right)$ mas sim previsto pelo modelo fenomenológico.

$\mathrm{Na}$ seção seguinte procuramos corrigir esta dúvida incluindo a indução máxima e os parâmetros da distribuição de TG num modelo mais completo, o qual propõe a existência de uma histerese magnética como um todo, e não só um campo chave que provoca crescimento de domínios de remagnetização. 


\subsubsection{Dependência com a indução máxima}

Para analisar o efeito da indução máxima, podemos supor, inspirando-se no modelo de Preisach, que cada grão é um histerão. Neste caso, o campo coercivo de cada grão é igual ao valor calculado para o crescimento longitudinal das "minhocas de remagnetização". Desconsiderando as forças de interação, temos que, para cada grão, $\alpha=-\beta$.

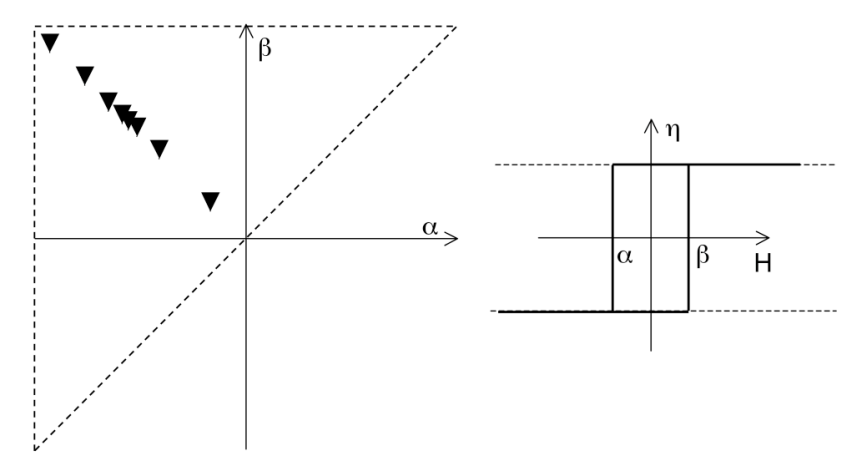

Ilustração 28 - Identificação de grãos com histerões com $H_{c}$ de Mager estendido.

E a densidade de histerões ao longo desta reta é dada pela distribuição de tamanho de grão. Quando um campo crescente é aplicado, temos primeiramente conversão dos grãos maiores cujo $\alpha$ é pequeno, e a seguir conversão de grãos cada vez menores.

Partindo do caso desmagnetizado, todos os grãos estão repartidos de alguma forma que $B=0$. Quando aplica-se um campo decrescente, por exemplo, até $H_{\max }$, o material atinge uma certa indução máxima $B_{\max }$ (supondo $J_{\max } \cong B_{\max }$ ), a qual corresponde à conversão de uma certa fração de grãos: 


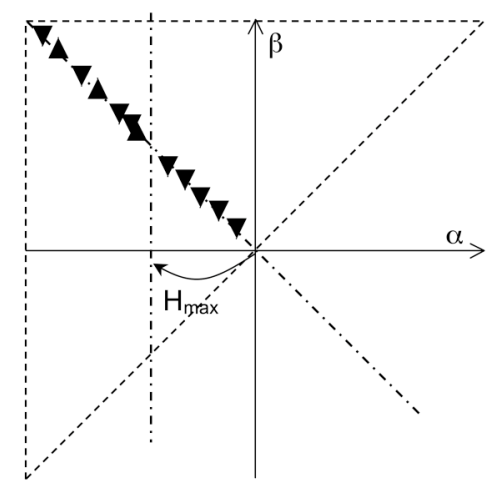

llustração 29 - Conversão de histerões/grãos a partir do estado desmagnetizado.

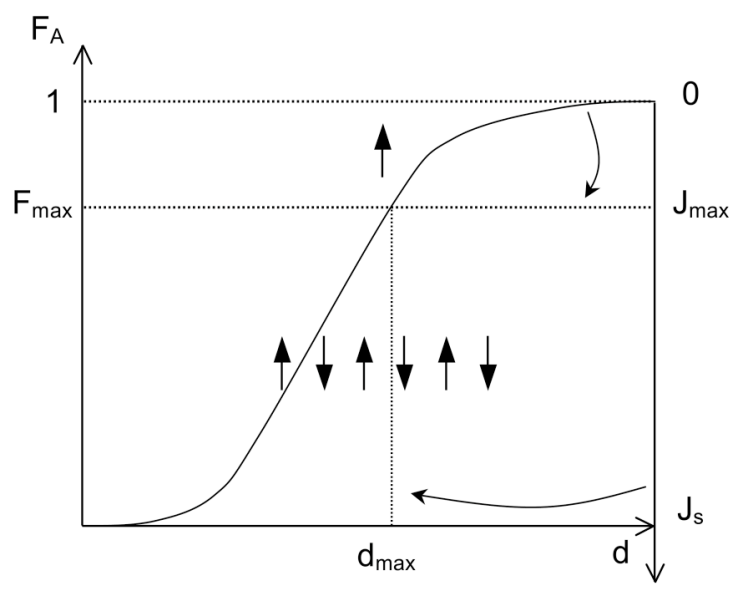

Ilustração 30 - Relação de $B_{\max } \operatorname{com} F_{\max }$.

À medida que o material é magnetizado até uma polarização de $J_{\max }$, temos a conversão primeiro dos grãos grandes e depois de grãos cada vez menores, até $d_{\max }$. Isto corresponde com uma fração de área convertida igual a $\left(1-F_{\max }\right)$.

$$
B_{\max }=\left(1-F_{\max }\right) J_{s}
$$

Equação 25 - Relação da indução máxima $B_{\max }$ com a fração máxima convertida $F_{\text {max }}$. 
A partir daí, se invertemos o sentido do campo, iniciando um estímulo alternado, sem nunca ultrapassar este $B_{\max }$, apenas os grãos que já haviam inicialmente sido convertidos estarão disponíveis para as transições, o restante ficando "inerte".

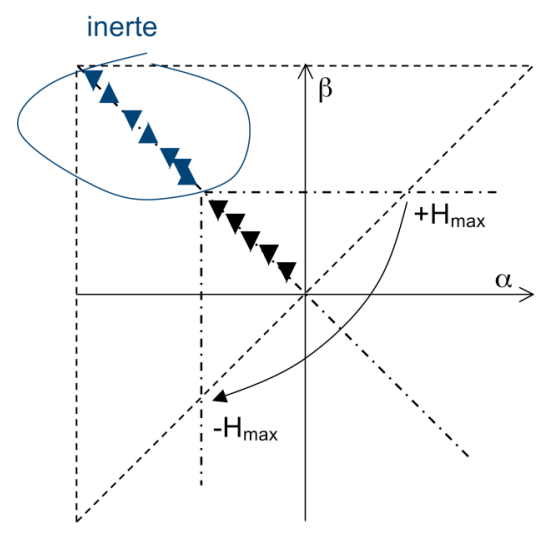

Ilustração 31 - Histerões/Grãos que não participam da histerese de amplitude $\boldsymbol{H}_{\max }$.

Atinge-se a condição da coercividade em que $B=0$ quando a fração convertida $\left(1-F_{p}\right)$ é igual à fração disponível $\left(1-F_{\max }\right)$ dividida pela metade:

$$
\left(1-F_{p}\right)=\left(1-F_{\max }\right) / 2
$$

\section{Equação 26 - Relação entre as frações de histerões/grãos convertidos e disponíveis.}

Ou seja, atinge-se $B=0$, quando precisamente aquele grão $p$ for convertido, o qual divide os grãos disponíveis em dois grupos de magnetização oposta e fração de área somada igual.

Tomando uma distribuição lognormal da fração de área e sabendo que os grãos são convertidos sempre do maior para o menor, podemos determinar qual o diâmetro $d_{p}$ deste grão de acordo com a fração convertida. 


$$
F_{p}=\frac{1}{2}+\frac{1}{2} \operatorname{erf}\left(\frac{\ln d_{p}-u_{A}}{\sqrt{2} s_{A}}\right)
$$

\section{Equação 27 - Distribuição lognormal de grãos.}

Podemos enfim propor uma equação que relacione $B_{\max }$ e $d_{p}$, substituindo a Equação 25 e a Equação 27 na Equação 26:

$$
\begin{gathered}
1-\frac{1}{2}-\frac{1}{2} \operatorname{erf}\left(\frac{\ln d_{p}-u_{A}}{\sqrt{2} s_{A}}\right)=\frac{B_{\max }}{2 J_{s}} \\
d_{p}=\exp \left(\operatorname{erf}^{-1}\left(1-\frac{B_{\max }}{J_{s}}\right) \sqrt{2} s_{A}\right) \cdot \exp \left(u_{A}\right)
\end{gathered}
$$

\section{Equação 28 - Diâmetro do grão médio convertido numa histerese com amplitude $B_{\text {max }}$}

Sendo que $d_{p}$ é o tamanho do grão cuja conversão garante que $B_{\text {total }}$ seja igual a zero. $\mathrm{A}$ forma complicada desta expressão se deve apenas à inversão da fórmula da distribuição de grão acumulada, $F_{p}$.

Então, se os grão se comportam como histerões independentes, podemos recuperar a Equação 23, e substituir o valor de tamanho de grão apropriado, $d_{p}$, o qual depende da indução máxima conforme obtido na Equação 28.

$$
H_{c}=\frac{2 \gamma}{0,7 J_{s} \cos \beta \cdot d_{p}\left(B_{\max }\right)}+\frac{J_{s}}{620 \mu_{0}} \frac{\Delta \cos ^{2} \beta}{\cos \beta}
$$

Equação 29 - Dependência de $H_{c}$ com indução máxima e distribuição de $T G$.

A qual é a equação desejada, correlacionando textura na forma do cosseno médio e da desorientação média, distribuição de tamanho de grão nos parâmetros largura e posição do pico, e indução máxima, estando os três últimos incluídos na fórmula de $d_{p}$. 
Além disso, sabemos que esta equação também é sensível à composição química, pela sua influencia na energia de parede $\gamma$ e na polarização de saturação, $J_{s}$, as quais já foram substituídas por seus valores numéricos na seção anterior.

Então, desconsiderando o crescimento lateral e as interações entre os grãos, temos que a magnetização varia com o campo aplicado através da conversão inicial dos grãos mais moles (textura favorável, TG grande) seguida pela conversão dos grão mais duros (textura desfavorável, TG pequeno). Assim, $H_{c}$ é o campo para converter o grão divisor de águas, causando $B=0$.

Foram utilizados valores estimados do cosseno a partir dos $B_{50}$ obtidos no quadro de Epstein, por serem os valores de textura que melhor refletem o comportamento geral do material.

O valor da desorientação média, $\Delta \cos \beta$, é difícil de ser estimado. Para tanto, é preciso levar em consideração a forma e orientação dos contornos de grão, além de considerar a possibilidade de domínios de fechamento. Por conveniência, foi utilizado um valor de 0,083.

$$
\begin{gathered}
H_{c}=\frac{2 \gamma}{0,7 J_{s} \cos \beta \exp \left(\operatorname{erf}^{-1}\left(1-\frac{B_{\max }}{J_{s}}\right) \sqrt{2} s_{A}\right) \exp \left(u_{A}\right)}+\frac{J_{s}}{620 \mu_{0}} \frac{\Delta \cos ^{2} \beta}{\cos \beta} \\
H_{c}=\frac{1,6}{\cos \beta \exp \left(\operatorname{erf}^{-1}\left(1-\frac{B_{\max }}{2,14}\right) \sqrt{2} s_{A}\right) \exp \left(u_{A}\right)}+\frac{19}{\cos \beta}
\end{gathered}
$$

\section{Equação 30 - Aplicação numérica da dependência de $H_{c}$ com a indução} máxima e distribuição de TG.

Aqui desaparece o problema da inclinação. Ao invés de determinar um valor único para todas as induções e questionar-se qual o melhor método de medida de tamanho de grão para realizar o ajuste, vemos que a inclinação depende com o valor de indução máxima e que a melhor variável para realizar o ajuste é a mediana da distribuição. 
Novamente, apresentamos o desvio absoluto médio em função da indução máxima:

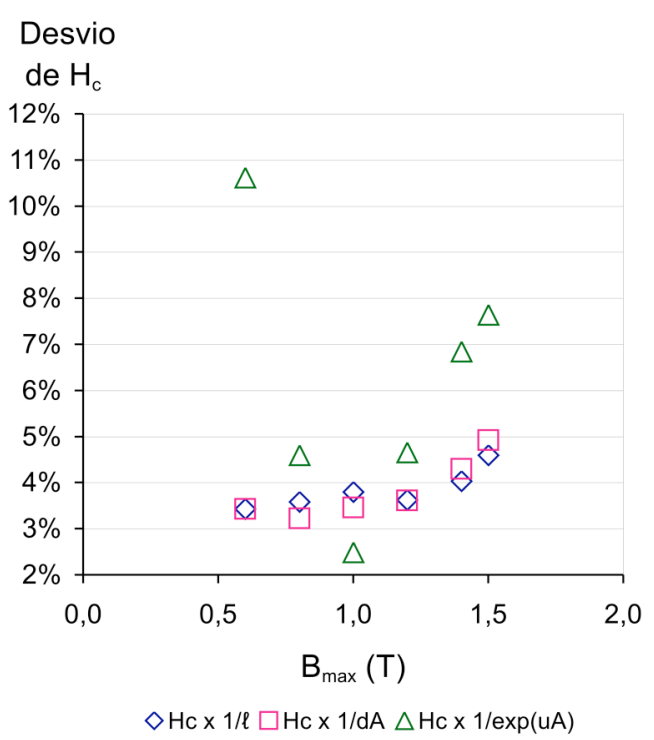

Ilustração 32 - Desvio de $H_{c}$ para modelos físico e fenomenológicos.

Notamos que existe um desvio muito elevado para a indução de 0,6 T. Além disso, o desvio apresenta um mínimo e varia muito com a indução máxima, o que indica que a regra de dependência de $H_{c} \operatorname{com} B_{\max }$ não está boa.

Isso se deve ao fato de que, no modelo físico, o termo independente de TG $(19 / \cos \beta)$ não é afetado pelo valor da indução máxima. No modelo fenomenológico vemos que este termo depende com a raiz quadrada de $B_{\max }$

Abaixo temos o gráfico de como varia com $B_{\max }$ o termo dependente do tamanho de grão do ajuste $H_{c} \times 1 / T G$ para os três modelos: fenomenológico com $T G(\ell)$, fenomenológico com $T G\left(d_{A}\right)$ e físico com $T G\left(d_{p}\right)$. Porém, como no modelo físico é o próprio tamanho de grão $\left(d_{p}\right)$ e não o coeficiente angular que varia com a indução máxima, foi introduzida a função $a\left(B_{\max }\right)$ : 


$$
\begin{gathered}
H_{c}=\frac{a}{\exp \left(u_{A}\right)}+b \\
a\left(B_{\max }\right)=\frac{1,6}{0,8 \exp \left(\operatorname{erf}^{-1}\left(1-\frac{B_{\max }}{2,14}\right) \sqrt{2} \cdot 0,14\right)}
\end{gathered}
$$

Equação 31 - Variação do termo dependente de TG com $B_{\max }$ para o modelo físico.

Por este motivo, na llustração 33 estão exibidos os valores de a como definido na Equação 31, sob a legenda $\mathrm{Hc} \times 1 / \exp (\mathrm{uA})$.

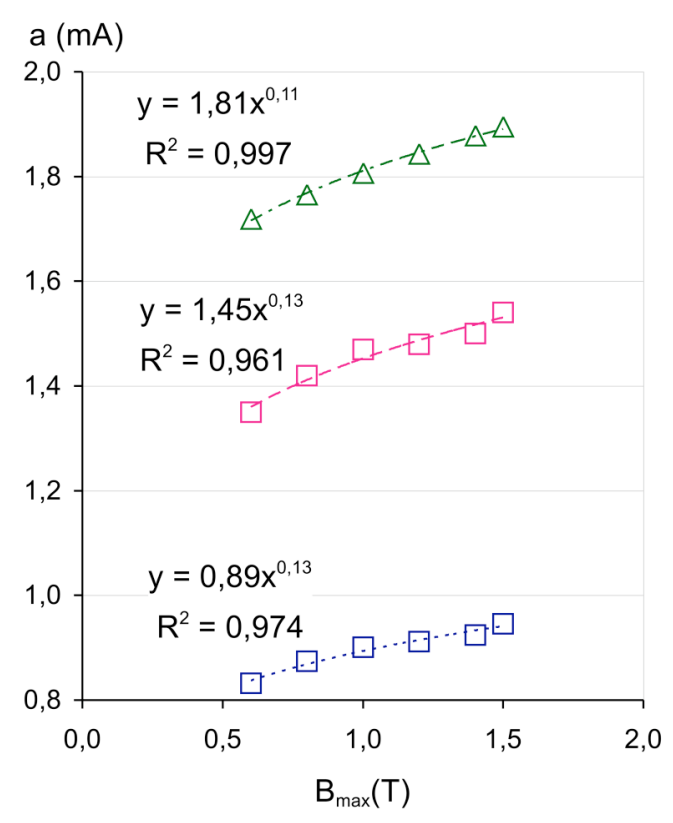

$\square \mathrm{Hc} \times 1 / \ell \square \mathrm{Hc} \times 1 / \mathrm{dA} \triangle \mathrm{Hc} \times 1 / \exp (\mathrm{uA})$

Ilustração 33 - Coeficiente angular dos ajustes $H_{c} \times 1 /$ TG em função de $B_{\max }$.

Vemos que a variação de a com $B_{\max }$, e portanto de $1 / d_{p} \operatorname{com} B_{\max }$, podem ser aproximadas por uma função do tipo potência com expoente 0,11 . Assim concluímos que a pequena variação do coeficiente angular do ajuste $H_{c} \mathrm{x}$ 1/TG observada no modelo fenomenológico pode ser explicada por um modelo físico no qual cada grão é identificado a um histerão. 
Por fim, temos um desvio médio geral de $6,2 \%$ para o modelo físico, e o desvio de $2,4 \%$ para a indução de $1 \mathrm{~T}$, ambos os quais atestam pela sua aplicabilidade.

Obviamente o objetivo passa a ser a compreensão do mecanismo segundo 0 qual o termo independente de TG varia com a raiz de $B_{\max }$. Numa perspectiva otimista, podemos imaginar que alguma hipótese realizada no cálculo da energia desmagnetizante levou à obtenção de seu valor para induções elevadas, e que o mesmo decairia com a raiz de $B_{\max }$.

Porém, a origem desta variação poderia estar em fenômenos completamente diferentes, como, por exemplo, a interação de paredes de domínios com inclusões não magnéticas.

É particularmente interessante notar que, em trabalhos anteriores sobre o modelo de Preisach, sem fazer nenhuma referência à microestrutura, obtevese também uma distribuição lognormal de histerões [37] para ímãs de NdFeB. E é essa a distribuição que melhor se enquadra ao tamanho de grão das amostras estudadas neste trabalho. 


\subsection{Visualização de domínios por efeito Kerr}

$\mathrm{Na}$ sequência de figuras que segue encontramos as micrografias de microscópio óptico com luz polarizada de contraste longitudinal. Conjuntamente temos a figura de pólo inversa obtida por EBSD marcada com cubos que caracterizam a orientação dos grãos.
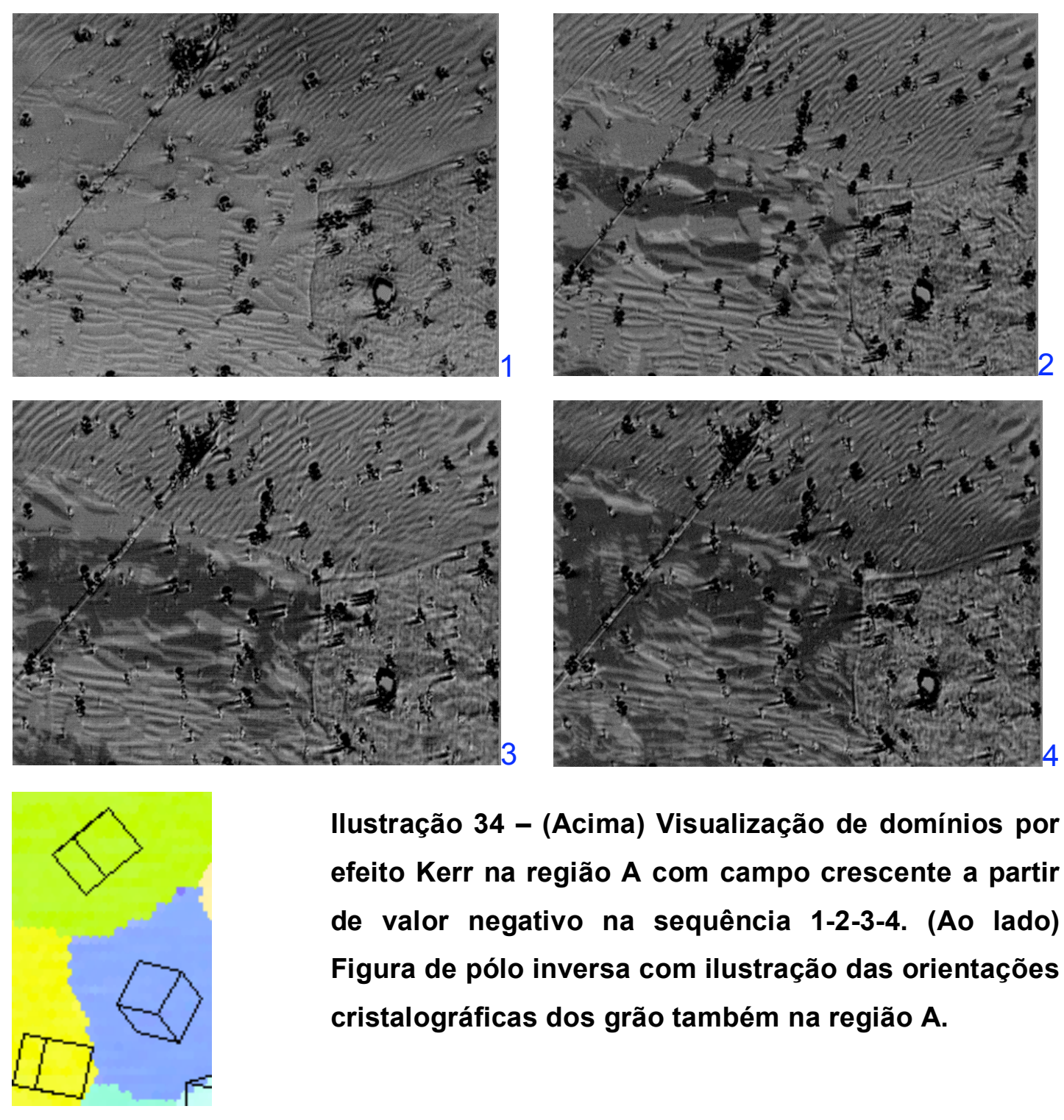

Ilustração 34 - (Acima) Visualização de domínios por efeito Kerr na região $A$ com campo crescente a partir de valor negativo na sequência 1-2-3-4. (Ao lado) Figura de pólo inversa com ilustração das orientações cristalográficas dos grão também na região $\mathrm{A}$.

$160.0 \mu \mathrm{m}=20$ steps 
A intensidade do campo aplicado não é suficiente para saturar o material. Podemos notar que à medida que o campo cresce, apenas os grãos mais magneticamente moles alteram sua magnetização. Quando a face do cubo está paralela à superfície do material, a magnetização pode ocupar direções próximas à do campo externo, sem gerar campo desmagnetizante.

Dessa forma, não é necessário que se constitua uma estrutura complexa de domínios de fechamento, liberdade esta que aumenta a permeabilidade do grão.
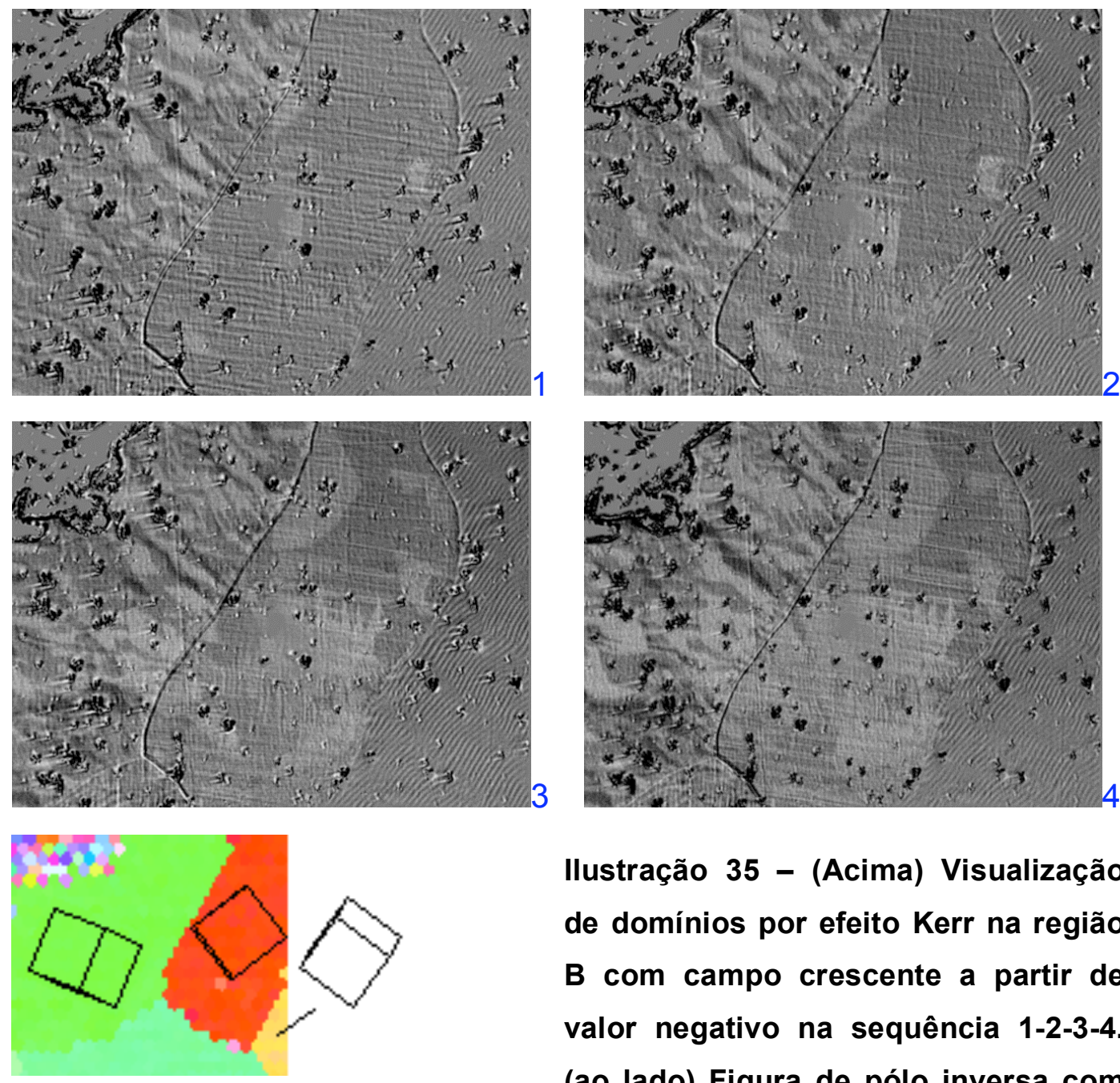

Ilustração 35 - (Acima) Visualização de domínios por efeito Kerr na região B com campo crescente a partir de valor negativo na sequência 1-2-3-4. (ao lado) Figura de pólo inversa com

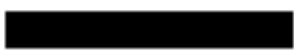
ilustração das orientações $160.0 \mu \mathrm{m}=20$ steps cristalográficas dos grão também na região $B$.

Notamos que nos grãos duros aparecem estruturas de domínios em estrias, orientadas na direção das arestas do cubo. 


\subsection{Simulação micromagnética}

$\mathrm{Na}$ figura a seguir, podemos observar a estrutura de domínios durante a histerese magnética da amostra simulada, cujos pixeles foram preenchidos com tons de cinza variando conforme o cosseno do momento magético com a horizontal, de forma a se assemelhar às imagens obtidas por efeito Kerr.

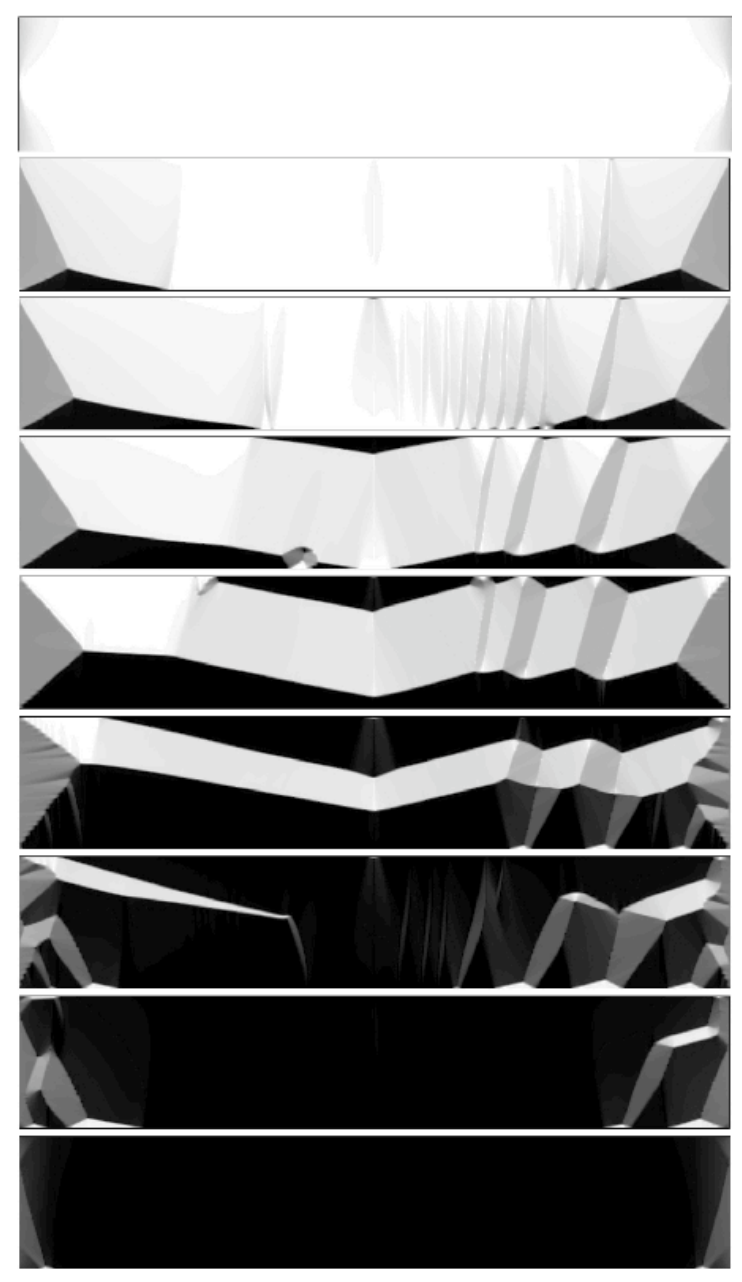

llustração 36 - Histerese de barra com dois grãos obtida por simulação micromagnética no programa OOMMF.

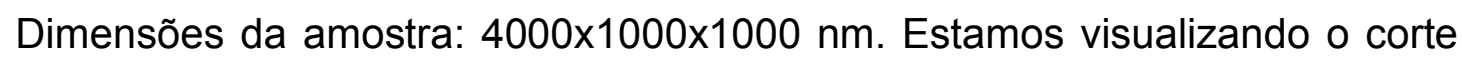
na altura de $500 \mathrm{~nm}$. Dimensão da célula $25 \mathrm{~nm}$. Ordem de grandeza do campo aplicado $10^{5} \mathrm{~A} / \mathrm{m}$.

A amostra está dividida na metade em dois grãos com orientações cristalográficas diferentes. No primeiro instante ela está quase saturada na direção de $x$ positivo. Cada figura representa um novo instante no qual $o$ 
campo foi reduzido. O conjunto de nove imagens representa o ramo descendente da histerese magnética, partindo de $+H_{\max }$ até $-H_{\max }$.

Quando o campo é reduzido a partir da saturação, vemos nuclearem-se pequenas regiões com rotação da magnetização nas extremidades da amostra e no contorno de grão, devido ao campo desmagnetizante. Uma estrutura de domínios de fechamento surge nas laterais da amostra.

A partir do $4^{\circ}$ instante, já vemos uma estrutura semelhante à "minhoca" de remagnetização atravessando o material como um todo. As regiões escuras representam magnetização alinhada no sentido de $x$ negativo. No $5^{\circ}$ instante, com campo aplicado nulo, temos a estrutura atravessando ambos os grãos, se alinhando com sua orientação fácil e evitando aflorar à superfície através de repetitivos desvios de $90^{\circ}$.

A partir daí a situação se inverte e temos o desaparecimento primeiro desta estrutura e depois dos domínios de fechamento, até que o material se encontra saturado no sentido de $\mathrm{x}$ negativo.

Embora promissoras no sentido de confirmar a estrutura da "minhoca" de remagnetização proposta por Mager, estas imagens devem ser tomadas com cuidado. Testes indicam que o tamanho de célula de $25 \mathrm{~nm}$ pode ser longo demais para que o programa calcule corretamente a influência de energia de troca.

Além disso, como estamos simulando uma amostra de dimensões micrométricas solta no espaço, a influência do campo desmagnetizante devido à superfície se sobrepõe ao campo desmagnetizante devido ao contorno de grão, possivelmente mascarando os resultados.

O principal desafio é superar estas duas dificuldades: realizar simulações com uma malha mais fina sem ultrapassar as capacidades de memória do computador e entender como transportar resultados obtidos em uma amostra de poucos micrometros quadrados para um material macroscópico. 


\section{Conclusões, sugestões para trabalhos futuros}

Foi um trabalho muito divertido. A inclinação da reta $H_{c} \times 1 /$ TG a 1,0T obtida neste trabalho é de 0,9 mA, resultado que está de acordo com trabalhos recentes realizados em aços elétricos. Foi obtida uma amostra com distribuição de tamanho de grão diferenciada. Comparando-a com amostras de tamanho de grão muito próximo, vemos que aquela que quanto mais larga a distribuição (maior desvio padrão do TG) menor o campo coercivo.

Há diferença entre a textura cristalográfica das amostras recristalizadas e das amostras de crescimento de grão. Porém, variações de textura ao longo da espessura das lâminas e entre as diferentes lâminas do mesmo conjunto são tão ou mais significativas do que as variações entre um conjunto e outro.

Desta forma, não se pode estabelecer uma correlação nem da energia de anisotropia média nem de $B_{50}$ com o campo coercivo. Em trabalhos futuros, seria necessário partir de uma chapa de grão orientado e, se possível, através e deformação e recozimento, criar amostras com texturas significativamente diferentes entre si.

Foram propostas duas fórmulas fenomenológicas para a influência do tamanho de grão e indução máxima no campo coercivo a partir das equações de Mager e Steinmetz. Em ambos os casos, notamos que a influência da indução máxima é muita mais elevada no termo independente de TG.

Em uma delas, contabilizou-se a influência da distribuição do tamanho de grão a partir da variável $d_{A}$. A fórmula que contém $d_{A}$ apresentou desvio (= $4 \%$ ) equivalente àquela que utilizou $\ell$, o tamanho de grão medido pelo método dos interceptos.

Em termos de modelamento físico, como um acréscimo ao equacionamento de Mager podemos propor um termo independente o qual está associado à energia de campo desmagnetizante no contorno de grão. O valor obtido (34 
$\mathrm{A} / \mathrm{m}$ ) se aproxima dos resultados experimentais (29 $\mathrm{A} / \mathrm{m}$ a $1,5 \mathrm{~T})$, porém apenas para induções elevadas. Considera-se que o valor foi sobreestimado, pois o modelo está baseado em uma estrutura idealizada na remanência, a qual teria energia desmagnetizante nula.

Quando consideramos um modelo de Preisach em que cada grão é um histerão cujo campo de conversão é o $H_{c}$ de Mager, podemos obter uma fórmula física para a influência da textura cristalográfica, distribuição do tamanho de grão e indução máxima no campo coercivo.

O desvio médio para esta fórmula é menor do que $10 \%$, mas varia demasiadamente com a indução. A variação do termo dependente de $T G$ (coeficiente angular) com $B_{\max }$ está de acordo com o que foi determinado pelo modelo fenomenológico. Investigando-se o efeito da indução máxima no termo independente de $T G$ se poderá encontrar uma expressão que se adequa melhor à realidade.

A partir da observação do domínios por efeito Kerr, notamos que, embora haja interações entre grãos, na superfície do material, o processo de magnetização ocorre com grande independência em cada grão, e é condicionado pelo ângulo da direção fácil com a superfície, ou seja, pelo campo desmagnetizante.

Primeiras tentativas de simulação micromagnética por diferenças finitas parecem comprovar a presença de uma estrutura de domínios do tipo "minhoca de remagnetização" em materiais policristalinos. Espera-se que afinando a malha e reduzindo a influência do campo desmagnetizante devido à superfície se mantenham estes resultados. 


\section{Referências}

[1] Hubert, A., Schäfer, R., "Magnetic domains: the analysis of magnetic microstructures", Springer-Verlag, Heidelberg, 1998

[2] Preisach, F., "Über die magnetische Nachwirkung", Zeitschrift für Physik v. 74 , pp. $277-302,1935$

[3] Jiles, D.C., Atherton, D.L., "Theory of ferromagnetic hysteresis", Journal of Magnetism and Magnetic Materials, v. 61, pp. 48-60, 1986

[4] Alessandro, B., Beatrice, C., Bertotti, G., Montorsi, A., "Domain-wall dynamics and Barkhausen effect in metallic ferromagnetic materials. 1. Theory", Journal of Applied Physics, v. 68 n. 6, pp. 2901-2907, Sept. 1990

[5] Landgraf, F.J.G., "Microestrutura e histerese magnética nos aços para fins eletromagnéticos", 2007, 117p. Tese (Livre Docência), Escola Politécnica, Universidade de São Paulo, São Paulo, 2007

[6] Shimanaka, H., Ito, Y., Matsumura, K., Fukuda, B., "Recent developmento of non-oriented electrical steel sheets", Journal of magnetism and magnetic materials, v.26, pp. 57-64, 1982

[7] Yensen, "Magnetically soft materials", T. D., "Magnetically soft materials", Tansactions of the A.S.M. p.796-820, Sep. 1939

[8] Döring, W., "Über das Anwachsen der Ummagnetisierungskeime bei großen Barkhausen-Sprüngen", Zeitschrift für Physic, v.108, p. 137-152, 1938

[9] Mager, A., "About the influence of the grain size on coercitivity", Annalen der Physic, p. 11-15, 1952 
[10] Adler, E., Pfeiffer, H., "The influence of grain size and impurities on the magnetic properties of the soft magnetic alloy $47,5 \%$ NiFe", IEEE Transactions on magnetics, v. mag-10 n.2, pp.172-174, 1974

[11] Della Torre, E., "Problems in physical modelling of magnetic materials", Physica B 343, 2004

[12] Fuller Brown Jr., W., "Magnetostatic principles in ferromagnetism", NorthHolland publishing company, 1962

[13] Pasquale, M., Bertotti, G., Jiles, D. C., Bi, Y., "Application of the Preisach and Jiles-Atherton to the simulation of hysteresis in soft magnetic materials", Journal of Applied Physics, v. 85, n. 8, pp. 4373-4375, 1999

[14] Sixtus, K.J., Tonks, L., "Propagation of large Barkhausen discontinuities", Physical Review, v. 37, pp. 930-958, 1931

[15] Becker, R., Döring, W., “Ferromagnetismus”, Springer Berlin, 1939

[16] Döring, W., "Über das Anwachsen der Ummagnetisierungskeime bei großen Barkhausen-Sprüngen”, Zeitschrift für Physic, v.108, p. 137-152, 1938

[17] Goodenough, J. B., "A theory of domain creation and coercive force", Physical Review v. 95, p. 917-932, 1954

[18] Williams, H.J., Bozorth, R.M., Shockley, W., "Magnetic domain patterns on single crystars of silicon iron”, Physical Review, v. 54, pp. 155-178, 1949

[19] Kittel, C., "Physical theory of ferromagnetic domains", Review of Modern Physics, v. 21, pp. 541-583, 1949

[20] Tannous, C., Gieraltowsky, J., "The Stoner-Wohlfarth model of ferromagnetism", European journal of physics, v.29, pp. 475-487, 2008 
[21] Koehler, T.R., Fredkin, D.R., "Finite elements for micromagnetics", IEEE Transactions on Magnetics, v. 28, mar. 1992

[22] Disponível na rede, 01/2011: http://euclid.ucc.ie/hysteresis/node17.htm

[23] Silveira, J.R.F., "Efeito do tamanho de grão obtido por laminação e recozimento sobre as perdas histeréticas em aço para fins elétricos", 2008, 89p., Trabalho de Conclusão de Curso, Escola Politécnica da Universidade de São Paulo, São Paulo

[24] ASTM Standard, E 1121996 (2004), "Standard test methods for determining average grain size", ASTM International, West Conshohocken, www.astm.org

[25] ASTM Standard, E 13821997 (2004), "Standard test methods for determining average grain size using semi-automatic and automatic image analysis", ASTM International, West Conshohocken, www.astm.org

[26] Vaz, M. F., Fortes, M. A., "Grain size distribution: the lognormal and the gamma distribution functions", Scripta Metallurgica, v. 22, pp. 35-40, 1998

[27] Yonamine, T., Landgraf, F.J.G., "Correlation between magnetic properties and crystallographic texture of silicon steel", Journal of magnetism and magnetic materials, v.274-276, pp. e565-e566, 2004

[28] Donahue, M. J., Porter, D. G., "OOMMF user's guide, version 1.0", Interagency report NISTIR 6376, NIST, Gaithersburg, MD, 1999

[29] Disponível na rede, acesso janeiro 2011: http://math.nist.gov/oommf 
[30] Yonamine, T., Campos, M.F., Castro, N.A., Landgraf, F.J.G. "Modeling magnetic polarization $J_{50}$ by different methods", Journal of magnetism and magnetic materials, v. 304, pp. e589-e992, 2006

[31] Rodrigues-Jr, D. L., et al., "Efeito do tamanho de grão sobre as perdas magnéticas em aços elétricos", anais do $64^{\circ}$ congresso anual da ABM, 2009

[32] Degauque, J., Astie, B., Porteseil, J. L., "Influence of the grain size on the magnetic and magnetomechanic properties of high-purity iron", Journal of magnetism and magnetic materials, v.26, pp. 261-262, 1982

[33] Steinmetz, C. P., "On the law of hysteresis", Proceedings of the IEEE, v. 72, pp. 197-221, 1984

[34] Rodrigues Jr., D. L., "Efeito do tamanho de grão e do indução magnético sobre o campo coercivo e a dissipação de energia por histerese em aços para fins elétricos", 2009, 120p., Dissertação de mestrado (enga . de materiais), Escola Politécnica da Universidade de São Paulo, São Paulo

[35] Bozorth, R.M. "Ferromagnetism", Van Nostrand, 1951

[36] Sheiko, L., et al., "Calculation of the magnetostatic energy referred to magnetic charges on surfaces of the grain boundaries", Journal of magnetism and magnetic materials, v. 215-126, pp. 24-25, 200

[37] Cornejo, D. R., "Aplicação do modelo de Preisach em ímãs nanocristalinos", 1998, 194p., Tese de doutorado (física do estado sólido), Instituitio de Física da Universidade de São Paulo, São Paulo

[38] Chikazumi, S., "Physics of Magnetism", John Wiley \& Sons, 1964 


\section{Apêndice}

\subsection{Prólogo}

Dentre as diferentes contribuições energéticas que afetam a orientação dos momentos magnéticos atômicos em materiais magneticamente moles, aquela que apresenta a maior dificuldade para ser calculada é, sem dúvida, a energia magnetostática devida ao campo desmagnetizante.

Seu valor só pode ser obtido de forma analítica em condições muito simplificadas (comparado como o material real) ou de forma numérica através de um cálculo computacionalmente muito dispendioso.

Para evitar complicações, aqui tentou-se reduzir o problema do campo desmagnetizante no contorno de grão àquilo que é lhe mais essencial, inspirando-se nas hipóteses de MAGER [1]:

- Geometria cilíndrica, visto que durante a histerese a magnetização tende a alinhar-se paralelamente ao campo aplicado, sendo todas as outras direções equivalentes;

- Efeito da rotação homogênea, fenômeno pelo qual se reduz o valor da energia desmagnetizante;

- Presença de dois domínios concêntricos no grão (um ao redor do outro), condição que permite relacionar o diâmetro do domínio com o tamanho de grão quando ocorre crescimento de um domínio de remagnetização no interior do grão.

Os resultados obtidos obviamente não devem ser tomados como a última palavra em termos do valor da energia desmagnetizante, visto que uma simetria cúbica e arranjos de 2 domínios lado a lado também são comuns nos esforços de modelamento da literatura. 
Porém, através desta avaliação, podemos entender melhor qual a dinâmica do campo desmagnetizante no contorno de grão segundo as hipóteses de MAGER [1].

Numa postura muito conservadora, podemos encarar este texto não como um cálculo preciso que determina o valor da energia a ser comparado com valores experimentais, mas sim como uma elucidação das ferramentas matemáticas que determinam o efeito de cada hipótese sobre o resultado final, ou seja, um estudo do método de determinação do valor da energia magnetostática devida ao campo desmagnetizante no contorno de grão.

É importante notar que os métodos aplicados aqui já foram, cada qual, explorados por diferentes autores na literatura do magnetismo.

Se por um lado GOODENOUGH [2] explorou o cálculo analítico ao longo do eixo central de um grão cilíndrico, por outro lado os métodos numéricos foram empregados por RHODES \& ROWLANDS [3] numa geometria retangular.

Além disso, o método $\mu^{*}$ introduzido por BOZORTH [4] para contabilizar o campo desmagnetizante que se produz na superfície do material foi utilizado por SHEIKO [5] para tratar do contorno de grão, porém em aços GO.

Aqui foram reunidas estas diferentes formulações para o caso do crescimento de um domínio de remagnetização cilíndrico, de forma a realizar o estudo do modelamento matemático do efeito do tamanho de grão sobre o campo coercivo conforme feito na dissertação de mestrado do autor.

\subsection{Introdução}

Na formulação teórica de MAGER [1], o campo desmagnetizante associado ao conjunto de domínios de remagnetização como um todo foi desconsiderado com base na afirmação de que, devido ao seu formato, com um grande comprimento e pequeno raio, o fator desmagnetizante assume um 
valor muito baixo.

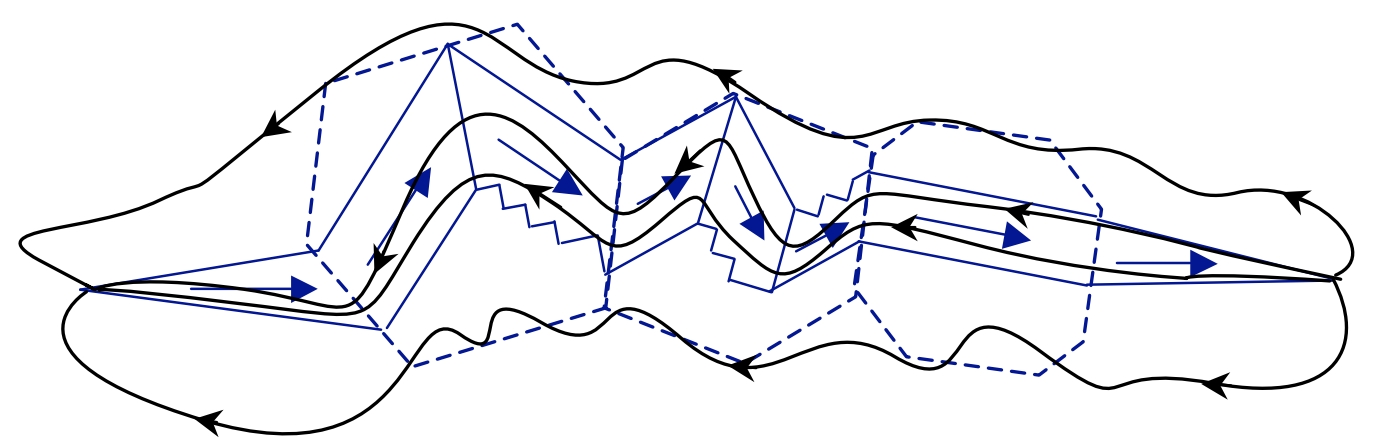

llustração 1 - Campo desmagnetizante associado à estrutura de remagnetização como um todo

Aqui, mantém-se esta aproximação. No entanto, nota-se que o valor do campo desmagnetizante associado a cada contorno de grão atravessado por esta estrutura não pode ser desconsiderado frente ao campo aplicado.

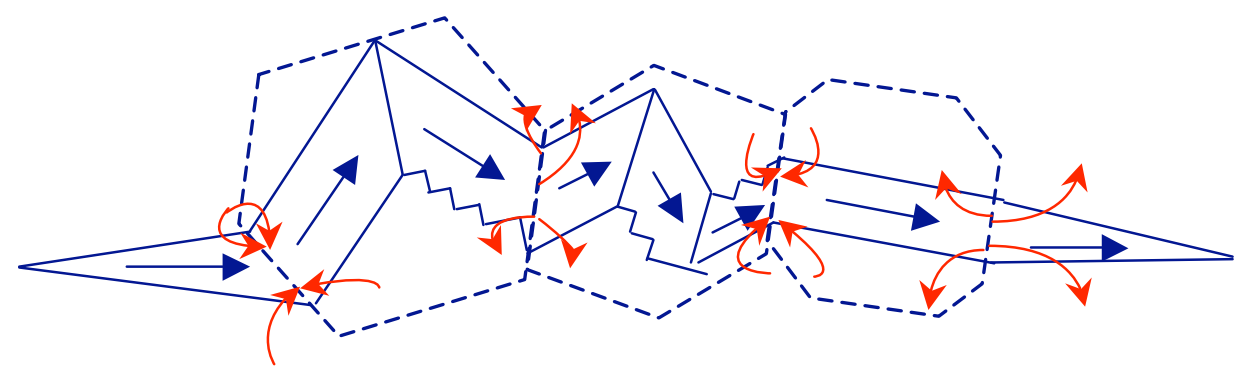

llustração 2 - Campo desmagnetizante associado ao contorno de grão

O objetivo final do cálculo que segue consiste na obtenção de uma expressão analítica para a energia devido ao campo desmagnetizante associado ao contorno de grão para que se possa tomá-la em consideração na equação de equilíbrio energético a qual fornece o campo coercivo em função do tamanho de grão e variáveis associadas à textura cristalográfica.

A primeira etapa envolve a realização de um cálculo simplificado, válido apenas para o eixo central de um grão monodomínio cilíndrico, caso este que 
foi explorado por GOODENOUGH [2], e que possui uma formulação semelhante ao cálculo comum em livros-texto do campo observado no exterior de um ímã cilíndrico.

O objetivo da primeira etapa é mostrar através de uma formulação familiar ao pesquisador qual o processo que será seguido para obter a expressão da energia, em quais suposições ele se baseia e qual a equação obtida.

Nas etapas seguintes serão propostos fatores de correção que não alteram a expressão obtida na etapa inicial. Desta forma, podemos partir de uma equação determinada em condições simples e progredir até uma estimativa mais razoável do valor da energia.

O primeiro fator de correção corresponde à rotação homogênea, fenômeno pelo qual os momentos magnéticos do grão todo se afastam por um pequeno ângulo da direção de fácil magnetização de forma a reduzir a divergência da magnetização no contorno de grão. Este efeito foi contabilizado de acordo com o método $\mu^{*}$. Nota-se, como colocado por SHEIKO [5], que a energia cai por uma ordem de grandeza devido a esta rotação.

Como um segundo fator de correção, temos que considerar o fato de que o valor do potencial no eixo $z$ é máximo e decai à medida em que nos afastamos dele, com $x$ e $y$ crescentes. Através do cálculo numérico podemos obter os valores do potencial ao longo do grão todo e propor uma expressão de "decaimento" exponencial a partir da expressão já conhecida para o eixo $z$.

Por fim, consideramos o caso em que há dois domínios concêntricos no grão, um cilíndrico interno e outro anelar, externo, ocupando completamente o grão. Este caso pode ser reduzido a uma sobreposição de dois potenciais os quais podem ser calculados com a equação conhecida e seu atenuamento 
exponencial. O resulto final é a energia magnetostática devida ao campo desmagnetizante em função do raio do domínio interno.

\subsection{Cálculo analítico ao longo do eixo central}

Para calcular a energia magnetostática devida ao campo desmagnetizante relacionado ao contorno de grão, utilizamos uma geometria simplificada cilíndrica. O cálculo é feito de forma analítica tomando-se os valores para o potencial magnetostático ao longo do eixo $z$.

Este cálculo tem por objetivo elucidar as etapas necessárias para a obtenção da fórmula da energia desmagnetizante em função do tamanho de grão, a ser utilizada para complementar o modelo de MAGER [1].

Dois aspectos são negligenciados nesta aproximação: o efeito $\mu^{*}$, ou seja, rotação homogênea dos momentos magnéticos no interior do domínio para reduzir a divergência da magnetização; e a redução do valor do potencial à medida que nos distanciamos do eixo $z$.

Mais para frente veremos que ambos aspectos podem ser contabilizados cada um por um fator multiplicativo. Desta forma, o desenvolvimento que vêm a seguir mostrará de forma clara o equacionamento da energia desmagnetizante, enquanto seu valor será contabilizado após o cálculo dos fatores multiplicativos.

O grão $A$ é aproximado por um cilindro de eixo principal orientado na direção do campo externo aplicado $H_{\text {ext }}$. Considera-se que cada grão está preenchido por um único domínio magnético, cuja orientação corresponde à direção de fácil magnetização <100> mais próxima do campo externo. No interior do grão $A$, esta direção faz um ângulo $\alpha$ com o eixo central. No grão $B$, situado imediatamente abaixo, este ângulo é $\beta$. 


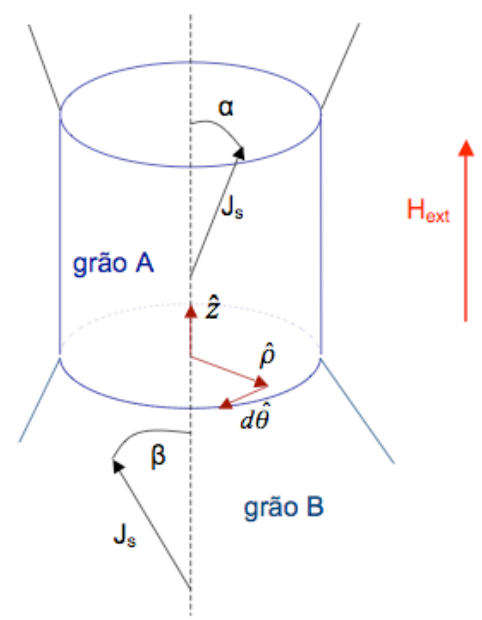

Ilustração 3 - Grão cilíndrico e referencial de coordenadas.

Desta forma, podemos definir a divergência da magnetização ao longo da base cilíndrica, $\sigma_{M}$, em função da magnetização de saturação do material, $M_{s}$ :

$$
\begin{gathered}
\operatorname{div} \vec{M}=\sigma_{M}=M_{s}(\cos \beta-\cos \alpha) \\
\text { Equação } 1 \text { - Divergência da } \\
\text { magnetização. }
\end{gathered}
$$

Notamos que muitas das aproximação realizadas ao longo deste texto só são possíveis pois $\sigma_{M}$ é constante ao longo da base e lembramos que esta variável também é comumente referida como densidade de "polos magnéticos" na superfície, por analogia com a eletrostática.

O cálculo do campo desmagnetizante, $H_{d}$, pode ser obtido a partir da função potencial magnético:

$$
\vec{H}_{d}=-\nabla \Phi_{\text {mag }}
$$

\section{Equação 2 - Campo desmagnetizante}

Sendo que a função fi magnetostático é a integral da divergência da magnetização dividida pela distância do ponto em questão até cada ponto da base cilíndrica.

$$
\Phi_{\text {mag }}(\vec{r})=\frac{1}{4 \pi} \int_{\text {base }} \frac{\nabla \cdot \vec{M}}{\left|\vec{r}-\vec{r}^{\prime}\right|} d \vec{r}^{\prime}
$$

Equação 3 - Potencial magnetostático. 
Para prosseguir com os cálculos, posiciona-se a origem de um sistema de coordenadas cilíndricas no centro da base inferior do cilindro (grão $A$ ) de forma que o versor $\hat{z}$ é paralelo ao eixo central, e o versor $\hat{\rho}$ está contido no plano da base.

Devido à simetria cilíndrica, podemos expressar o vetor posição $r$ em função de duas variáveis, $\rho$ e $z$. Escrevemos o vetor $r$ ' que percorre a base cilíndrica num sistema de coordenadas cartesiano conveniente, e então o módulo da distância fica:

$$
\begin{gathered}
\vec{r}=(0, \rho, z) \\
\vec{r}^{\prime}=(\theta, r, 0)_{\Theta \mathrm{OPZ}}=(r \cos \theta, r \operatorname{sen} \theta, 0)_{X Y Z} \\
\left|\vec{r}-\vec{r}^{\prime}\right|=\sqrt{(\rho-r \cos \theta)^{2}+(r \cos \theta)^{2}+z^{2}}
\end{gathered}
$$

\section{Equação 4 - Condições geométricas para a integração do potencial magnetostático.}

Considerando que o raio da base vale $R$ :

$$
\begin{gathered}
\Phi_{\text {mag }}(r, z)=\frac{\sigma_{M}}{4 \pi} \int_{0}^{2 \pi} \int_{0}^{R} \frac{r}{\sqrt{\left(\rho^{2}+2 \rho \cos \theta+r^{2} \cos ^{2} \theta+r^{2} \operatorname{sen}^{2} \theta+z^{2}\right)}} d r d \theta \\
\Phi_{\text {mag }}(r, z)=\frac{\sigma_{M}}{4 \pi} \int_{0}^{2 \pi} \int_{0}^{R} \frac{r}{\sqrt{\left(\rho^{2}+2 \rho \cos \theta+r^{2}+z^{2}\right)}} d r d \theta
\end{gathered}
$$

Equação 5 - Potencial magnetostático sem solução analítica.

A qual não possui solução analítica. Como uma aproximação inicial, podemos calcular o potencial magnético, campo desmagnetizante e energia magnetostática utilizando os valores ao longo do eixo $z$, posição na qual $\rho=$ 0. 
O cálculo numérico mostra que estas funções todas apresentam um pico ao longo do eixo central e decaem em valor à medida que nos afastamos dele. Portanto, ao realizar o cálculo ao longo do eixo $z$, obtemos o valor máximo para elas.

Por outro lado, também obtém-se a lei de dependência da energia magnetostática devida ao campo desmagnetizante com o tamanho de grão, a única diferença é que fora do eixo central os valores de $H_{d}$ são menores, então o valor real da energia é menor do que o obtido por esta aproximação.

Parte-se da equação do potencial magnetostático ao longo do eixo central:

$$
\Phi_{m a g}^{\text {eixoz }}(r, z)=\frac{\sigma_{M}}{2} \int_{0}^{R} \frac{r}{\sqrt{r^{2}+z^{2}}} d \rho=\frac{\sigma_{M}}{2}\left(\sqrt{R^{2}+z^{2}}-\sqrt{z^{2}}\right)
$$

Equação 6 - Potencial magnetostático ao longo do eixo central de um grão monodomínio cilíndrico.

A seguir, temos o campo desmagnetizante (para $z>0$ ):

$$
\begin{gathered}
\vec{H}_{d}^{\text {eixoz }}=-\frac{\sigma_{M}}{2}\left\{\frac{\partial}{\partial \theta}\left(\sqrt{R^{2}+z^{2}}-\sqrt{z^{2}}\right), \frac{\partial}{\partial \rho}\left(\sqrt{R^{2}+z^{2}}-\sqrt{z^{2}}\right), \frac{\partial}{\partial z}\left(\sqrt{R^{2}+z^{2}}-\sqrt{z^{2}}\right)\right\} \\
\vec{H}_{d}^{\text {eixoz }}=-\frac{\sigma_{M}}{2}\left\{0,0, \frac{z}{\sqrt{R^{2}+z^{2}}}-\frac{z}{\sqrt{z^{2}}}\right\} \\
\vec{H}_{d}^{\text {eixoz }}=\frac{\sigma_{M}}{2}\left(1-\frac{z}{\sqrt{R^{2}+z^{2}}}\right) \hat{z}
\end{gathered}
$$

Equação 7 - Campo desmagnetizante ao longo do eixo central de um grão monodomínio cilíndrico.

Por fim, a energia magnetostática devido ao campo desmagnetizante pode 
ser calculada de acordo com:

$$
E_{d}=-\mu_{0} / 2 \iint_{g r a ̃ o A} \vec{H}_{d} \cdot \vec{M} d V-\mu_{0} / 2 \iiint_{g r \tilde{a} O B} \vec{H}_{d} \cdot \vec{M} d V
$$

\section{Equação 8 - Energia magnetostática devida ao campo desmagnetizante no contorno de grão.}

A energia atribuída ao contorno envolve o efeito do campo desmagnetizante que surge nele sobre ambos os grão que o compõe. Por isso somamos a integral no grão A com a mesma no grão B.

Como a energia depende do potencial magnético e este possui seu valor máximo ao longo do eixo $z$ decaindo à medida que nos afastamos dele com $\rho$ crescente, ao utilizar a expressão obtida para $H_{d}{ }^{e i x o z}$, podemos majorar (realizar uma estimativa a qual sabemos ser mais elevada do que o valor real para) a energia.

Para facilitar a exposição, realiza-se o cálculo para o grão A, sabendo que o cálculo no grão B será quase idêntico, por analogia. Consideramos que a altura do cilindro vale $L$.

Ao realizar o produto escalar do campo desmagnetizante com a magnetização, vemos que $H_{d}$ possui apenas uma componente na direção do eixo z. Isso se deve à utilização do potencial magnético ao longo do eixo z. Mesmo que não fosse feita esta aproximação, devido à simetria cilíndrica, o produto escalar de $H_{d}$ e $M$ na direção de $\rho$ seria nulo.

$$
\begin{gathered}
E_{d}^{\max , A}=-\frac{\mu_{0}}{2} \int_{0}^{L} \int_{0}^{2 \pi} \int_{0}^{R}\left[\frac{\sigma_{M}}{2}\left(1-\frac{z}{\sqrt{R^{2}+z^{2}}}\right) \hat{z}\right] \cdot\left[M_{s} \cos \alpha \hat{z}+M_{s} \operatorname{sen} \alpha \cos \theta \hat{\rho}\right] \rho d \rho d \theta d z \\
E_{d}^{\max , A}=-\frac{\mu_{0} \sigma_{M}}{4} M_{s} \cos \alpha \int_{0}^{L} \int_{0}^{2 \pi} \int_{0}^{R}\left(1-\frac{z}{\sqrt{R^{2}+z^{2}}}\right) \rho d \rho d \theta d z
\end{gathered}
$$




$$
\begin{gathered}
E_{d}^{\mathrm{max}, A}=-\frac{\mu_{0} \sigma_{M}}{4} M_{s} \cos \alpha R^{2} \int_{0}^{L}\left(1-\frac{z}{\sqrt{R^{2}+z^{2}}}\right) 2 \pi d z \\
E_{d}^{\max , A}=-\frac{\pi \mu_{0} \sigma_{M}}{4} M_{s} \cos \alpha R^{2}\left(L-\sqrt{R^{2}+L^{2}}+R\right)
\end{gathered}
$$

Equação 9 - Valor majorado para a energia desmagnetizante no grão A.

Por analogia, temos a energia no grão $B$, no qual o ângulo entre o eixo central e a magnetização é $\beta$ e o campo desmagnetizante $H_{d}$ terá sinal contrário.

$$
E_{d}^{\max , B}=\frac{\pi \mu_{0} \sigma_{M}}{4} M_{s} \cos \beta R^{2}\left(L-\sqrt{R^{2}+L^{2}}+R\right)
$$

\section{Equação 10 - Valor majorado para a energia desmagnetizante no grão B}

Somando ambas, relembrando a definição de $\sigma_{M}$ e rearranjando:

$$
\begin{gathered}
E_{d}^{\max , A}+E_{d}^{\max , B}=\frac{\pi \mu_{0} \sigma_{M}{ }^{2}}{4} R^{2}\left(L-\sqrt{R^{2}+L^{2}}+R\right) \\
E_{d}^{\max , t t}=\frac{\mu_{0} \sigma_{M}^{2}}{4} \pi R^{2} L\left(1+\frac{R}{L}-\sqrt{1+\left(\frac{R}{L}\right)^{2}}\right)=\frac{\mu_{0} \sigma_{M}^{2}}{4} V G
\end{gathered}
$$

\section{Equação 11 - Valor majorado para a energia desmagnetizante devida ao contorno de grão.}

Esta análise simplificada nos leva à interessante conclusão de que a energia devida ao campo desmagnetizante varia com o quadrado da divergência da magnetização (ou seja, com o quadrado da desorientação) e com o volume do grão. $O$ fator $G$ depende apenas da razão $R / L$, ou seja, da forma do grão.

Este desenvolvimento matemático é idêntico ao utilizado por GOODENOUGH 
[2] no apêndice 4 de seu artigo, sendo que ele exprimiu $R$ como $L ' / 2$, e utilizou as variáveis densidade de polos na superfície, $\omega^{*}=I_{s}\left(\cos \theta_{1}-\cos \theta_{2}\right)$ equivalente a $\sigma_{M}$ (exceto pela unidade da magnetização e sinal) e densidade de energia na superfície $\sigma_{0}=E_{d}{ }^{\max } / \pi R^{2}$, equivalente à energia total divida pela área da tampa.

Por fim, para chegar às equações de GOODENOUGH [2] é preciso realizar a multiplicação por um fator $4 \pi$ ao invés de $\mu_{0}$ já que $I_{s}\left(\right.$ e $\left.\omega^{\star}\right)$ está no sistema gaussiano de unidades.

$$
\vec{H}_{d}^{e i x o z}=-2 \pi \omega *\left[1-\frac{z}{\sqrt{\left(L^{\prime} / 4\right)^{2}+z^{2}}}\right] ; \quad \sigma_{0}=\pi \omega^{*^{2}} L G
$$

\section{Equação 12 - Formulação de GOODENOUGH [2].}

Podemos notar, por inspeção direta, que o valor de $G$ quando $L=2 R$ é aproximadamente 0,38 . Porém, talvez por analogia com 0 fator desmagnetizante $\left(N=M / H_{d}\right)$ em esferas uniformemente magnetizadas, GOODENOUGH [2] afirma que $G$ vale $1 / 3$ para cilindros quadrados (cilindros em que $L=2 R$ ).

É interessante citar o resultado do artigo de RHODES \& ROWLANDS [3] quando os mesmos avaliaram para uma geometria retangular as "autoenergias", $E_{s}$, relacionadas com o campo desmagnetizante de cada superfície e as "energias-mútuas", $E_{m}$, relacionadas com a interação entre as diversas superfícies.

$$
E_{s}=a^{3} \sigma^{2} F(b / a, 0) ; \quad E_{m}=2 a^{3} \sigma^{2} F(b / a, c / a)
$$

Equação 13 - Formulação de RHODES \& ROWLANDS [3].

Nas quais $\sigma$ é a divergência da magnetização e $F$ é uma função adimensional 
que varia com a forma do grão. Supondo que estas superfícies retangulares fazem parte de um grão paralelepípedo com largura $a$, comprimento $b$ e altura $c$, o volume do grão $V=a b c$ pode então ser expresso como $V=$ $a^{3} . b / a . c / a$. Graças à função $F$, a qual contém os fatores $b / a$ e $c / a$, as equações são expressas em função de $a^{3}$.

Vê-se que a dependência da energia com o volume do grão e com o quadrado da divergência da magnetização se mantém; e a equação também é afetada por um fator dependente da forma do grão.

\subsection{Método $\mu^{*}$ de Bozorth}

GOODENOUGH [2] afirma que, para calcular o efeito do campo desmagnetizante sobre o campo coercivo, apenas os contornos de grão aproximadamente normais ao campo aplicado são considerados. Portanto, não há necessidade de uma correção devida à rotação homogênea segundo o método $\mu^{*}$.

Com efeito, quando o contorno é aproximadamente normal ao campo (o ângulo entre o campo e todas as direções contidas no plano do contorno é $90^{\circ}$ ) o efeito da rotação homogênea será minimizado. Porém, através de uma aplicação numérica, veremos que mesmo para estes contornos e mesmo para pequenos ângulos entre a direção fácil de cada grão e o campo, há necessidade de contabilizar o efeito da rotação homogênea através do método $\mu^{*}$ de BOZORTH [4].

Relembrando a fórmula do campo desmagnetizante ao longo do eixo central e substituindo para valores $\alpha=10^{\circ}$ e $\beta=20^{\circ}$, a título de exemplo, obtém-se: 


$$
\begin{gathered}
\vec{H}_{d}^{\text {eixoz }}=\frac{\sigma_{M}}{2}\left(1-\frac{z}{\sqrt{R^{2}+z^{2}}}\right) \hat{z} \\
H_{d}^{\text {eixoz }}=\frac{M_{s}(\cos \alpha-\cos \beta)}{2}\left(1-\frac{z}{\sqrt{R^{2}+z^{2}}}\right)=0,0451 \cdot M_{s} \cdot\left(1-\frac{z}{\sqrt{R^{2}+z^{2}}}\right)=\xi \cdot M_{s}
\end{gathered}
$$

\section{Equação 14 - Aplicação numérica para campo desmagnetizante ao londo do} eixo central.

Colocando um valor arbitrário de $R=1$, temos o gráfico de $\xi$ em função da distância da base:

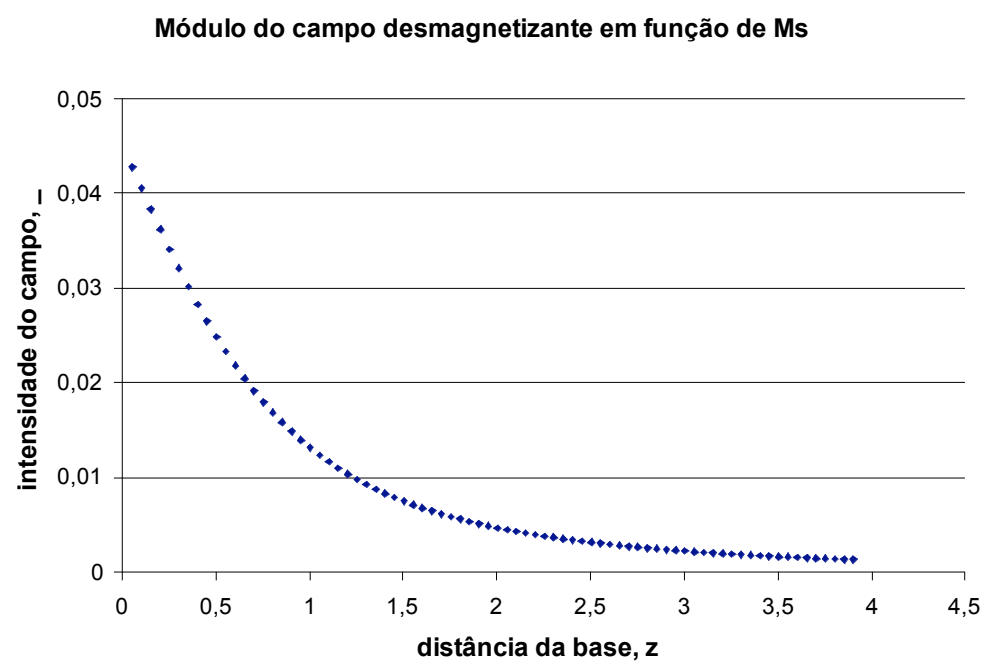

llustração 4 - Razão entre $H_{d}$ e $M_{s}$ ao longo do eixo z.

De forma que o campo desmagnetizante é máximo exatamente sobre a base e decai à medida que em se afasta dela. O que é notável, é que para distâncias entre $R$ e $2 R$, ou seja, no seio de um grão cilíndrico com altura e diâmetro iguais a $2 R$, o valor do campo desmagnetizante está na casa de centésimos do $M_{s} \approx 10^{\prime} 000 \mathrm{~A} / \mathrm{m}$.

O campo externo aplicado, $H_{\text {ext }}$, necessário para que o material atinja esta condição, na qual cada grão é um monodomínio alinhado segundo a melhor das direções de fácil magnetização, porém sem que haja rotação reversível, 
está por volta de $400 \mathrm{~A} / \mathrm{m}$, que é a posição do joelho da histerese a 1,5T de indução máxima. Dessa forma, ele está na ordem de décimos de milésimos da $M_{s}$.

$$
\frac{H_{e x t}}{M_{s}}=\frac{H_{e x t} \mu_{0}}{J_{s}}=400 \frac{\mathrm{A}}{\mathrm{m}} \cdot 4 \pi \cdot 10^{-7} \frac{\mathrm{Tm}}{\mathrm{A}} \cdot \frac{1}{2,14} T=2,35 \cdot 10^{-4}
$$

\section{Equação 15 - Razão entre campo aplicado e $M_{s}$.}

É completamente incoerente que o campo desmagnetizante seja ordens de grandeza maior do que o campo externo, porque aí o campo efetivo sequer estaria no sentido correto.

A diferença de inclinação dos grãos $A$ e $B$ deve cair para menos de $3^{\circ}$ para que o $H_{d}$ esteja na ordem de milésimos do $M_{s}$. Isso é pouco provável em aços GNO, donde se conclui que esta diferença de ordens de grandeza não pode se dever a ângulos $\alpha$ e $\beta$ mal escolhidos.

Uma possível solução para este dilema está na rotação dos momentos magnéticos para fora das direções fáceis nas proximidades do contorno de grão, onde o campo desmagnetizante é extremamente elevado.

Teríamos então uma larga "parede de domínio", se estendendo do centro do grão em direção ao contorno, sendo que no seu interior os momentos magnéticos se rotacionam progressivamente para fora da direção fácil até um ângulo que permita anular a presença de "polos magnéticos". 


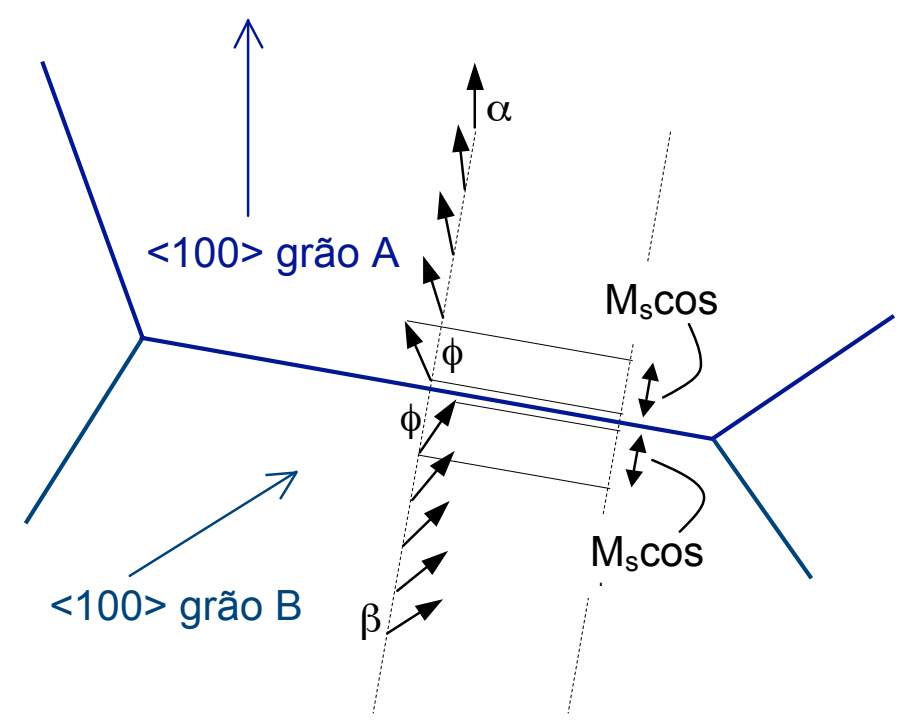

llustração 5 - "Longa parede" no contorno de grão.

A implicação contraditória desta parede seria anular o efeito do campo desmagnetizante por completo, de forma que o próprio efeito do tamanho de grão no campo coercivo fosse negligenciável.

Mais ainda, nos aços de grão não orientado, ao contrário do que foi relatado por SHEIKO [6] para GO, a observação de domínios magnéticos por efeito Kerr não indica a presença de rotação inomogênea.

Isso se deve ao fato de que a energia de anisotropia magnetocristalina acumulada quando esta "parede longa" se produz é muito menor no GO (porque os ângulos são menores) do que seria necessário no caso do GNO.

Portanto, consideramos apenas o caso de rotação homogênea, no qual todos os momentos magnéticos do grão se encontram a um mesmo ângulo da direção fácil de forma a reduzir a divergência da magnetização no contorno. Devido ao grande aumento da energia de anisotropia magnetocristalina, por se tratar do volume completo do grão, este ângulo deverá ser bem pequeno.

O método $\mu^{*}$ introduzido por BOZORTH [4] permite calcular a contribuição de uma pequena rotação da magnetização provocada por $H_{d}$, através da simples 
introdução de um fator multiplicativo.

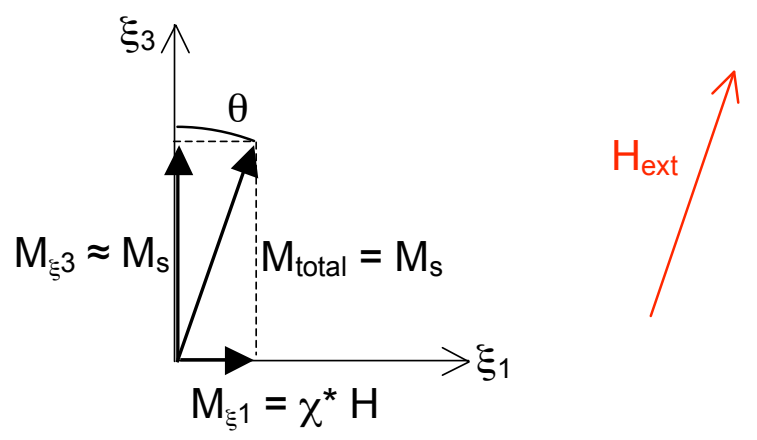

\section{llustração 6 - Efeito do campo externo sobre $M_{s}$, no sistema $\xi_{1} \xi_{2} \xi_{3}$.}

No interior de um domínio magnético, considera-se que o vetor magnetização se mantém constante ao longo do eixo fácil (neste caso $\xi_{3}$ ), com módulo $M_{s}$.

No entanto, ao longo de outros eixos, devido a presença de campo aplicado, pode surgir uma pequena componente $M_{i}=\chi^{*} H$. $\mathrm{O}$ valor da susceptibilidade é dado por um equilíbrio entre a energia magnetostática devido ao campo aplicado e a energia de anisotropia magnetocristalina. Para as coordenadas esféricas convencionais, com $H$ na direção de $\xi_{1}$, fazendo as aproximações indicadas para ângulos pequenos, temos:

$$
\begin{gathered}
\alpha_{1}=\operatorname{sen} \theta \cos \phi ; \quad \alpha_{2}=\operatorname{sen} \theta \operatorname{sen} \phi ; \quad \alpha_{3}=\cos \theta \\
\alpha_{1}=\operatorname{sen} \theta \cos \phi \approx \theta \cdot 1 ; \quad \alpha_{2}=\operatorname{sen} \theta \operatorname{sen} \phi \approx \theta \cdot 0 ; \\
E=K_{1}\left(\alpha_{2}^{2} \alpha_{3}^{2}+\alpha_{1}^{2} \alpha_{3}^{2}+\alpha_{1}^{2} \alpha_{2}^{2}\right)-H J_{s} \alpha_{1} \\
E=K_{1}\left(\operatorname{sen}^{2} \theta \cos ^{2} \theta+\operatorname{sen}^{4} \theta \operatorname{sen}^{2} \phi \cos ^{2} \phi\right)-H J_{s} \operatorname{sen} \theta \cos \phi \approx 1 \\
E=K_{1} \theta^{2}-H J_{s} \theta
\end{gathered}
$$

Equação 16 - Equilíbrio energético na rotação homogênea.

Sendo que a energia atinge seu mínimo para $\theta=H J_{S} / 2 K_{1}$. Donde se conclui que, para minimizar a energia acumulada, a magnetização necessária vale $M$ $=M_{S} \alpha_{1}=H J_{S}{ }^{2} / 2 \mu_{0} K_{1}$ e a susceptibilidade $\chi^{*}=J_{S}{ }^{2} / 2 \mu_{0} K_{1}$ para um campo 
aplicado na direção $\xi_{1}$ (ou $\xi_{2}$ por simetria):

Dada a escolha de um sistema de coordenadas coincidente com as direções de fácil magnetização no aço, supõe-se que a presença de campo desmagnetizante em um domínio cuja magnetização está orientada, por exemplo, ao longo do eixo $\xi_{3}$, leva ao surgimento de pequenas componentes de magnetização ao longo dos eixos $\xi_{1}$ e $\xi_{2}$, sem que a magnetização em z seja afetada:

$$
\delta \vec{M}=\left[\begin{array}{ccc}
\chi^{*} & 0 & 0 \\
0 & \chi^{*} & 0 \\
0 & 0 & 0
\end{array}\right]\left[\begin{array}{l}
H_{\xi_{1}} \\
H_{\xi_{2}} \\
H_{\xi_{3}}
\end{array}\right] ; \quad \vec{M}_{\text {total }}=M_{s} \hat{\xi}_{3}+\delta \vec{M}
$$

Equação 17 - Tensor de susceptibilidade efetiva para o sistema $\xi_{1} \xi_{2} \xi_{3 \text { * }}$

Este método permite o conhecimento da dependência de $M$ com $H$ ao longo de um sistema de coordenadas $\xi_{1} \xi_{2} \xi_{3}$ alinhado com as direções de fácil magnetização do grão $\mathrm{A}:[\delta M]^{\xi_{1} \xi_{2} \xi_{3}}=\left[\chi^{*}\right]^{\xi_{1} \xi_{2} \xi_{3}}[H]^{\xi_{1} \xi_{2} \xi_{3}}$.

Porém, os valores do campo $H$ são conhecidos para o sistema $X Y Z$ alinhado com o contorno de grão, como calculado acima. Por simplicidade, vamos considerar o caso em que $X$ e $\xi_{1}$ são coincidentes, dessa forma, a matriz de mudança de base entre os sistemas se reduz a uma matriz com uma única rotação. 


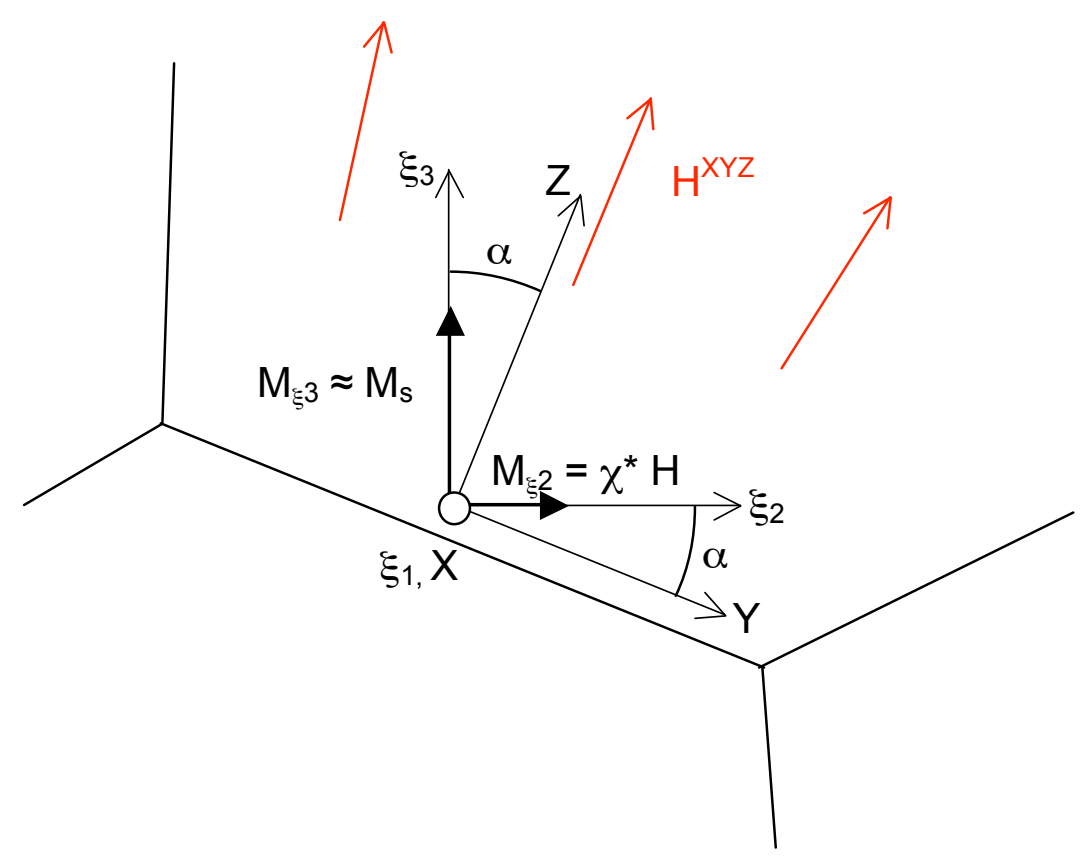

Ilustração 7 - Posição relativa dos sistemas $X Y Z$ e $\xi_{1} \xi_{2} \xi_{3}$.

$$
[C]_{X Y Z}^{\xi_{1} \xi_{2} \xi_{3}}=\left[\begin{array}{ccc}
1 & 0 & 0 \\
0 & \cos \alpha & \operatorname{sen} \alpha \\
0 & -\operatorname{sen} \alpha & \cos \alpha
\end{array}\right] ; \quad[C]_{\xi_{1} \xi_{2} \xi_{3}}^{X Y Z}=\left[\begin{array}{ccc}
1 & 0 & 0 \\
0 & \cos \alpha & -\operatorname{sen} \alpha \\
0 & \operatorname{sen} \alpha & \cos \alpha
\end{array}\right]
$$

Equação 18 - Matrizes de mudança de base para os sistemas $X Y Z$ e $\xi_{1} \xi_{2} \xi_{3}$.

De forma que o tensor da susceptibilidade efetiva para o sistema $X Y Z$ fica:

$$
\left[\chi^{*}\right]^{X Y Z}=[C]_{\xi_{1} \xi_{2} \xi_{3}}^{X Y Z}\left[\chi^{*}\right]^{\xi_{1} \xi_{2} \xi_{3}}[C]_{X Y Z}^{\xi_{1} \xi_{2} \xi_{3}}=\chi^{*}\left[\begin{array}{ccc}
1 & 0 & 0 \\
0 & \cos ^{2} \alpha & \operatorname{sen} \alpha \cos \alpha \\
0 & \operatorname{sen} \alpha \cos \alpha & \operatorname{sen}^{2} \alpha
\end{array}\right]
$$

Equação 19 - Tensor da susceptibilidade efetiva para o sistema XYZ.

E o acréscimo na magnetização, sabendo que estamos considerando uma rotação homogênea e não há efeito de $H_{Y}$, porque seu valor é ora positivo, ora negativo, sendo simétrico com relação ao eixo central de um grão cilíndrico: 


$$
\begin{gathered}
\delta \vec{M} \cdot \hat{z}=\chi *\left[\begin{array}{lll}
0 & \operatorname{sen} \alpha \cos \alpha & \operatorname{sen}^{2} \alpha
\end{array}\right]\left[\begin{array}{l}
H_{X} \\
H_{Y} \\
H_{Z}
\end{array}\right]=\chi *\left(\operatorname{sen} \alpha \cos \alpha H_{Y}+\operatorname{sen}^{2} \alpha H_{Z}\right) \\
\delta M=\chi^{*} \operatorname{sen}^{2} \alpha \cdot H_{Z}
\end{gathered}
$$

Equação 20 - Acréscimo da magnetização.

Então consideramos que a presença de um campo desmagnetizante pode provocar a surgimento de um desvio na magnetização, o qual depende da susceptibilidade efetiva do domínio, afetada por um fator geométrico: $\chi^{*} \operatorname{sen}^{2} \alpha$ $=\operatorname{sen}^{2} \alpha \mathrm{J}_{\mathrm{S}}^{2} / 2 \mu_{0} K_{1}$. Esta mudança na configuração da magnetização, causa, por sua vez, uma mudança no campo desmagnetizante.

É preciso encontrar uma configuração auto-conformada, de forma que não sejam necessárias diversas iterações para encontrar o campo. Assim poderemos encontrar a magnetização $M$ e o campo $H$ que implicam um no outro e são a solução final do problema.

Desconsiderando a rotação, a função potencial magnetostático assume as seguintes condições de contorno:

$$
\begin{gathered}
\Delta \Phi_{m a g}=\frac{\partial^{2} \Phi}{\partial x^{2}}+\frac{\partial^{2} \Phi}{\partial y^{2}}+\frac{\partial^{2} \Phi}{\partial z^{2}}=0, \quad \text { para } z>0 \text { ou } z<0 ; \\
\left.\frac{\partial \Phi}{\partial z}\right|_{z=+0}-\left.\frac{\partial \Phi}{\partial z}\right|_{z=-0}=-\sigma_{M}, \quad \text { para } z=0 .
\end{gathered}
$$

\section{Equação 21 - Condições de contorno a priori da função potencial magnetostático, sem levar em conta o efeito da rotação.}

A primeira condição equivale a dizer que não há divergência de $M$ no volume do grão, portanto não há fontes volumétricas de campo desmagnetizante. 
A segunda condição impõe que a diferença entre o campo desmagnetizante de um lado e do outro do contorno seja igual em módulo com sentido oposto à diferença entre a magnetização de um lado e de outro. O campo desmagnetizante está representado pela derivada da função potencial, e a divergência da magnetização pela densidade de "pólos magnéticos".

O problema passa a ser encontrar $\psi\left(\Phi, \chi^{*}, \alpha\right)$ que satisfaça:

$$
\begin{aligned}
& \Delta \psi_{\text {mag }}=\frac{\partial^{2} \psi}{\partial x^{2}}+\frac{\partial^{2} \psi}{\partial y^{2}}+\frac{\partial^{2} \psi}{\partial z^{2}}=0, \quad \text { para } z>0 \text { ou } z<0 \\
& \left.\frac{\partial \psi}{\partial z}\right|_{z=+0}-\left.\frac{\partial \psi}{\partial z}\right|_{z=-0}=-\sigma_{M}+\left.\chi^{*} \operatorname{sen}^{2} \alpha \frac{\partial \psi}{\partial z}\right|_{z=-0}, \text { para } z=0 .
\end{aligned}
$$

Equação 22 - Condições de contorno levando em conta a rotação homogênea.

Toma-se: $\psi(x, y, z)=A \Phi(x, y, z)$ :

$$
\begin{gathered}
A\left(\left.\frac{\partial \psi}{\partial z}\right|_{z=+0}-\left.\frac{\partial \psi}{\partial z}\right|_{z=-0}\right)=-\sigma_{M}+\left.\chi^{*} \operatorname{sen}^{2} \alpha A \frac{\partial \psi}{\partial z}\right|_{z=-0} \\
A\left[\left(-\frac{\sigma_{M}}{2}\right)-\left(+\frac{\sigma_{M}}{2}\right)\right]=-\sigma_{M}+\chi^{*} \operatorname{sen}^{2} \alpha A\left(+\frac{\sigma_{M}}{2}\right) \\
A\left(1+\frac{\chi^{*} \operatorname{sen}^{2} \alpha}{2}\right)=1 \\
A=\frac{2}{2+\chi^{*} \operatorname{sen}^{2} \alpha}=\frac{1}{1+\frac{J_{S}^{2}}{4 K_{1} \mu_{0}} \operatorname{sen}^{2} \alpha}=\frac{1}{1+\frac{2,14^{2}}{4 \cdot 48000 \cdot 4 \pi 10^{-7}} \frac{2^{2}}{\pi^{2}}} \cong \frac{1}{8,7}
\end{gathered}
$$

Equação 23 - Cálculo do fator multiplicativo da rotação homogênea. 
Donde se conclui, por fim, que a forma da função potencial magnético e a direção do campo desmagnetizante não são alterados; ou seja, é possível contabilizar o efeito da rotação através de um simples fator multiplicativo. Este fator multiplicativo reduz em uma ordem de grandeza o valor do campo desmagnetizante, mas o mesmo ainda permanece muito acima do esperado.

$\mathrm{H}_{\mathrm{d}} \approx 1150 \mathrm{~A} / \mathrm{m}$

$\mathrm{H}_{\mathrm{ext}} \approx 400 \mathrm{~A} / \mathrm{m}$

Muito embora pontualmente o campo desmagnetizante seja muito elevado, considera-se que energeticamente não é favorável que haja inversão da magnetização devido à contribuição da energia de troca.

\subsection{Cálculo semi-analítico para o grão todo}

\subsubsection{Introdução}

Será adotada a rota tradicional com auxilio de integração numérica pelo método de Simpson, dividida em duas etapas:

Primeiro obtém-se a função potencial magnetostático, a qual representa uma solução para as equações diferenciais que são resultado direto da lei de Gauss do magnetismo.

A seguir temos a forma reduzida do potencial a ser utilizada nos cálculos numéricos. A função potencial $\Phi_{m a g}$ é multiplicada pela divergência da magnetização, para que a função $\varphi$ revele apenas o formato da curva e seja adimensional. 


$$
\varphi(R, \vec{r})=\Phi_{m a g} \frac{4 \pi}{\sigma_{M}}=\int_{\partial V} \frac{1}{\left|\vec{r}-\vec{r}^{\prime}\right|} d S=\int_{0}^{2 \pi} \int_{0}^{R} \frac{1}{\left|\vec{r}-\vec{r}^{\prime}\right|} \rho d \rho d \theta
$$

\section{Equação 24 - Forma reduzida do potencial magnetostático.}

Após calcular pelo método de Simpson o valor desta integral em função da posição $\boldsymbol{r}$, podemos propor uma equação para o potencial que se ajusta bem aos valores obtidos, e que não poderia ser obtida pela integração direta. Assim, temos uma aproximação semi-analítica para $\varphi$.

Em um segundo momento temos a energia magnetostática devido ao campo desmagnetizante, a qual pode ser obtida pela integração, ao longo do volume do grão, do produto escalar entre o campo desmagnetizante e a magnetização.

Para facilitar o cálculo, nota-se que não há necessidade de calcular o campo desmagnetizante por derivação do potencial magnetostático. Como $H_{d}$ será novamente integrado, podemos utilizar $\varphi$ diretamente no cálculo da energia magnetostática.

Partimos da variável reduzida $(\varepsilon)$, a qual corresponde à energia magnetostática real divida pelo quadrado da divergência além da permeabilidade do vácuo, para obter no final uma equação adimensional dependente da energia em função do potencial.

$$
\begin{gathered}
\varepsilon(R, L)=-\frac{8 \pi}{\mu_{0} \sigma_{M}^{2}} E_{d}=-\frac{8 \pi}{\mu_{0} \sigma_{M}^{2}}\left(-\frac{\mu_{0}}{2} \int_{V} \vec{M} \cdot \vec{H}_{d} d V\right)= \\
=\frac{4 \pi}{\sigma_{M}^{2}} \int_{V} \vec{M} \cdot\left(-\nabla \Phi_{\text {mag }}\right) d V=\frac{4 \pi}{\sigma_{M}^{2}} \int_{V} \vec{M} \cdot\left(-\frac{\sigma_{M}}{4 \pi} \nabla \varphi\right) d V=
\end{gathered}
$$




$$
\begin{gathered}
=\frac{1}{\sigma_{M}} \int_{V}\left[M_{x} \hat{x}+M_{y} \hat{y}+M_{z} \hat{z}\right] \cdot\left[-\frac{\partial \varphi}{\partial x} \hat{x}-\frac{\partial \varphi}{\partial y} \hat{y}-\frac{\partial \varphi}{\partial z} \hat{z}\right] d V= \\
=\frac{1}{\sigma_{M}} \int_{V}\left[M_{s} \operatorname{sen} \alpha \cos \theta \hat{x}+M_{s} \operatorname{sen} \alpha \operatorname{sen} \theta \hat{y}+M_{s} \cos \alpha \hat{z}\right] \cdot\left[-\frac{\partial \varphi}{\partial x} \hat{x}-\frac{\partial \varphi}{\partial y} \hat{y}-\frac{\partial \varphi}{\partial z} \hat{z}\right] d V
\end{gathered}
$$

Equação 25 - Início do cálculo da forma reduzida da energia desmagnetizante.

Devido à natureza cilíndrica do problema, a integral do produto escalar entre o campo desmagnetizante e a magnetização se anulam ao longo dos eixos $x$ e $y$. Como $\varphi$ tem direção radial no plano x0y, ao longo da integração, para cada ângulo de 0 a $\pi$, teremos um caso complementar de $\pi$ a $2 \pi$ no qual o produto escalar de $\varphi$ com a magnetização tem o mesmo valor porém sinal contrário.

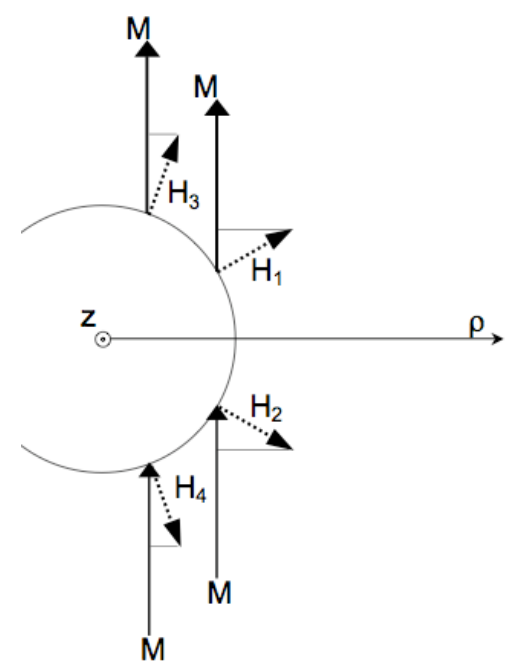

Ilustração 8 - Simetria cilíndrica de $\boldsymbol{H}_{d}$.

A título de exemplo, temos a seguir o valor da integral calculada para o grão $A$, na direção $x$. 


$$
\begin{gathered}
-\frac{1}{\sigma_{M}} \int_{0}^{L} \int_{0}^{R} \int_{0}^{2 \pi} \frac{\partial \varphi}{\partial x} M_{s} \operatorname{sen} \alpha \cos \theta \rho d \theta d \rho d z= \\
-\frac{M_{s} \operatorname{sen} \alpha}{\sigma_{M}} \int_{0}^{L} \int_{0}^{R}\left[2 \pi\left(\sqrt{R^{2}+z^{2}}-\sqrt{z^{2}}\right) \frac{\rho \cos \theta}{R^{2}+z^{2}} \exp \left[\frac{-0,5 \rho \cos ^{2} \theta}{R^{2}+z^{2}}\right] \rho \cos \theta\right]_{0}^{2 \pi} d \rho d z=0
\end{gathered}
$$

Equação 26 - Contribuição nula para $E_{d}$ ao longo da direção $x$ no grão $A$.

Por analogia vemos que o resultado também é nulo na direção $y$ e para o grão B. Dessa forma, pode-se ignorar as componentes em $x$ e $y$ ao calcular a fórmula reduzida da energia magnetostática devida ao campo desmagnetizante.

$$
\begin{gathered}
\varepsilon(R, L)=\frac{1}{\sigma_{M}} \int_{V} \vec{M} \cdot \vec{H}_{d} d V=\frac{1}{\sigma_{M}}\left[\int_{0}^{L} \int_{0}^{2 \pi} \int_{0}^{R} M_{s} \cos \alpha \frac{\partial \varphi}{\partial z} \rho d \rho d \theta d z+\int_{-L}^{0} \int_{0}^{2 \pi} \int_{0}^{R} M_{s} \cos \beta \frac{\partial \varphi}{\partial z} \rho d \rho d \theta d z\right]= \\
\varepsilon(R, L)=\frac{M_{s} \cos \alpha-M_{s} \cos \beta}{\sigma_{M}} \int_{0}^{R} \int_{0}^{2 \pi} \int_{0}^{L} \frac{\partial \varphi}{\partial z} \rho d z d \theta d \rho=-\int_{0}^{2 \pi} \int_{0}^{R} \rho[\varphi(r, z)]_{0}^{L} d \rho d \theta \\
\varepsilon(R, L)=\int_{0}^{2 \pi} \int_{0}^{R}[\varphi(r, 0)-\varphi(r, L)] \rho d \rho d \theta
\end{gathered}
$$

Equação 27 - Finalização do cálculo da forma reduzida da energia desmagnetizante.

Desta forma, a fórmula aproximada para $\varphi$ pode ser integrada diretamente para fornecer a equação da energia. Estes valores são então comparados com os valores para a energia obtidos por métodos numéricos.

\subsubsection{Potencial magnetostático}

Parte-se do equacionamento para o grão cilíndrico, como feito no cálculo para o eixo $z$, porém, consideramos um vetor posição $r=(0, \rho, z)$ afastado do eixo $z$, ao invés do vetor $(0,0, z)$ utilizado anteriormente. 
O vetor posição $r$ é:

$$
\vec{r}=(0, \rho, z)
$$

E o vetor $\boldsymbol{r}^{\prime}$ que percorre a base: $\quad \vec{r}^{\prime}=(\theta, r, 0)_{\Theta R Z}=(r \cos \theta, r \operatorname{sen} \theta, 0)_{X Y Z}$

Então o módulo da distância fica: $\quad|\vec{r}-\vec{r}|=\sqrt{(\rho-r \cos \theta)^{2}+(r \cos \theta)^{2}+z^{2}}$

Equação 28 - Condições geométricas para integração do potencial.

Considerando que o raio da base vale $R$ :

$$
\varphi(R, \vec{r})=\int_{0}^{2 \pi} \int_{0}^{R} \frac{r}{\sqrt{\rho^{2}+z^{2}+r^{2}+2 \rho r \cos \theta}} d r d \theta
$$

Equação 29 - Potencial magnetostático adimensional da base do cilindro.

A qual não possui solução analítica. Partimos então para uma integração numérica utilizando o método do Simpson. A mesma resulta numa função com formato de sino, simétrica com descontinuidade no ponto zero ao longo do eixo $z$, e simétrica sem descontinuidade com um máximo no ponto zero com relação ao eixo $\rho$. Por simetria, vemos que a função não depende de $\theta$. 


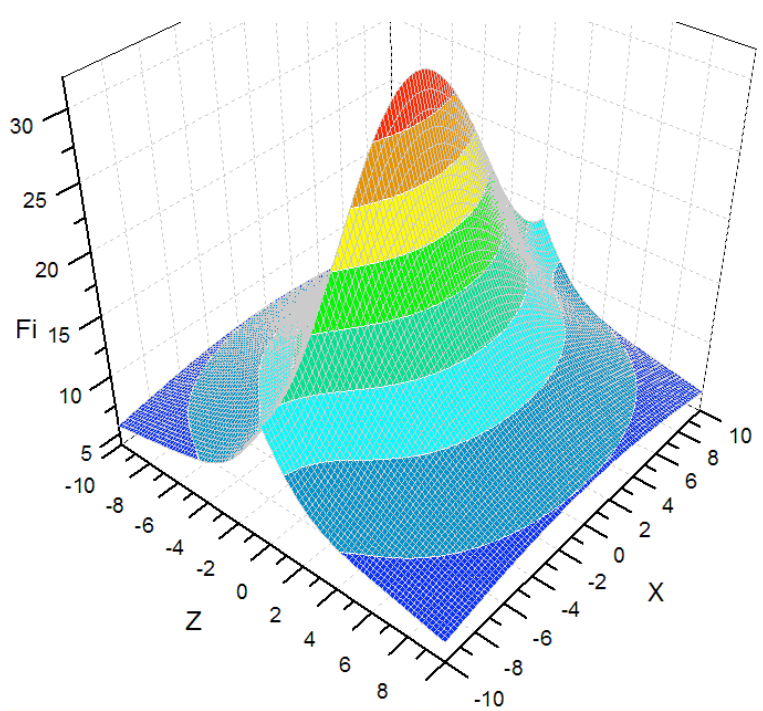

llustração 9 - Valores numéricos obtidos por integração pelo método de Simpson para a Equação 29.

O erro realizado ao cometer esta aproximação pode ser majorado, segundo o método de Simpson pela equação:

$$
\text { Erro }<\frac{(b-a)^{5}}{2880} \varphi^{(4)}(\xi)
$$

Equação 30 - Estimativa do erro cometido na integração pelo método de Simpson. 


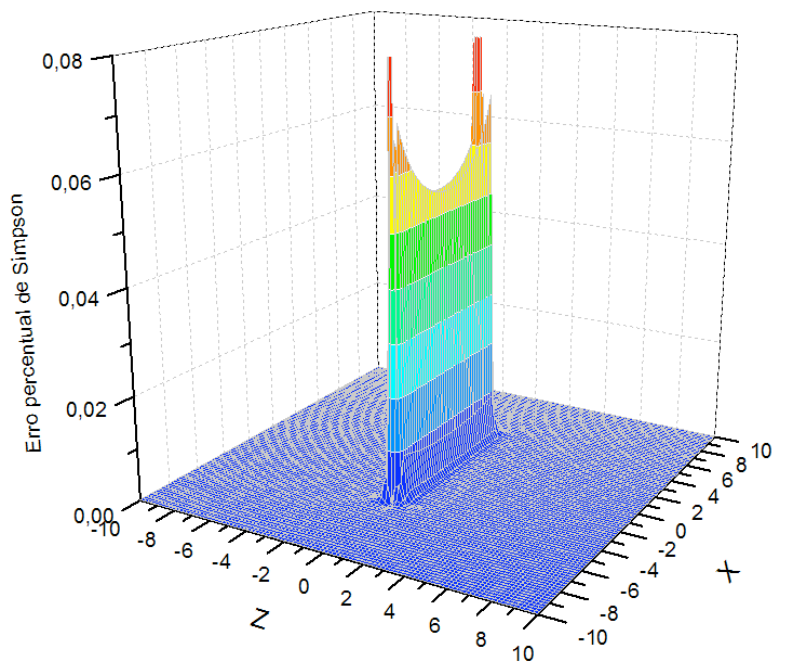

Ilustração 10 - Valores numéricos para a Equação 30.

A figura mostra que o erro máximo é praticamente nulo, exceto na região $z=$ 0 . Isso se deve ao fato de que a fórmula do erro utiliza valores da derivada quarta da função, a qual tende a infinito nesta região, devido à descontinuidade de $\varphi$ quando atravessa-se o contorno de grão. Se o passo de integração é reduzido, o valor da derivada cresce, mas (b-a) diminui, de forma que o erro cai. Para o passo escolhido, o erro se manteve abaixo de $0,8 \%$, atestando à qualidade dos valores obtidos.

Através de tentativa e erro, foi obtida uma função analítica de grande simplicidade a qual se aproxima relativamente bem dos valores de $\varphi$ obtidos pelo método numérico. Seja:

$$
\varphi(R, \rho, z)=2 \pi\left(\sqrt{R^{2}+z^{2}}-\sqrt{z^{2}}\right) \exp \left[\frac{-0,5 \rho^{2}}{R^{2}+z^{2}}\right]
$$

Equação 31 - Aproximação analítica para o potencial magnetostático. 


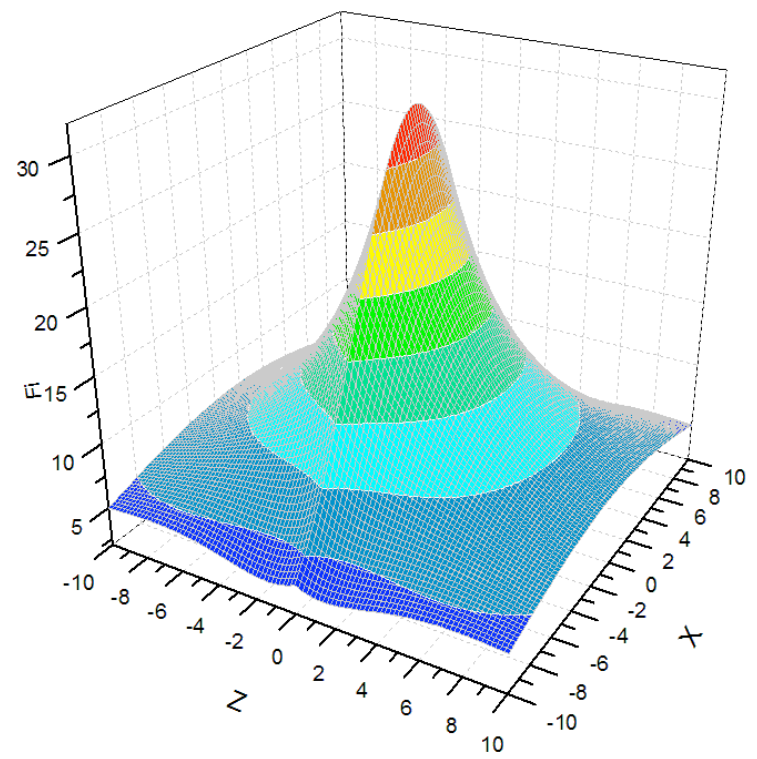

Ilustração 11 - Valores numéricos para a Equação 31.

O erro percentual cometido ao adotar esta expressão pode chegar a valores relativos elevados de até $50 \%$, como visto na figura abaixo. No entanto, o valor absoluto do erro sempre se mantém baixo. Sobretudo, no interior do domínio em questão (o qual para este exemplo se estende até 5 unidades), o valor do erro relativo permanece inferior a $10 \%$, de forma que podemos considerar que a expressão obtida aproxima de forma satisfatória os resultados numéricos. 


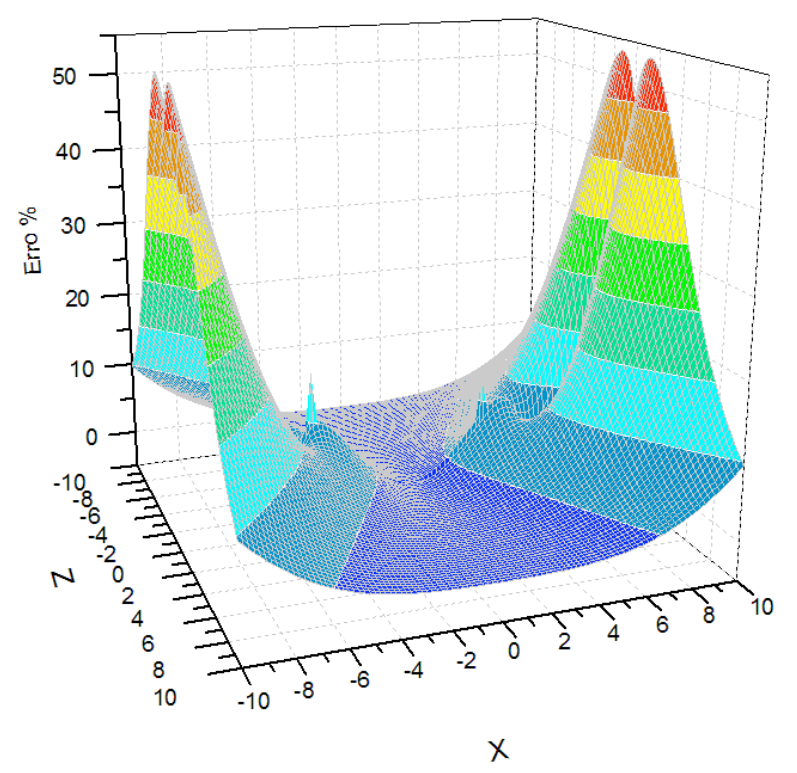

Ilustração 12 - Erro percentual cometido ao utilizar aproximação analítica para $\varphi$.

Assim completamos a etapa inicial dos cálculos. Existe uma integral facilmente obtenível para o potencial magnetostático no contorno de grão, para a qual não há solução analítica. Após calcular seus valores numericamente, encontramos uma expressão analítica que a aproxima. $O$ erro relativo desta aproximação atinge valores muito altos quando $z=0$ e $x>$ $e$, porém nosso intervalo de interesse se estende apenas na região para a qual $\mathrm{x}<e$, de forma que consideramos a aproximação como adequada.

\subsubsection{Energia magnetostática}

Obtém-se os valores da energia magnetostática devida ao campo desmagnetizante também através de integração numérica pelo método de Simpson, a partir dos valores já calculados para o potencial magnetostático. 


$$
\varepsilon(R, L)=\int_{0}^{2 \pi} \int_{0}^{R}[\varphi(r, 0)-\varphi(r, L)] \rho d \rho d \theta
$$

Equação 32 - Energia devida ao campo desmagnetizante a partir da integral do potencial magnetostático.

Temos a energia em função do raio da tampa:

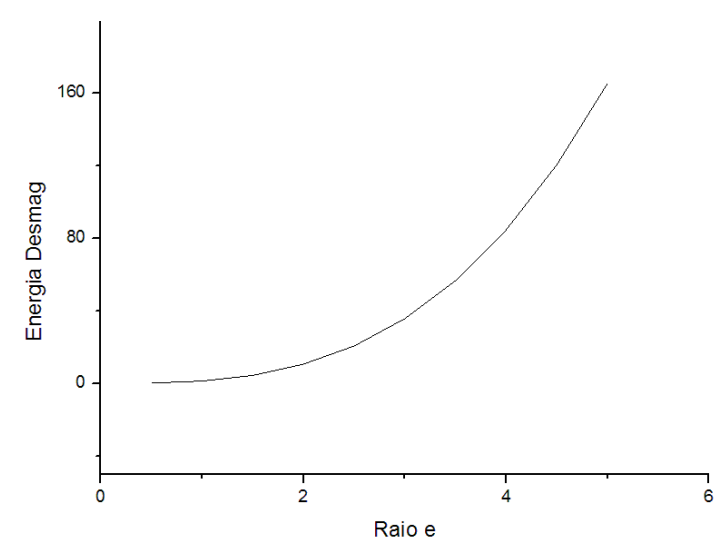

Ilustração 13 - Energia devida ao campo desmagnetizante em função do raio do contorno de grão.

Notamos, como já era de se esperar pelo cálculo realizado ao longo do eixo central, que a energia devida ao campo desmagnetizante varia com o cubo do raio de um cilindro quadrado, ou seja, com seu volume.

Podemos visualizar este resultado através da aproximação analítica de $\varphi$, tomando $L=2 R$ : 


$$
\begin{gathered}
\varepsilon(R, L)=\int_{0}^{2 \pi} \int_{0}^{R}[\varphi(R, \rho, 0)-\varphi(R, \rho, L)] \rho d \rho d \theta \\
\varepsilon(R, L)=2 \pi \int_{0}^{2 \pi} \int_{0}^{R}\left(\sqrt{R^{2}+0^{2}}-\sqrt{0^{2}}\right) \exp \left[\frac{-0,5 \rho^{2}}{R^{2}+0^{2}}\right] \rho d \rho d \theta-2 \pi \int_{0}^{2 \pi} \int_{0}^{R}\left(\sqrt{R^{2}+L^{2}}-\sqrt{L^{2}}\right) \exp \left[\frac{-0,5 \rho^{2}}{R^{2}+L^{2}}\right] \rho d \rho d \theta \\
\varepsilon(R)=2 \pi R^{2} \sqrt{R^{2}} \int_{0}^{2 \pi} \int_{0}^{R} \frac{-\rho}{R^{2}} \exp \left[\frac{-0,5 \rho^{2}}{R^{2}}\right] d \rho d \theta-2 \pi 5 R^{2}\left(\sqrt{5 R^{2}}-\sqrt{4 R^{2}}\right) \int_{0}^{2 \pi} \int_{0}^{R} \frac{-\rho}{5 R^{2}} \exp \left[\frac{-0,5 \rho^{2}}{5 R^{2}}\right] d \rho d \theta \\
\left.\varepsilon(R)=(2 \pi)^{2} \mid R^{3}\left(\exp \left[\frac{-0,5 \cdot R^{2}}{R^{2}}\right]-\exp \left[\frac{-0,5 \cdot 0^{2}}{R^{2}}\right]\right)-(2 \pi)^{2} 5(\sqrt{5}-2)\right) R^{3}\left(\exp \left[\frac{-0,5 \cdot R^{2}}{5 R^{2}}\right]-\exp \left[\frac{-0,5 \cdot 0^{2}}{5 R^{2}}\right]\right)
\end{gathered}
$$

Equação 33 - Aproximação analítica para a energia desmagnetizante adimensional.

Para simplificar a expressão, introduzimos o fator geométrico $Q$, tomando $5 \sqrt{ } 5-10 \cong 1,18$ :

$$
\begin{gathered}
Q(R) \cong \exp [-0,5]-1,18 \exp [-0,1]+0,18 \cong-0,28 \\
\varepsilon(R)=(2 \pi)^{2}\left|R^{3}\right| Q(R)
\end{gathered}
$$

\section{Equação 34 - Utilização do fator geométrico Q.}

Relembrando $\varepsilon(R, s, t)=\frac{8 \pi E_{d}}{\mu_{0} \sigma_{M}{ }^{2}}$, temos, com $V=\pi R^{2} 2 R$ :

$$
E_{d}=\varepsilon(R) \frac{\mu_{0} \sigma_{M}{ }^{2}}{8 \pi}=(2 \pi)^{2}\left|R^{3}\right| Q \frac{\mu_{0} \sigma_{M}{ }^{2}}{8 \pi}=\frac{\mu_{0} \sigma_{M}{ }^{2}}{4} V Q
$$

Equação 35 - Energia magnetostática devida ao campo desmagnetizante num grão monodomínio cilíndrico. 
De forma que obtemos a mesma equação que no caso simplificado, calculado utilizando os valores ao longo do eixo central. A energia magnetostática devida ao campo desmagnetizante depende do quadrado da divergência da magnetização, do volume de grão e de um fator geométrico.

Aqui notamos a presença do fator geométrico $Q$, assim chamado pois é adimensional e seu valor depende exclusivamente das restrições geométricas que impusemos ao formular o problema. Se ao invés de um grão cilíndrico tivéssemos um grão cúbico, o desenvolvimento matemático seria muito semelhante, resultando numa equação final quase idêntica, exceto pelo valor do fator geométrico.

No presente caso, o fator $Q$ não diz respeito apenas à geometria cilíndrica, mas também à escolha da função de aproximação para $\varphi$, isto é, ele nos permite contabilizar o fato de que os valores da função potencial decaem à medida que nos afastamos do eixo $z$ através de uma atenuação exponencial verificada pelo cálculo numérico.

$O$ fator geométrico $G$ calculado por GOODENOUGH [2] se encontrava nas proximidades de $1 / 3$ para $L=2 R$, como comentado em seu artigo. Aqui notamos que $o$ valor cai de $\mathrm{G}=0,38$ para $\mathrm{Q}=0,28$ quando consideramos a diminuição do valor do potencial à medida que nos afastamos do eixo $z$.

Desta forma, percebe-se que a atenuação exponencial resulta em valores inferiores e mais próximos da realidade para a energia em relação à aproximação de GOODENOUGH [2].

\subsection{Aplicação para dois domínios}

Considera-se que a inversão da magnetização do material se inicia através do crescimento de domínios de remagnetização. Quando quase todo material se encontra magnetizado, por exemplo, na direção $+z$, à medida que um 
campo cada vez mais intenso é aplicado na direção $-z$, alguns poucos domínios que possuem a mesma direção do campo crescem, em detrimento dos outros, até que quase todo material esteja magnetizado na direção -z.

A questão passa a ser sobrepor dois domínios cilíndricos concêntricos de magnetizações opostas e raios diferentes e calcular como varia a energia quando um cresce lateralmente em relação ao outro. Para facilitar a integração, é possível reformular o problema e calcular os potenciais de cada domínio de forma independente.
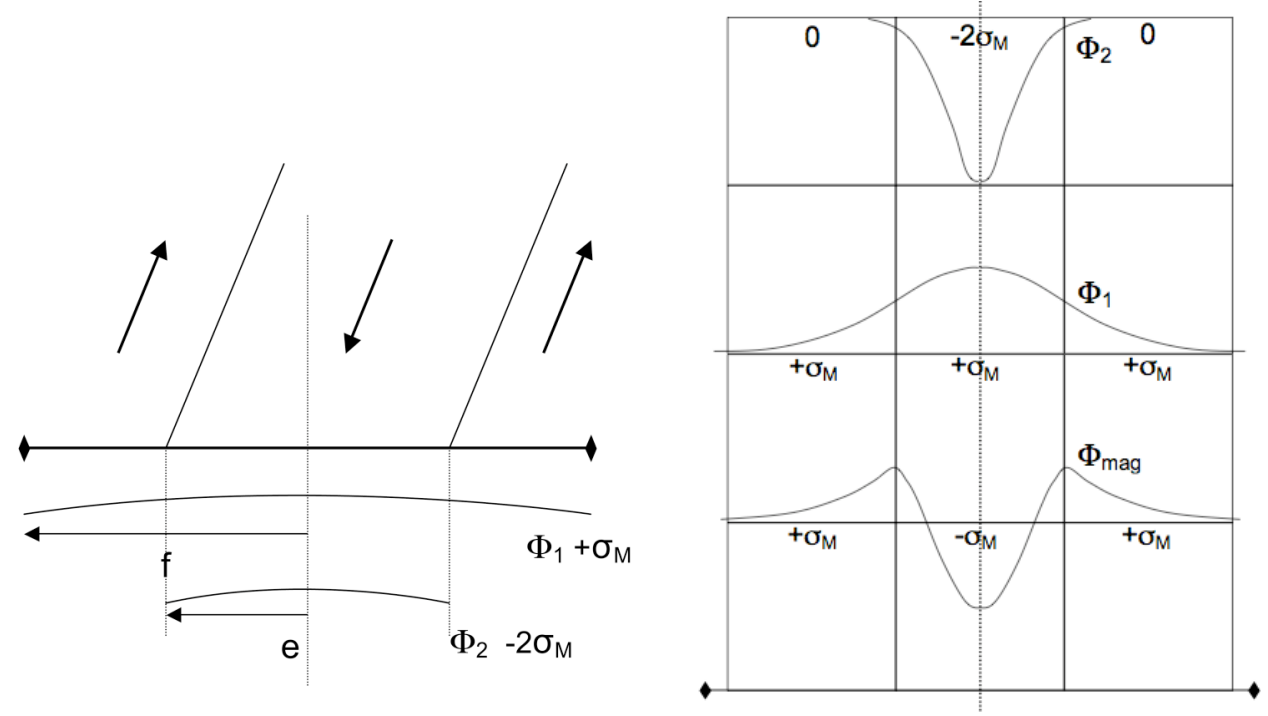

Ilustração 14 - Sobreposição de potenciais magnetostáticos para representar dois domínios no contorno de grão. À esquerda: definição das variáveis e e $f$ em função da posição dos domínios magnéticos. À direita:

valores ao longo do grão das duas componentes do potencial magnetostático bem como sua soma, o valor total.

$$
\begin{gathered}
\Phi_{\text {mag }}=\Phi_{1}+\Phi_{2} \\
\Phi_{1}=\frac{\sigma_{M}}{4 \pi} \varphi(\rho, z, f) ; \quad \Phi_{2}=-\frac{\sigma_{M}}{2 \pi} \varphi(\rho, z, e)
\end{gathered}
$$

Equação 36 - Divisão do potencial magnetostático em duas componentes. 
Como a divergência da magnetização é um fator escalar constante em cada área, podemos reescrever o perfil no contorno como a soma de dois potenciais. Para obter a energia total, temos o recurso de calcular as energias devidas ao campo desmagnetizante gerado por cada potencial separadamente, através de seu produto escalar com a magnetização dentro de cada domínio:

$$
\begin{gathered}
\mathrm{E}_{1}=-\frac{\mu_{0}}{2} \int_{0}^{L} \int_{0}^{2 \pi} \int_{0}^{e} \vec{M}_{1} \cdot \vec{H}_{d}^{1} \rho d \rho d \theta d z-\frac{\mu_{0}}{2} \int_{0}^{L} \int_{0}^{2 \pi} \int_{e}^{f} \vec{M}_{2} \cdot \vec{H}_{d}^{1} \rho d \rho d \theta d z \\
\mathrm{E}_{1}=-\frac{\mu_{0}}{2} \int_{0}^{2 \pi} \int_{0}^{e}\left(-\sigma_{M}\right)\left[\Phi_{1}(f, \rho, 0)-\Phi_{1}(f, \rho, L)\right] \rho d \rho d \theta-\frac{\mu_{0}}{2} \int_{0}^{2 \pi} \int_{e}^{f}\left(+\sigma_{M}\right)\left[\Phi_{1}(f, \rho, 0)-\Phi_{1}(f, \rho, L)\right] \rho d \rho d \theta \\
\mathrm{E}_{1}=\frac{\mu_{0} \sigma_{M}}{2} \int_{0}^{2 \pi} \int_{0}^{e} \frac{\sigma_{M}}{4 \pi}[\varphi(f, \rho, 0)-\varphi(f, \rho, L)] \rho d \rho d \theta-\frac{\mu_{0} \sigma_{M}}{2} \int_{0}^{2 \pi} \int_{e}^{f} \frac{\sigma_{M}}{4 \pi}[\varphi(f, \rho, 0)-\varphi(f, \rho, L)] \rho d \rho d \theta \\
\mathrm{E}_{1}=-\frac{\mu_{0}}{2} \frac{\sigma_{M}^{2}}{4 \pi}\{-\varepsilon(f, 0, e)+\varepsilon(f, e, f)\}
\end{gathered}
$$

Equação 37 - Componente energética de campo desmagnetizante num grão com 2 domínios devida ao domínio externo.

$\mathrm{E}$, analogamente para $E_{2}$ :

$$
\begin{gathered}
\mathrm{E}_{2}=-\frac{\mu_{0}}{2} \int_{0}^{L} \int_{0}^{2 \pi} \int_{0}^{e} \vec{M}_{1} \cdot \vec{H}_{d}^{2} \rho d \rho d \theta d z-\frac{\mu_{0}}{2} \int_{0}^{L} \int_{0}^{2 \pi} \int_{e}^{f} \vec{M}_{2} \cdot \vec{H}_{d}^{2} \rho d \rho d \theta d z \\
\mathrm{E}_{2}=-\frac{\mu_{0}}{2} \frac{\sigma_{M}{ }^{2}}{2 \pi}\{\varepsilon(e, 0, e)-\varepsilon(e, e, f)\}
\end{gathered}
$$

Equação 38 - Componente energética devida ao domínio interno.

A energia total do sistema é simplesmente: $E_{d}=E_{1}+E_{2}$. Lembrando que os valores da função reduzida $\varepsilon$ podem ser obtidos diretamente por integração numérica, oferecendo os resultados seguintes, $\operatorname{com} f=5$ e $e \in[0,5]$ : 


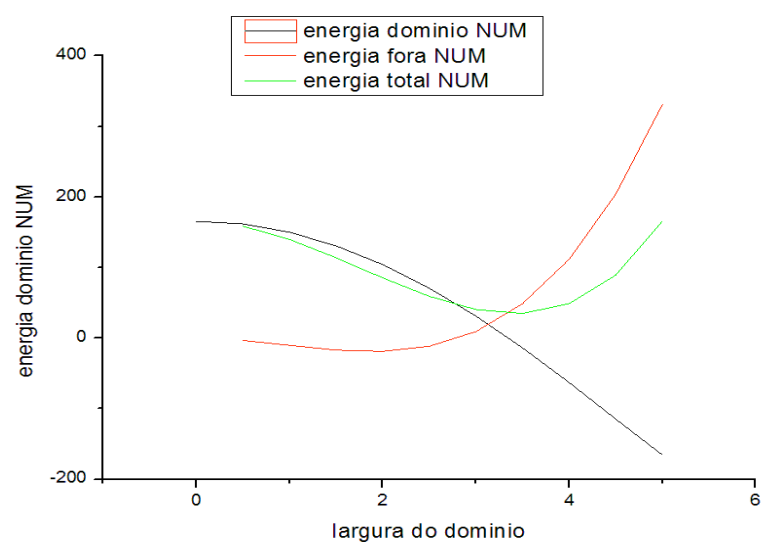

Ilustração 15 - Perfil de energia desmagnetizante em função da largura do domínio interno.

Nota-se que a energia do domínio interno cresce com sua largura, sendo que a energia do domínio externo decai. A energia total, a qual corresponde à soma das duas, atinge um mínimo quando a largura do domínio interno corresponde a 0,7 vezes a largura do grão.

O que, para o método analítico, com $p=e / f$ e introduzindo a função geométrica $F(p)$, corresponde a:

$$
\begin{gathered}
\mathrm{E}_{d}=-\frac{\mu_{0}}{2} \frac{\sigma_{M}{ }^{2}}{4 \pi}\{-\varepsilon(f, 0, e)+\varepsilon(f, e, f)+2 \varepsilon(e, 0, e)-2 \varepsilon(e, e, f)\} \\
\mathrm{E}_{d}=-\frac{\mu_{0} \sigma_{M}{ }^{2}}{4} V F(p) \\
F(p)=p^{3}\left[-2 \exp \left(\frac{-0,5}{p^{2}}\right)+2,36 \exp \left(\frac{-0,1}{p^{2}}\right)-1,485\right]-2 \exp \left(-0,5 p^{2}\right)+2,36 \exp \left(-0,1 p^{2}\right)-0,64
\end{gathered}
$$

Equação 39 - Aproximação analítica para a energia desmagnetizante num grão cilíndrico com 2 domínios concêntricos.

Sabendo que o fator geométrico para dois domínios, $F$, se reduz ao fator para um domínio, $Q$, quando o domínio interno ocupa o grão todo: $F(1)=Q=0,28$. 
Assim, $\operatorname{com} f=5$ e e $\in[0,5]$ :

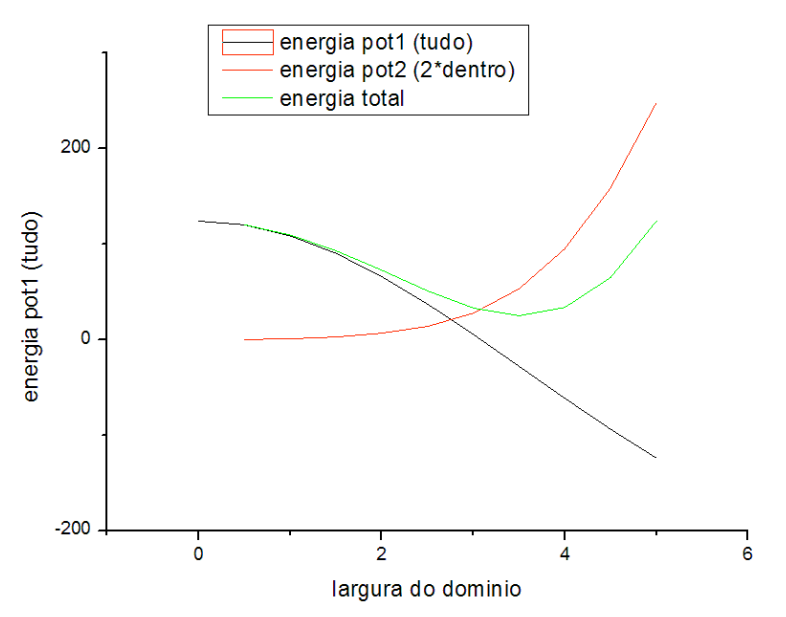

Ilustração 16 - Valores numéricos para a Equação 39.

Percebemos que o comportamento é o semelhante à integração numérica; a energia de campo desmagnetizante devido à região externa parte de um valor positivo e decai, à medida que o domínio central preenche o grão e a energia devido à região no interior do domínio parte do valor zero e cresce continuamente.

A energia total, a qual corresponde à soma das duas outras tem seu valor máximo em dois casos equivalentes, quando não há domínio de remagnetização, ou quando ele já ocupa o grão todo.

O erro da aproximação analítica na energia total, objetivo final dos cálculos, fica entre 0 e $35 \%$, com média 15.

Após realizar testes para o método numérico, com diferentes parâmetros de integração, determinou-se que esta energia atinge um mínimo para uma razão entre o raio do domínio e o raio do grão de aproximadamente 0,7 .

No trabalho de formatura do autor mencionou-se a importância deste resultado, pois viu-se que a razão entre o tamanho de domínio e o tamanho de grão havia sido abordada de forma incompleta por MAGER [1] e 
GOODENOUGH [2].

Podemos notar grandes semelhanças entre este resultado e a alternativa de grão retangular, explorada também por métodos numéricos por RHODES \& ROWLANDS [3]. Eles estudaram o caso de uma partícula na forma de um prisma quadrado, dividido por uma parede planar entre dois domínios de magnetização paralela e antiparalela à aresta mais longa.

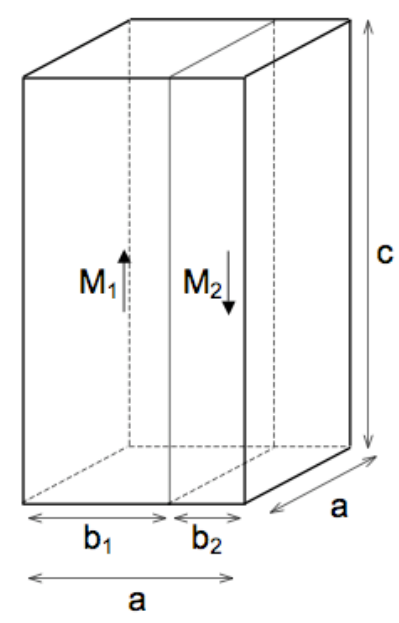

Ilustração 17 - Geometria retangular com domínios lado a lado utilizada por RHODES \& ROWLANDS [3].

O gráfico da energia desmagnetizante adimensional $\left(A_{d}=E_{d} / a^{3} \sigma^{2}\right)$ em função da posição relativa da parede $\left(p=b_{1} / a\right)$ se assemelha muito com o obtido para a geometria cilíndrica: 


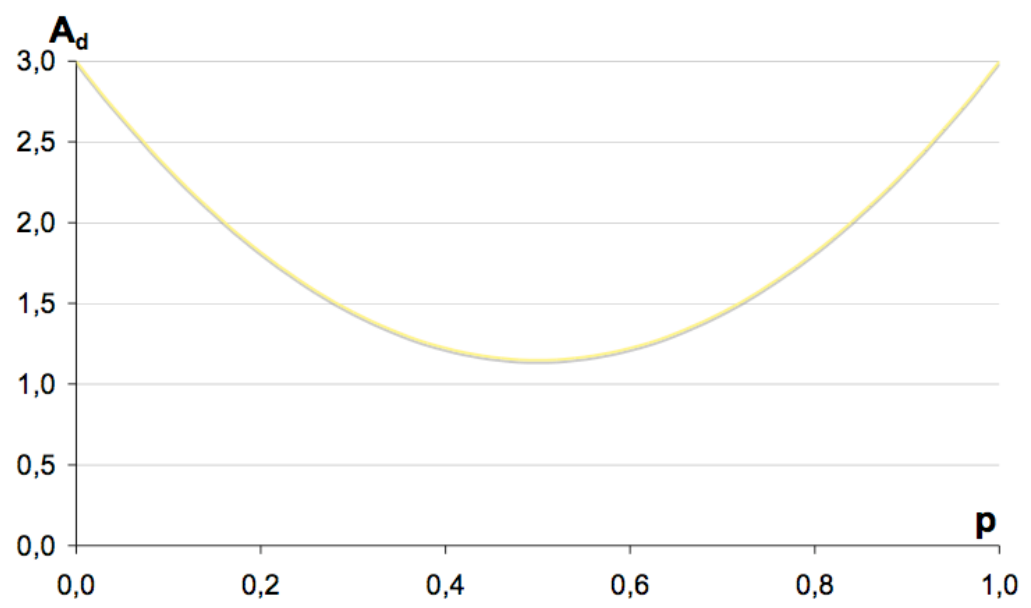

llustração 18 - Energia desmagnetizante adimensional em função da posição da parede de domínio, adaptado de [3].

Uma função que varia suavemente $\operatorname{com} p$, parte de um máximo quando não há domínio de remagnetização $(p=0)$, passa por um mínimo quando ele ocupa metade do volume do grão $(p=0,5)$ e volta a atingir um máximo quando o domínio de remagnetização ocupa o grão todo. 


\subsection{Referências}

[1] Mager, A., "About the influence of the grain size on coercitivity", Annalen der Physic, pp. 11-15, 1952

[2] GOODENOUGH, J. B., "A theory of domain creation and coercive force", Physical Review, v. 95, pp. 917-932, 1954

[3] RHODES, P., ROWLANDS, G., "Demagnetizing energies of uniformly magnetised rectangular blocks", Proceedings of the Leeds Philosophical and Literary Society, pp. 191-210, 1954

[4] WILLIAMS, H.J., BOZORTH, R.M., SHOCKLEY, W., "Magnetic domain patterns on single crystars of silicon iron", Physical Review, v. 54, pp. 155178,1949

[5] SHEIKO, L., et al., "Calculation of the magnetostatic energy referred to magnetic charges on surfaces of the grain boundaries", Journal of Magnetism and Magnetic Materials, v. 215-126, pp. 24-25, 2000

[6] SHEIKO, L., et al., "Experimental investigation of $\mu^{*}$-effect near the grain boundaries in grain-oriented silicon steel sheets", Journal of Magnetism an d Magnetic materials, v. 215-216, pp. 86-88, 2000 